\title{
Polymer
}

\section{Ferrocene-based (photo)redox polymerization under long wavelengths}

\begin{tabular}{|r|l|}
\hline Journal: & Polymer Chemistry \\
\hline Manuscript ID & PY-ART-01-2019-000059.R1 \\
\hline Article Type: & Paper \\
\hline Author: & 05-Feb-2019 \\
\hline Complete List of Authors: & $\begin{array}{l}\text { Lalevée, Jacques; Mulhouse University, IS2M } \\
\text { Garra, Patxi; Institut de Sciences des Materiaux de Mulhouse, } \\
\text { Dumur, Frederic; Institut de Chimie Radicalaire, UMR 7273 CNRS } \\
\text { Gigmes, Didier; Aix-Marseille Université, Institut de Chimie Radicalaire - } \\
\text { UMR7273 } \\
\text { Fouassier, Jean Pierre; Institut de Sciences des Materiaux de Mulhouse } \\
\text { Morlet-Savary, Fabrice; Institut de Sciences des Materiaux de Mulhouse } \\
\text { Duche, D.; Institut de Chimie Radicalaire, UMR 7273 CNRS } \\
\text { Brunel, Damien; Institut de Chimie Radicalaire, UMR 7273 CNRS } \\
\text { Graff, Bernadette; Universite de Haute-Alsace, } \\
\text { guillaume, noirbent; Laboratoire de Physicochimie des Polymères et des } \\
\text { Interfaces LPPI, Université de Cergy-Pontoise, 5 mail Gay Lussac, } \\
\text { Neuville-sur-Oise, 95031 Cergy-Pontoise Cedex, France, } \\
\text { Sidorkin, Valery; A. E. Favorsky Irkutsk Institute of Chemistry, } \\
\text { laboratory of physical chemistry } \\
\text { Dietlin, Céline; Institut de Sciences des Materiaux de Mulhouse }\end{array}$ \\
\hline
\end{tabular}




\title{
Polymer Chemistry
}

\author{
Full paper submission
}

2017 Impact Factor: 4.927

Immediacy Index: 1.397

Polymer Chemistry is a publication from the Royal Society of Chemistry, encompassing all aspects of synthetic and biological macromolecules, and related emerging areas.

The following paper has been submitted to Polymer Chemistry for consideration as a Full paper.

The primary criterion for acceptance of a contribution for publication is that it must report highquality new science and make a significant contribution to its field. Routine or incremental work, however competently researched and reported, should not be recommended for publication. Full papers in Polymer Chemistry should contain original scientific work that has not been published previously. Read more about the scope of Polymer Chemistry.

Thank you for your effort in reviewing this submission. It is only through the continued service of referees that we can maintain both the high quality of the publication and the rapid response times to authors.

We would greatly appreciate if you could review this paper in two weeks. Please let us know if that will not be possible. Please support all comments with scientific justifications or we may be unable to use your report/ask for extra feedback.

Once again, we appreciate your time in serving as a reviewer. To acknowledge this, the RSC offers referees a $25 \%$ discount on its books. Please also consider submitting your next manuscript to Polymer Chemistry.

Best wishes,

Christopher Barner-Kowollik

Editor-in-Chief, Polymer Chemistry 

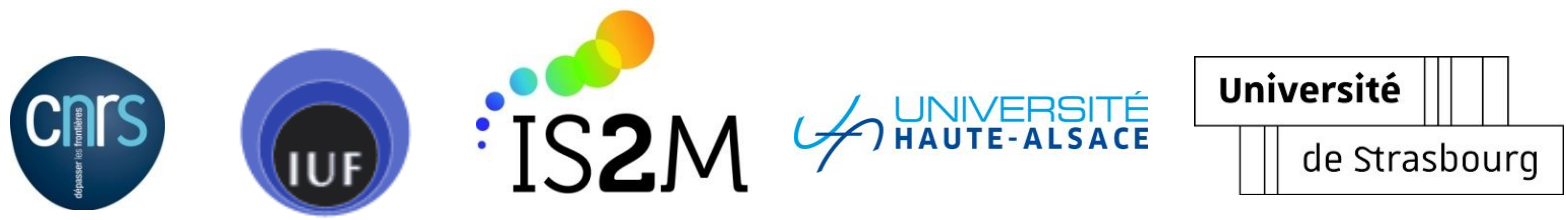

Prof. Jacques Lalevée

Institut Universitaire de France (IUF)

Institut de Science des Matériaux de Mulhouse (IS2M),

CNRS - UMR 7361.

15 rue Jean Starcky, 68057 Mulhouse (FRANCE).

Tel office: + 33389608803 .

e-mail: jacques.lalevee@uha.fr

January-14th-2018.

\section{Polymer Chemistry}

\section{Dear Editor,}

We are submitting for your consideration an article "Ferrocene-based (photo)redox polymerization under long wavelengths" for publication in Polymer Chemistry.

In the present article, Ferrocene-based photoredox catalysis is proposed here for the first time. Aryl radicals generated from a Fe(II)*/Ar$\left.{ }_{2}\right|^{+}$reaction can be used as initiating species for efficient free radical photopolymerization of methacrylate resins. Remarkably, these photoredox catalysts can also be used for redox free radical polymerization (without light) in combination with ammonium persulfate for a unique access to dual cure (photochemical/thermal redox) systems. The addition of a third component (amine, phosphine or Vitamin C reducing agents) enables the regeneration of the catalysts and greatly enhances the radical generation. The motivation of these dual cure systems is to develop orthogonal chemistries where a latent redox polymerization (without light) is able to cure any thickness of polymer (or composite) in combination with fast photopolymerization processes in the irradiated areas. Chemical mechanisms will be discussed in detail using cyclic voltammetry, electron spin resonance spin trapping (ESR-ST), UV-vis-NIR spectroscopy, free energy calculations and molecular modeling at density functional theory (DFT) level. This study represents, to the best of our knowledge, the first photochemically active Iron catalysts that are also efficient in thermal redox catalysis.

As the article proposes the development of orthogonal chemistries such as redox photoactivated polymerization: a redox reaction can take place without light and NIR light can be used on demand to trigger a second light induced reaction. This study also paves the way towards the use of $\mathrm{Fe}$ (II) structures for highly efficient (photo)redox catalysis upon mild conditions (NIR light, room temperature and under air). We do believe that this article meets the high standards of the journal and will find a large audience as an article among the readership of Polymer Chemistry.

Best regards,

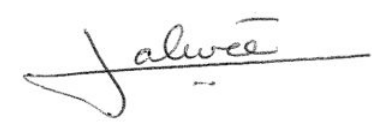




\title{
Ferrocene-based (photo)redox polymerization under long wavelengths
}

\section{Patxi Garra ${ }^{1,2}$, Damien Brunel ${ }^{3}$, Guillaume Noirbent ${ }^{3}$, Bernadette Graff ${ }^{1,2}$, Fabrice Morlet- Savary ${ }^{1,2}$, Céline Dietlin ${ }^{1,2}$, V. F. Sidorkin ${ }^{4}$, Frédéric Dumur ${ }^{3}$, David Duché ${ }^{5}$, Didier Gigmes ${ }^{3}$, Jean-Pierre Fouassier ${ }^{1,2}$, Jacques Lalevée ${ }^{1,2^{*}}$}

\author{
${ }^{1}$ Université de Haute-Alsace, CNRS, IS2M UMR 7361, F-68100 Mulhouse, France \\ 2Université de Strasbourg, France \\ ${ }^{3}$ Aix Marseille Univ, CNRS, ICR UMR 7273, F-13397 Marseille, France \\ ${ }^{4}$ A. E. Favorsky Irkutsk Institute of Chemistry, Siberian Branch of the Russian \\ Academy of Sciences, Favorsky, 1, Irkutsk 664033, Russian Federation. \\ ${ }^{5}$ Aix Marseille Univ, CNRS, IM2NP UMR 7334, F-13397 Marseille, France \\ *Corresponding author: jacques.lalevee@uha.fr
}

\begin{abstract}
:
Ferrocene-based photoredox catalysis is proposed here for the first time. Aryl radicals generated from a $\mathrm{Fe}(\mathrm{II}) * / \mathrm{Ar}_{2} \mathrm{I}^{+}$reaction can be used as initiating species for efficient free radical photopolymerization of methacrylate resins. Remarkably, these photoredox catalysts can also be used for redox free radical polymerization (without light) in combination with ammonium persulfate for a unique access to dual cure (photochemical/thermal redox) systems. The addition of a third component (amine, phosphine or Vitamin C reducing agents) enables the regeneration of the catalysts and greatly enhances the radical generation. The motivation of these dual cure systems is to develop orthogonal chemistries where a latent redox polymerization (without light) is able to cure any thickness of polymer (or composite) in combination with fast photopolymerization processes in the irradiated areas. Chemical mechanisms will be discussed in detail using cyclic voltammetry, electron spin resonance spin trapping (ESR-ST), UV-vis-NIR spectroscopy, free energy calculations and molecular modeling at density functional theory (DFT) level. This study represents, to the best of our knowledge, the first photochemically active Iron catalysts that are also efficient in thermal redox catalysis.
\end{abstract}




\section{Introduction}

The shift towards higher actinic wavelengths in light induced reactions is a constant challenge in many academic/industrial works. ${ }^{1-4}$ During the last decade ${ }^{5}$, the use of visible light in photoredox catalysis instead of harmful UV irradiations allowed significant advances in i) the selectivity of the photoreaction and ii) in the harmfulness of the actinic setup. Particularly, visible light-emitting diodes (LED) and laser diodes (LD) with their sharp emission spectra allows taylor-made light absorption by photoredox catalysts. Nevertheless, photoredox catalysis - partial and convenient regeneration of the catalyst - remained mostly restricted to actinic lights below $500 \mathrm{~nm} \cdot \cdot^{6-9}$ Indeed, near infrared (NIR) induced photoredox catalysis remains an old dream which is particularly difficult to achieve as a NIR photon is much less energetic than a UV one (e.g. at $900 \mathrm{~nm}$, it is three times less energetic than at $300 \mathrm{~nm})$.

Out of the challenge, there is a real interest in using NIR wavelengths: it offers several advantages such as an excellent penetration in filled, dispersed or even heterogeneous samples, and a higher selectivity of the photoreaction as the process is less energetic. ${ }^{10}$ Therefore, there is a clear need to answer these questions: $\mathrm{i}$ ) is it possible to actually perform a photoredox reaction under NIR lights and ii) can the photoreaction occur at high rate? In the literature, two elegant examples of direct NIR photoreactions can be more particularly mentioned : i) the work of Strehmel et coworkers around cyanine sensitization of iodonium salts ${ }^{11-14}$ and ii) the work of Boyer et coworkers using a bacteriochlorophyl derivative or an aluminium phtalocyanine complex in photocontrolled radical polymerization. ${ }^{15,16}$ In these cases, either slow reactions or rather high irradiances were required. We propose in the present manuscript to explore newly developed ferrocene dyes (Fe(II)) as potential photoredox catalysts for the reduction of iodonium salts $\left(\mathrm{Ar}_{2} \mathrm{I}^{+}\right)$. These ferrocene dyes were mainly proposed in the literature for applications in non-linear optics. ${ }^{17,18}$ The shift towards higher wavelengths of the maximum of absorption in these compounds is made possible through their substitution by donor and/or acceptor (scheme 1) to induce a bathochromic charge-transfer 
transition, ${ }^{19}$ more particularly by introducing strong acceptors on the cyclopentadienyl ring (scheme 1)..$^{20}$

We propose to apply the photo-oxidation reaction of $\mathrm{Fe}(\mathrm{II})$ in presence of an iodonium salt leading to a reaction between the excited state of the ferrocenes and the iodonium salt $\left(\mathrm{Fe}(\mathrm{II}) * / \mathrm{Ar}_{2} \mathrm{I}^{+}\right)$ - to the highly challenging field of photopolymerization: the radicals generated will be useful to induce the free radical polymerization (FRP) of a methacrylate resin. Indeed, in that field, high reaction rates are required to overcome the inhibition reactions (e.g. the oxygen inhibition). ${ }^{21-27}$ Also, there is a real challenge to have access to filled samples (thanks to NIR photopolymerization) for thick photocomposites. ${ }^{28-30}$ Additionally and for the first time, we will also explore the possibility to use $\mathrm{Fe}$ (II) to decompose ammonium persulfate (APS) without light in redox polymerization: with two cartridges (one containing the oxidizing agent, the other one containing the reducing agent or system $)^{31}$ are mixed together to induce the FRP of methacrylates. The motivation of this is to develop orthogonal chemistries where a latent redox polymerization (without light) is able to cure any thickness of polymer (or even composite); light can then be used on demand to accelerate and enhance the slow redox processes. This dual-curing was recently defined as redox photoactivated polymerization. ${ }^{29,32,33}$ The chemical mechanisms involved in the polymerization process will be discussed thanks to the molecular modeling of the reactants/intermediates and to UV-vis-NIR absorption, cyclic voltammetry (CV) and electron spin resonance spin trapping (ESR-ST) experiments. 


\section{Ferrocenes (Fe(II))}

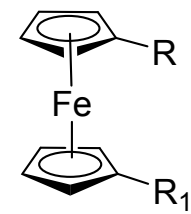

$\mathrm{R}=\mathrm{R}_{1}=\mathrm{H} ; \mathrm{Fe}$

$\mathrm{R}=(\mathrm{HC}=\mathrm{O}) ; \mathrm{R}_{1}=\mathrm{H}$

$\mathrm{R}=\mathrm{R}_{1}=\mathrm{CH}_{3} ; \mathbf{F e} 2$

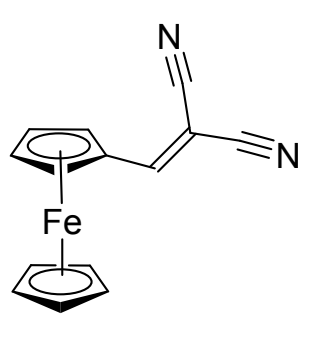

Fe5

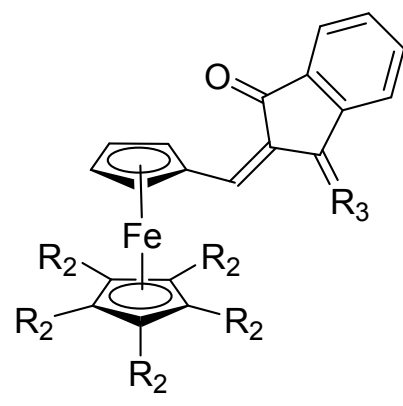

$\mathrm{R}_{2}=\mathrm{H} ; \mathrm{R}_{3}=\mathrm{O} ; \mathrm{Fe} 6$

$\mathrm{R}_{2}=\mathrm{H} ; \mathrm{R}_{3}=\mathrm{C}(\mathrm{CN})_{2} ; \mathrm{Fe} 7$

$\mathrm{R}_{2}=\mathrm{CH}_{3} ; \mathrm{R}_{3}=\mathrm{C}(\mathrm{CN})_{2} ; \mathrm{Fe} 7 \mathrm{Me}$

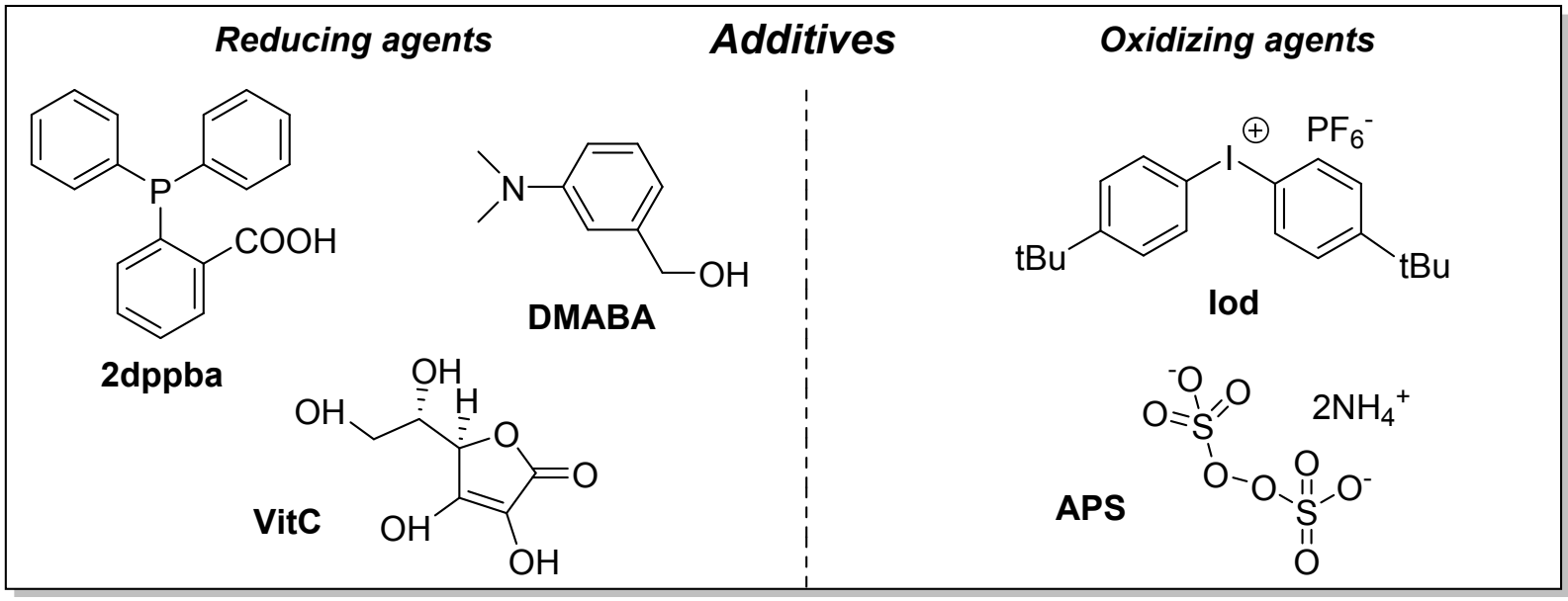

Scheme 1: Compounds investigated in the present study

\section{Experimental section}

\section{1/ Chemical compounds}

All the reactants were selected with the highest purity available and used as received; their chemical structures are summed-up in Schemes 1 and 2. Ferrocene (Fe), 1,1'-dimethylferrocene (Fe2), 4- $N, N$ trimethylaniline (4-N,N TMA), 3-(dimethylamino)benzyl alcohol (DMABA), 2diphenylphosphinobenzoic acid (2dppba), ascorbic acid (VitC), $N$-tert-butyl- $\alpha$-phenyl-nitrone (PBN), and ammonium persulfate (APS) were purchased from Sigma-Aldrich. Di-tert-butyl-diphenyl iodonium hexafluorophosphate (lod) was obtained from Lambson Ltd (UK). Toluene, acetonitrile (ACN) and dichloromethane (DCM) were purchased from Carlo Erba. 
Synthesis of the ferrocene derivatives were directly inspired by the literature (see Supplementary information, Figures S1 and S2). ${ }^{34}$

The efficiency of the different photoinititing systems (PISs) was checked in benchmarked methacrylate resins (viscosities given in Table 1): i) a first reference methacrylate mixture (resin 1, Scheme 2) with a low viscosity of 0.053 Pa.s containing $33.3 \mathrm{wt} \%$ of 1,4-butanediol-dimethacrylate (1,4-BDMA), $33.3 \mathrm{wt} \%$ of hydroxypropylmethacrylate (HPMA), $33.3 \mathrm{wt} \%$ of urethane-dimethacrylate; ii) a second methacrylate resin noted resin 2 (Scheme 2) having a much higher viscosity (5.7 Pa.s) with a BisGMA/TEGDMA (30/70 wt\%) blend and iii) pure hydroxyethylmethacrylate (HEMA). All the monomers were obtained from Sigma Aldrich.

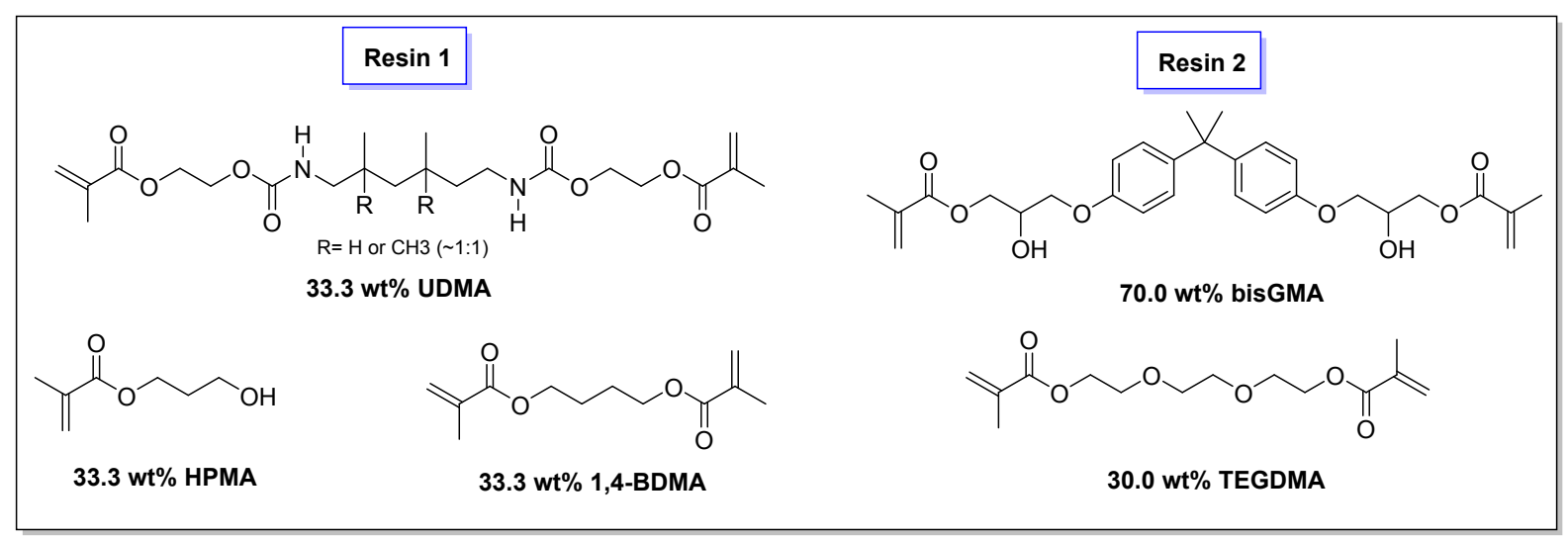

Scheme 2. Composition of the methacrylate resins (resins 1\&2) used.

Table 1: Viscosities of monomers (or solvent) used in the study 35,36

\begin{tabular}{|c|c|}
\hline Fluids & Viscosities (at 25 $\left.{ }^{\circ} \mathbf{C}\right):$ \\
\hline water & 0.001 Pa.s \\
\hline HEMA & 0.004 Pa.s \\
\hline Resin 1 & 0.053 Pa.s \\
\hline Resin 2 & 5.7 Pa.s \\
\hline
\end{tabular}

\section{2/ RT-FTIR spectroscopy}

A Jasco 6600 Real-Time Fourier Transformed Infrared Spectrometer (RT-FTIR) was used to follow the $\mathrm{C}=\mathrm{C}$ double bond conversion versus time for polymerizations of $1.4 \mathrm{~mm}$ thick samples. All the 
photopolymerization experiments were carried out at room temperature (RT) $\left(21-25^{\circ} \mathrm{C}\right)$ under air (oxygen inhibition expected ${ }^{22}$ ).

The evolution of the near infrared methacrylate $\mathrm{C}=\mathrm{C}$ double bond peak was followed from 6130 to $6200 \mathrm{~cm}^{-1}$. A laser diode LD@785 nm (CNI lasers) having an irradiance of $400 \mathrm{~mW} / \mathrm{cm}^{2}$ at the sample position was used for the photopolymerization experiments (see emission spectrum in Figure S3). The intensity of this laser diode can also be increased to $2.55 \mathrm{~W} / \mathrm{cm}^{2}$. A LED@405 nm (Thorlabs, 110 mW/cm²), LED@470nm (Thorlabs, 80 mW/cm²), a LED@530 nm (Thorlabs, $30 \mathrm{~mW} / \mathrm{cm}^{2}$ ) and a LED@660 nm (Thorlabs, $80 \mathrm{~mW} / \mathrm{cm}^{2}$ ) were also used. The emission spectra are already available in the literature. ${ }^{37}$

\section{3/ Definition of the two components used for redox experiments}

All redox formulations were prepared from the bulk resins in two separate cartridges at room temperature $(\mathrm{RT})\left(21-23^{\circ} \mathrm{C}\right)$ : a first cartridge with the oxidizing agent (APS) with the same amount of water (for solubility) and the other one containing the Fe(II) with or without additional reducing agent. A 1:1 Sulzer $\operatorname{mixpac}^{\circledR}$ mixer was used to mix both components together at the beginning of each polymerization experiment. The contents of reduction or oxidation agents will be given in weight with respect to the final resin after mixing.

\section{4/ Redox polymerization followed by optical pyrometry}

The use of optical pyrometry to follow polymerization reactions was developed by Crivello et al. ${ }^{38,39}$ Optical pyrometry is an interesting technique to monitor polymerization ${ }^{38,40}$ : qualitative assessment of the polymerization is provided (through exothermicity) with simultaneous measurement of the gel time. Gel time will be defined here as the time to reach the temperature maximum. Temperature versus time profiles were followed here using an Omega OS552-V1-6 Industrial Infrared Thermometer (Omega Engineering ${ }^{\circledR}$, Inc., Stamford, CT) having a sensitivity of \pm 1 ${ }^{\circ} \mathrm{C}$ for $2 \mathrm{~g}$ samples (thickness $\sim 4 \mathrm{~mm}$ ).

\section{5/ UV-visible-NIR absorption spectroscopy}


UV-vis-NIR absorption spectra in $\mathrm{ACN}$ (quartz cell) were acquired using a $\operatorname{Varian}^{\circledR}$ Cary 3 spectrophotometer.

\section{6/ Computational Procedure}

Geometry optimizations ${ }^{41}$ were calculated at UB3LYP/6-31G* level; geometries were frequency checked. The electronic absorption spectra were calculated from the time-dependent density functional theory at MPW1PW91/6-31G* level of theory on the relaxed geometries calculated at the UB3LYP6-31G*level of theory. The molecular orbitals (MOs) involved in these transitions were extracted.

\section{7/ Electron Spin Resonance-Spin Trapping (ESR - ST)}

\subsection{1/ Experimental}

Electron spin resonance experiments were carried out using a X-band spectrometer (Bruker EMXplus Biospin). ESR-ST experiments were performed using $N$-tert-butyl- $\alpha$-phenylnitrone (PBN) as a spin trapping agent in a similar way as described in other works. ${ }^{42} \mathrm{For}$ the Fe7*/lod interaction, the radical adducts were directly observed at room temperature under nitrogen saturated media in a toluene solution after NIR irradiation (under a LED@780 nm (Thorlabs) operating at $80 \mathrm{~mW} / \mathrm{cm}^{2}$ ). For the Fe(II)/APS interaction, a first solution was prepared with APS in water when a second one contained ferrocene and PBN in toluene. After a short mixing of both phases (10 seconds), the toluene phase was extracted and inserted in an ESR tube (under air). That latter was then degassed under nitrogen and analyzed at room temperature. The ESR spectra simulations were carried out using the WINSIM software.

\subsection{2/ ESR Spectra calculations}

For ESR spectra calculations, the radical/spin trap adducts were optimized at anUB3LYP/6$31 \mathrm{G}$ (d) level of theory. ${ }^{41} \mathrm{~A}$ solvent effect on the geometry of radical/PBN adducts was estimated in the 
framework of the conductor-like polarizable continuum model, C-PCM. ${ }^{43}$ Thegeometries were frequency checked. An UB3LYP method was combined with the NO7D basis set in order to calculate of the isotropic hyperfine coupling constants (HFCCs) according to a method recently published. ${ }^{43}$

\section{8/ Cyclic Voltammetry (CV)}

The redox potentials ( $E_{o x}$ VS. SCE) of the reducing agents were determined by cyclic voltammetry (at $0.1 \mathrm{~V} / \mathrm{s}$, uncertainty of $\pm 0.05 \mathrm{~V}$ ) in an $\mathrm{ACN}$ solution containing $0.2 \mathrm{M}$ tetrabutylammonium hexafluorophosphate (Aldrich) as a supporting electrolyte. A platinum electrode was used as a working electrode and a saturated calomel electrode (SCE) was used as a reference electrode.

\section{9/ Free Energy Calculations for Electron Transfer $\left(\Delta G_{e t}\right)$}

The free energy change $\Delta G_{\text {et }}$ for an electron transfer reaction was calculated from the classical equation (eq. 1$)^{44}$ where $E_{o x}, E_{r e d}, E_{S}$, and $C$ are the oxidation potential of the electron donor, the reduction potential of the electron acceptor (here $-0.59 \mathrm{~V}$ vs SCE for $\operatorname{lod}^{3,12}$ ), the excited state energy and the Coulombic term for the initially formed ion pair, respectively. $\mathrm{C}$ is neglected as usually done in polar solvents.

$$
\Delta G_{\text {et }}=E_{o x}-E_{r e d}-E_{S}+C
$$

As no fluorescence was detected for the ferrocene derivatives, we used the UV-vis absorption end tail of the UV-vis absorption band for the calculation of the excited state energy as commonly done. ${ }^{45}$ This method generally leads to a slight underestimation of the excited state energy.

\section{Results and discussion}

\section{1/ Light and NIR photoredox catalysis behavior}

\subsection{1/ Light absorption properties}

The light absorption properties of the ferrocene derivatives studied are presented in Figure 1 and the results are summed up in Table 2 for different excitation wavelengths. Two transitions are 
causing some visible light absorption in the ferrocenes bearing acceptor moieties: a donor-acceptor charge-transfer transition (DA-CT) which is the lowest energy transition (highest wavelength) and an interligand $\pi-\pi^{*}$ transition (LL-CT, lower wavelength). ${ }^{20}$ Interestingly, a tuning of the acceptor moiety strongly influences the DA-CT (see changes of HOMO/LUMO in Figure S4) thus inducing a bathochromic shift and an enhancement of the absorptivity in the visible domain. Particularly, the derivatives Fe4 and Fe7 are absorbing NIR light with respectively $\varepsilon(785 \mathrm{~nm})=90 \mathrm{M}^{-1} \cdot \mathrm{cm}^{-1}$ and $\varepsilon(785 \mathrm{~nm})=190 \mathrm{M}^{-1} \cdot \mathrm{cm}^{-}$ ${ }^{1}$. Noteworthy, it was recently shown that the derivative Fe7 can undergo some slight solvatochromic shift to higher wavelengths $\left(\Delta \lambda_{\max }=19 \mathrm{~nm}\right)$ when going from hexane to chloroform through an increase of the acceptor strength in the complex. ${ }^{17}$ Finally, the original Fe7Me compound shows a greatly enhanced and red shifted light absorption (Figure1, curve i). It was indeed expected as the donor part involved in the last transition (DA-CT) is enhanced by the methyl groups on the cyclopentadienyl ring. Numerically, an enhanced absorption ability is evidenced for Fe7Me compared to Fe7, with a molar extinction coefficient of $\varepsilon(785 \mathrm{~nm})=3700 \mathrm{M}^{-1} \cdot \mathrm{cm}^{-1}$ for Fe7Me against $190 \mathrm{M}^{-1} \cdot \mathrm{cm}^{-1}$ for the Fe7 derivative.

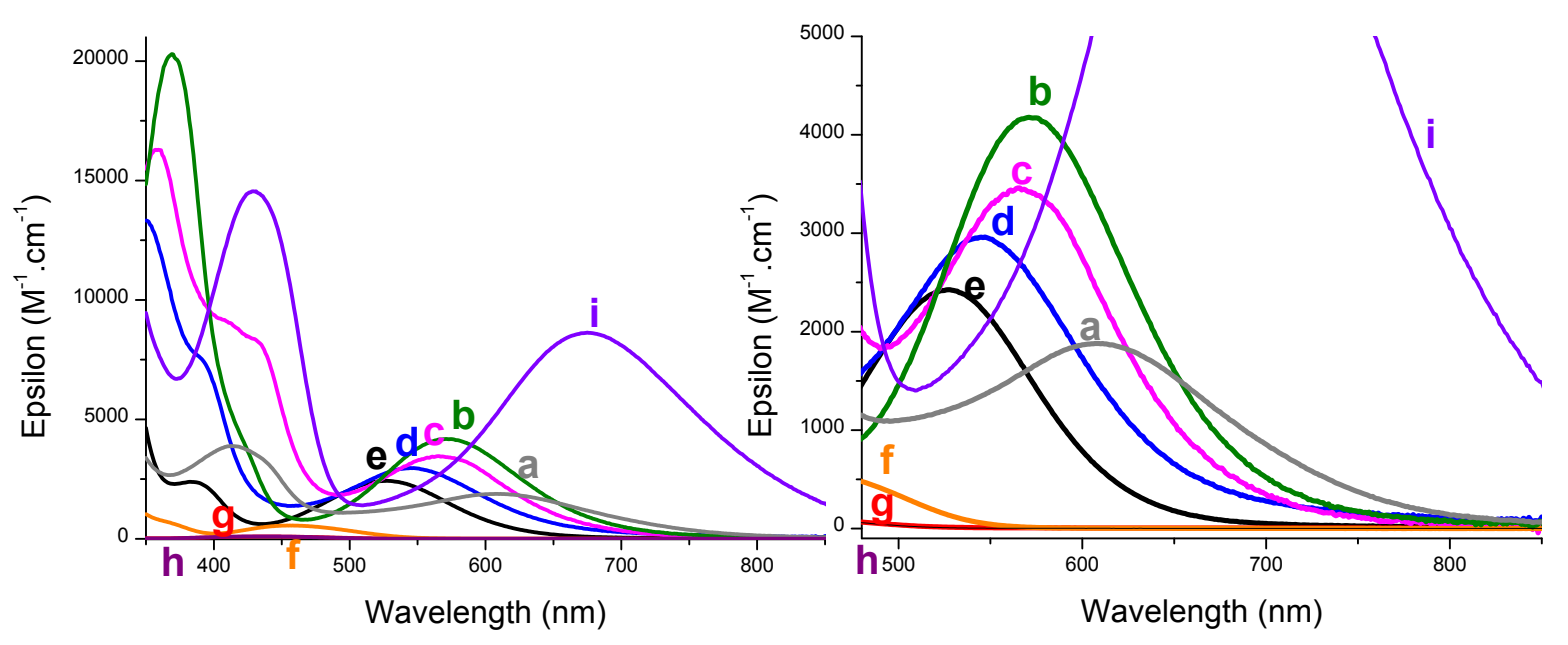

Figure 1: UV-vis-NIR Absorption properties in ACN of the ferrocene derivatives studied here: (a): Fe7; (b):Fe4; (c):Fe6; (d):Fe3; (e):Fe5; (f): Fe1; (g): Fe; (h): Fe2; (i): Fe7Me. 
Table 2: Main calculated (at an UB3LYP/6-31G* level of theory, see Figure S4) and experimental light absorption properties for the ferrocene derivatives studied.

\begin{tabular}{|c|c|c|c|c|}
\hline $\begin{array}{l}\text { Ferrocene } \\
\text { derivative }\end{array}$ & $\begin{array}{c}\lambda_{\max }(\text { calc. })^{\mathrm{a}} \\
\mathrm{nm}\end{array}$ & $\begin{array}{c}\lambda_{\max }(\exp .) \\
\mathrm{nm}\end{array}$ & $\begin{array}{c}\varepsilon(405 \mathrm{~nm}) \\
M^{-1} \cdot \mathrm{cm}^{-1}\end{array}$ & $\begin{array}{c}\varepsilon(785 \mathrm{~nm}) \\
M^{-1} \cdot \mathrm{cm}^{-1}\end{array}$ \\
\hline $\mathrm{Fe}$ & $<450$ & 440 & 75 & $\sim 0$ \\
\hline Fe1 & 549 & 455 & 230 & $\sim 0$ \\
\hline Fe2 & $<450$ & 438 & 75 & $\sim 0$ \\
\hline $\mathrm{Fe} 3$ & 601 & 545 & 5500 & $<30$ \\
\hline Fe4 & 611 & 571 & 6800 & 90 \\
\hline Fe5 & 584 & 525 & 5980 & $\sim 0$ \\
\hline Fe6 & 598 & 565 & 9220 & $<15$ \\
\hline Fe7 & 631 & 609 & 3780 & 190 \\
\hline Fe7Me & 659 & 675 & 11440 & 3700 \\
\hline
\end{tabular}

a: molecular modeling data.

Next, we tried to calculate the free energy change for an electron transfer to lod $\left(\Delta G_{\text {et }}\right)$ for these different derivatives at the lowest excited state energy using $\mathrm{CV}$ and the light absorption properties (Table 3). All the Fe derivatives exhibited excellent reversible oxidation in $\mathrm{CV}$ ranging from $0.22 \mathrm{~V}$ to $0.74 \mathrm{~V}$ (vs SCE). The introduction of methyl donor moieties in Fe2 lowers the oxidation potential compared to reference $\mathrm{Fe}(0.22 \mathrm{~V}$ against $0.33 \mathrm{~V})$ in line with the litterature. ${ }^{46}$ Similarly, the introduction of an acceptor moiety enhances the oxidation potential in Fe1 ( $\left.E_{o x}=0.65 \mathrm{~V}\right), \mathrm{Fe} 3\left(\mathrm{E}_{\mathrm{ox}}=0.62\right.$ V), Fe4 $\left(E_{o x}=0.65 \mathrm{~V}\right)$, Fe5 $\left(E_{o x}=0.74 \mathrm{~V}\right)$, Fe6 $\left(E_{o x}=0.59 \mathrm{~V}\right)$, Fe7 ( $\left.E_{o x}=0.65 \mathrm{~V}\right)$. Interestingly, the original Fe7Me compound has strong donor moieties (five methyl groups on the bottom cyclopentadienyl ring) which results in a lower oxidation potential $\left(E_{o x}=0.4 V\right)$ in line with the ferrocene literature ${ }^{46}$ but also a lower excited state energy (as the light absorption was red shifted) which leads to a $\Delta G_{\text {et }}$ for electron transfer roughly similar to the one of Fe7 (-0.37 eV for Fe7Me against $-0.31 \mathrm{eV}$ for Fe7). The * Fe/lod electron transfer is found possible for all the derivatives $\left(\Delta \mathrm{G}_{\mathrm{et}}<-0.3 \mathrm{eV}\right)$. We will apply this photooxidation reaction to photopolymer synthesis in the next part of the article (§3.1.2). 
Table 3: Calculation of Gibbs energy for electron transfer $\Delta G_{\mathrm{et}}$ for the photooxidation reaction with lod $\left(\mathrm{Ar}_{2} \mathrm{I}^{+}, \mathrm{E}_{\mathrm{red}}=-0.59 \mathrm{~V}\right.$ vs SCE$)$ using experimental parameters (see equation in §2.9).

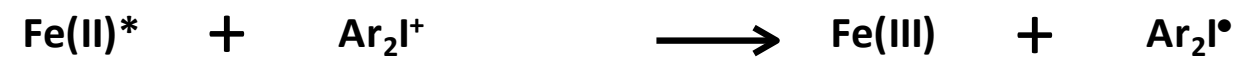

\begin{tabular}{|c|c|c|c|}
\hline $\begin{array}{c}\text { Ferrocene } \\
\text { derivative }\end{array}$ & $\mathrm{E}_{\text {ox }}(\mathbf{V}$ vs SCE $)$ & $\mathrm{E}_{\mathbf{s}}(\mathbf{e V})$ & $\Delta \mathbf{G}_{\text {et }}(\mathrm{eV})$ \\
\hline $\mathrm{Fe}$ & 0.33 & 2.25 & -1.33 \\
\hline Fe1 & 0.65 & 2.21 & -0.97 \\
\hline Fe2 & 0.22 & 2.34 & -1.53 \\
\hline Fe3 & 0.62 & 1.63 & -0.42 \\
\hline Fe4 & 0.65 & 1.63 & -0.39 \\
\hline Fe5 & 0.74 & 1.88 & -0.55 \\
\hline Fe6 & 0.59 & 1.66 & -0.48 \\
\hline Fe7 & 0.65 & 1.55 & -0.31 \\
\hline Fe7Me & 0.40 & 1.36 & -0.37 \\
\hline
\end{tabular}

\subsection{2/ Application to visible light and NIR induced polymerization}

Under mild LED@405 nm irradiation, slow polymerization efficiencies (final C=C function conversion (FC) below $40 \%$ after 400s, Figure $2 \mathrm{~A}$ ) are recorded for derivatives $\mathrm{Fe} / \mathrm{lod}$, Fe5/lod, Fe3/lod and Fe4/lod when no photoinitiating ability was recorded for Fe6 and Fe7. The low LED@405 nm irradiance may be involved. Poor polymerization is also obtained for Fe3/lod and Fe5/lod for other low irradiance visible LEDs at $660 \mathrm{~nm}$ and at 540 nm (Figure S5). More interestingly, the introduction of a third component, the2-diphenylphoshphinobenzoic acid also noted 2dppba (Scheme 1), spectacularly increases the radical production rate with more than $70 \%$ conversion after 25 s for an irradiation @ 405 $\mathrm{nm}$ (Figure 2A). As a reminder, a final conversion of $60 \%$ was obtained for a reference visible light (470 $\mathrm{nm}$ ) three-component system: camphorquinone (CQ) /amine(ethyl4(dimethylamino)benzoate)/phosphine(4-diphenylphosphino styrene) using the same resin and setup ${ }^{47}$ Similarly, Fe2/lod is not efficient under the LED@470 nm in the low viscosity resin (Figure 2B, 
curve 1); when adding reducing agent such as VitC in Fe2/lod/VitC (FC=66 \%) or 2 dppba in $\mathrm{Fe} 2 / \mathrm{lod} / 2 \mathrm{dppba}(\mathrm{FC}=78 \%$ ) spectacularly enhances radical generating rate under air.
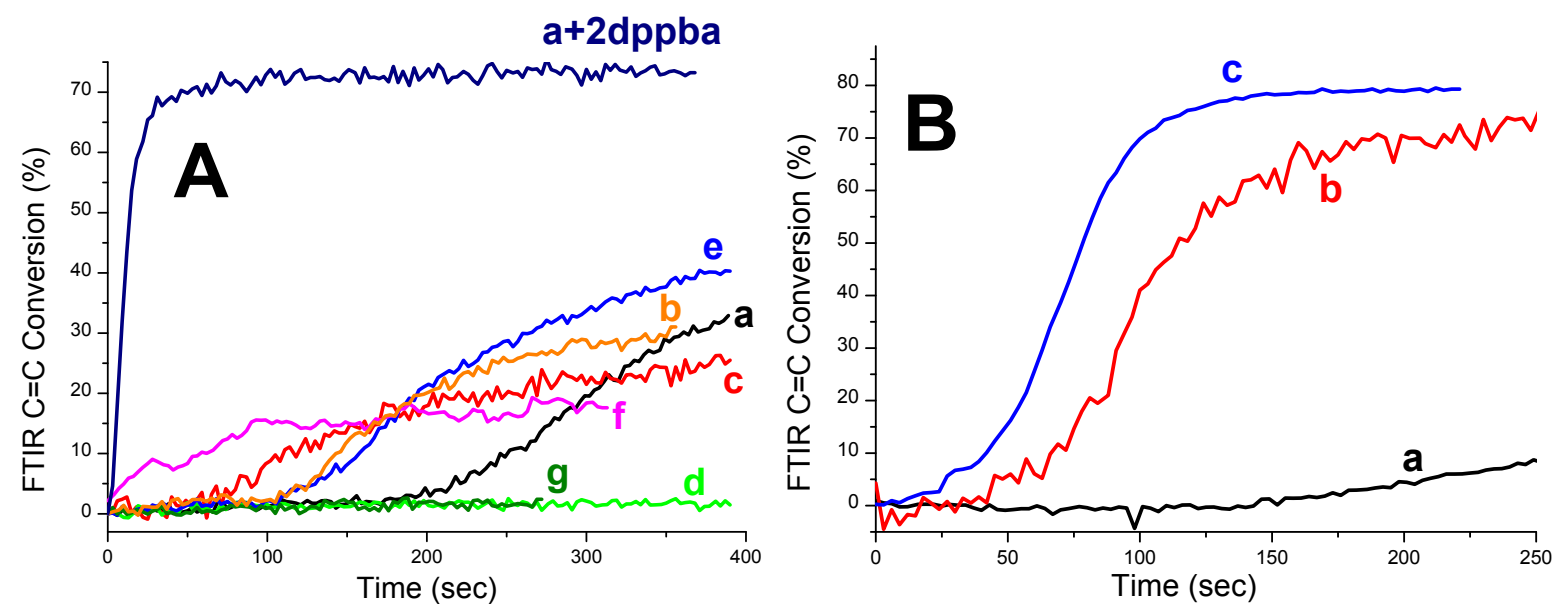

Figure 2: Photopolymerization profiles (methacrylate $C=C$ function conversion vs. irradiation time, irradiation starts at t=0s) measured in RT-FTIR; 1.4 mm thick samples, in air. A: upon LED@405nm irradiation (110 mW/ $\left.\mathrm{cm}^{2}\right)$, in resin 2, for 0.5 wt\% Fe(II) and $1.0 \mathrm{wt} \%$ lod. Initiating systems: (a): Fe/lod; (a+2dppba): Fe/lod/2dppba (1.5 wt\%); (b): Fe5/lod; (c): Fe3/lod; (d): Fe6/lod;(e):Fe1/lod;(f): Fe4/lod(g): Fe7/lod. B: upon LED@470nm irradiation $\left(80 \mathrm{~mW} / \mathrm{cm}^{2}\right)$, in resin 1, for 0.3 wt\% Fe2 and 2.0 wt\% lod. Initiating systems: (a): Fe2/lod; (b): Fe2/lod/2.5 wt\% VitC (+10 wt\% water);(c): Fe2/lod/1.5 wt\% 2 dppba.

Next, under mild LD@785 nm irradiation (Figure 3A, $0.4 \mathrm{~W} / \mathrm{cm}^{2}$ ), photopolymerization efficiency is recorded for the first time for a NIR Fe(II)*/Ar$I_{2}{ }^{+}$interaction. In detail, Fe4/lod system is not efficient when 0.1 wt\% Fe(II) is used but more efficient for 0.5 wt\% Fe4. Fe7Me/lod system is not at all efficient (though light absorption was enhanced at $785 \mathrm{~nm}$, see Table 2) which could be due to a lower excited states energy (Table 3). On the contraryFe7/lod system is still efficient at 1000 ppm (0.1 wt\%) Fe(II) (Figure $3 \mathrm{~A}$ curve a, $\mathrm{FC}=30 \%$ ) and can be improved for more concentrated Fe7 content $(0.5$ wt $\%$, Figure $3 \mathrm{~A}$ curve $\mathrm{b}, \mathrm{FC}=40 \%)$. This can be even improved using reducing agents in $\mathrm{Fe} 7 / \mathrm{lod} / 2 \mathrm{dppba}$ ( $\mathrm{FC}=48 \%$ after 300s Figure 3A curve c) or in Fe7/lod/DMABA (FC=50\% after 250s, Figure 3A curve d). Finally, that last formulation can be outstandingly enhanced when using a higher irradiance $\left(2.55 \mathrm{~W} / \mathrm{cm}^{2}\right.$, Figure $3 \mathrm{~B}$, curve b): up to $83 \% \mathrm{C}=\mathrm{C}$ conversion is obtained for a multifunctional resin. This result clearly outranks the previous visible light reference (CQ/amine/phosphine) as only a $60 \%$ conversion was 
obtained upon blue light $(470 \mathrm{~nm})$ irradiation. The improvement in conversion could be related to a slightly higher reaction temperature due to the high irradiance. ${ }^{48}$ Under selected conditions, the $\mathrm{Fe}(\mathrm{II})^{*} / \mathrm{Ar}_{2} \mathrm{I}^{+} /$reducing agent NIR photocatalysis can be very efficient. Noteworthy, the $\mathrm{Fe}(\mathrm{II}) /$ reducing agent systems are not strong enough to reduce the iodonium salt without light as all formulations were stable for more than 1 day at room temperature (iodonium salt have a too low reduction potential).
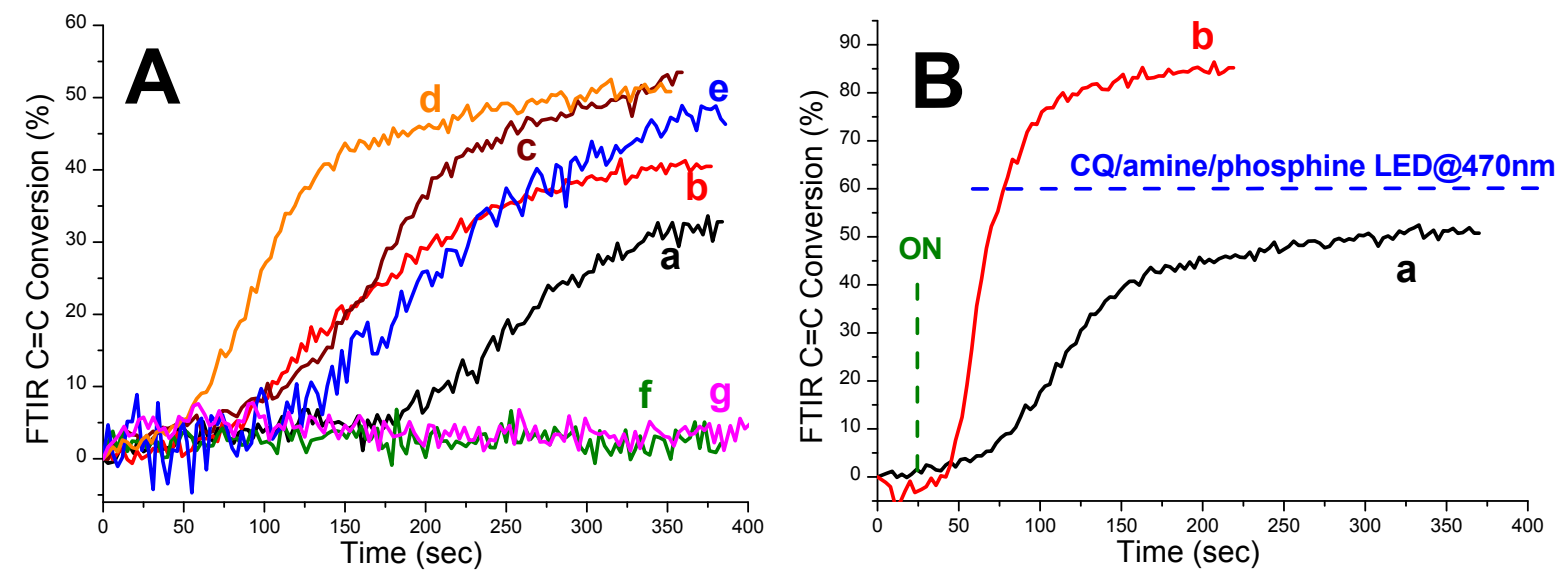

Figure 3: Photopolymerization profiles (methacrylate $\mathrm{C}=\mathrm{C}$ function conversion vs. irradiation time) measured in RT-FTIR for the resin 2; $1.4 \mathrm{~mm}$ thick samples, in air, upon NIR (LD@785nm) irradiation for $2.0 \mathrm{wt} \%$ lod and $1.5 \mathrm{wt} \%$ Reducing agent (2dppba or DMABA). A: $400 \mathrm{~mW} / \mathrm{cm}^{2}$ irradiation starts at t=0s (a): 0.1 wt\% Fe7/lod; (b):0.5 wt\% Fe7/lod; (c): 0.5 wt\% Fe7/lod/2dppba; (d): 0.5 wt\% Fe7/lod/DMABA; (e): 0.5 wt\% Fe4/lod; (f): 0.1 wt\% Fe4/lod);(g): 0.5 wt\% Fe7Me/lod. B: (curves, light irradiation starts at $\mathrm{t}=25 \mathrm{~s}$ ) for $0.5 \mathrm{wt} \% \mathrm{Fe} / / \mathrm{lod} / \mathrm{DMABA}$ upon (a): $400 \mathrm{~mW} / \mathrm{cm}^{2}$ irradiance and(b): 2.55 $\mathrm{W} / \mathrm{cm}^{2}$ irradiance. Embedded: Final conversion (60\%) obtained for a reference visible light $(470 \mathrm{~nm}) 3$ component PIS: CO/amine(ethyl 4-(dimethylamino)benzoate)/phosphine(4-diphenylphosphino styrene) using the same resin and setup but using the LED@470 nm.47

\section{2/ Fe(II) compatibility with redox initiated FRP}

Next, as Fe(II) complexes are able to decompose peroxides (though this reaction was i) slow and ii) under nitrogen in the literature ${ }^{49,50}$ ), we attempted to perform a redox decomposition of 
ammonium persulfate (APS) using newly developed catalytic cycles (without light). This could be useful in order to combine the ${ }^{*} \mathrm{Fe}(\mathrm{II}) / \mathrm{Ar}_{2} \mathrm{I}^{+}$photoredox catalysis with a potential $\mathrm{Fe}(\mathrm{II}) / \mathrm{APS}$ redox catalysis (no need of light) for redox photoactivated polymerization and dual-cure systems. In Figure 4A, Fe/APS system (curve a) is not really efficient with no exothermicity (thus very slow monomer conversion). The introduction of a reducing agent such as 2 dppba is strongly enhancing the radical generation (Figure 4A, curve b) similarly to the $\mathrm{Cu}(\mathrm{I}) /$ peroxide/reducing agent systems very recently developed for redox FRP. ${ }^{31,51} \mathrm{An}$ exothermicity of $70{ }^{\circ} \mathrm{C}$ is obtained which is rather good for that resin (roughly, a maximum of $90-100{ }^{\circ} \mathrm{C}$ exothermicity can be obtained for a reference amine/peroxide redox FRP system in that resin (same setup)). As water was necessarily present to dissolve APS in the methacrylate resin, we could not follow the reaction by RT-FTIR. For the other Fe(II) derivatives (Figures 4A and 4B), mixed results are obtained in Fe(II)/APS/2dppba systems (1000 ppm Fe(II) used). The trend in efficiency follows the maximum $\mathrm{T}^{\circ} \mathrm{C}$ reached: $\mathrm{Fe} 4\left(60^{\circ} \mathrm{C}\right)>\mathrm{Fe} 3\left(38^{\circ} \mathrm{C}\right) \approx \mathrm{Fe} 7\left(37^{\circ} \mathrm{C}\right)>>\mathrm{Fe} 5=$ Fe1 = Fe6 (no exothermicity). It is not yet clear what is the main factor leading to a good reactivity but the oxidation potential of Fe5 (too high) could explains the observed poor efficiency. Also, the concentration of $\mathrm{Fe}(\mathrm{II})$ cannot be too high as Fe(II) is capable to reduce radicals (e.g in $\mathrm{r} 1$ ) into inactive anions as exemplified in the Figure S6 using $1.3 \mathrm{wt} \%$ of Fe(II) (then, the redox FRP is slow down for too high Fe(II) concentrations).

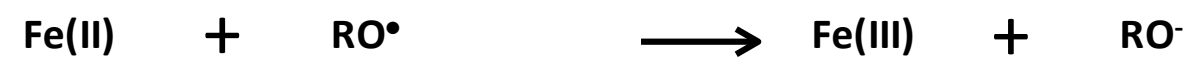

Remarkably, the redox FRP initiating system developed (Fe7/APS/2dppba) can be acceleratedon demand using NIR photoredox catalysis developed above (Figure 4C): Curing was occurring in only 400s using light (lod added for photoredox reaction) when 1300s were necessary without light. Noteworthy, the Fe/APS/2dppba redox initiating system is highly robust towards the oxygen inhibition as pure HEMA (viscosity close to water, see Table 1) is also polymerized in bulk (Figure 4D). Such systems could be applied to the synthesis of hydrogels. ${ }^{52}$ 

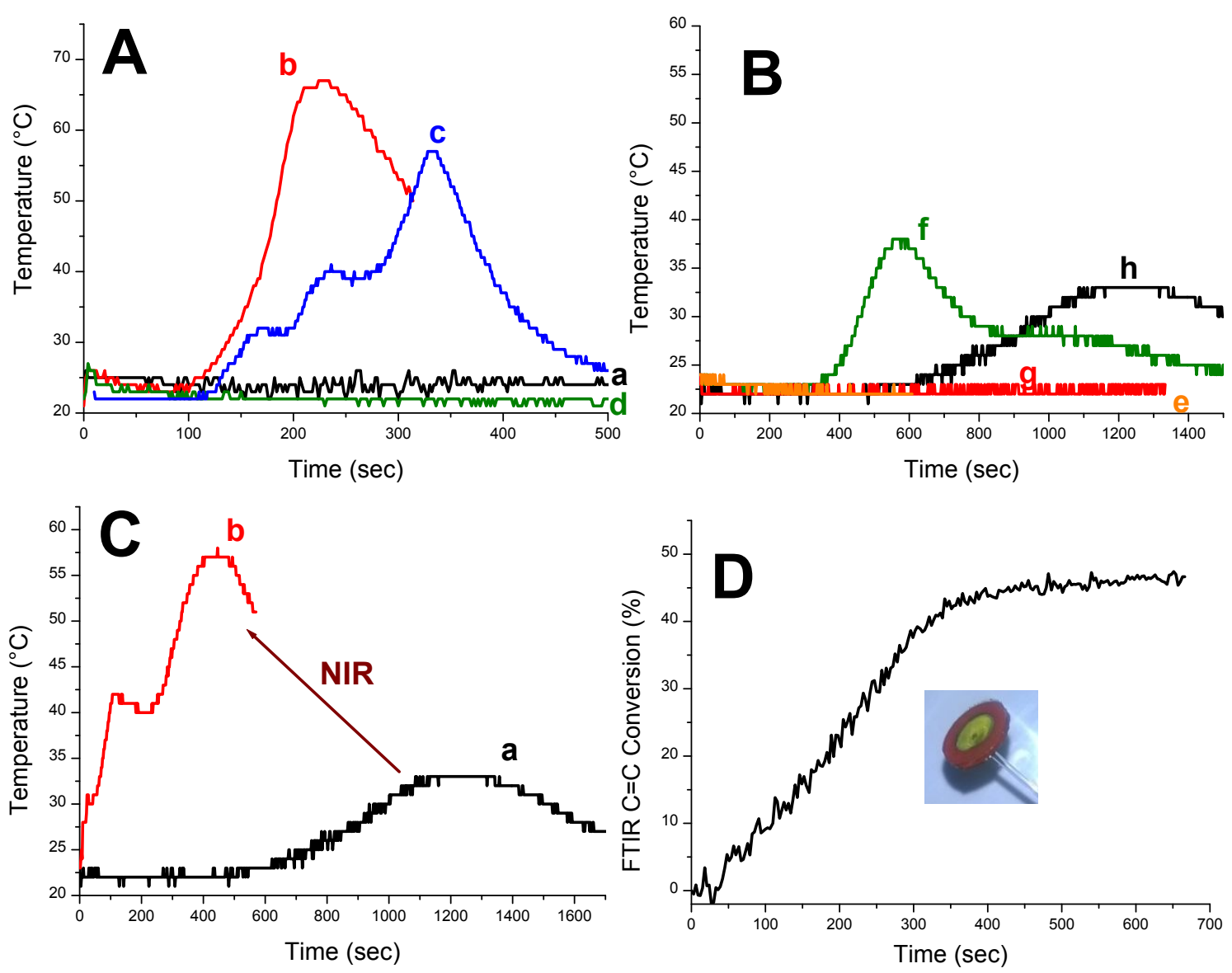

Figure 4: Redox polymerization A,B,C: Optical pyrometric measurements (Temperature vs. mixing time, $4 \mathrm{~mm}$ samples), under air for resin 1 for 2.0 wt\% APS (+2.0 wt\% water) mixed with $0.1 \mathrm{wt} \% \mathrm{Fe}(\mathrm{II})$ and (if mentioned) $1.5 \quad w t \% \quad 2 d p p b a ; A:(a) F e / A P S ; \quad$ (b)Fe/2dppba/APS;(c) $\mathrm{Fe} 4 / 2 \mathrm{dppba} / \mathrm{APS} ;(\mathbf{d}) \mathrm{Fe} 1 / 2 \mathrm{dppba} / \mathrm{APS} ; \quad$ B:(e)Fe5/2dppba/APS; $\quad$ (f) $\quad \mathrm{Fe} 3 / 2 \mathrm{dppba} / \mathrm{APS}$;(g) Fe6/2dppba/APS; (h)Fe7/2dppba/APS;C: (a) Fe7/2dppba/APS without light and (b) Fe7/2dppba/APS (+1.0 wt\% lod) under NIR light (redox photoactivation, LD@785 nm at 0.4 W/cm²);D: Redox polymerization profiles (methacrylate $\mathrm{C}=\mathrm{C}$ function conversion vs. mixing time) measured in RT-FTIR in pure HEMA; $1.4 \mathrm{~mm}$ thick samples, under air. Redox initiating system: $0.1 \mathrm{wt} \% \mathrm{Fe}+2 \mathrm{dppba}$ mixed with 2.5 w\% APS (+2.5 wt\% water). Embedded: image of the final HEMA polymer. 


\section{3/ Proposed chemical mechanisms}

\subsection{1/ Radical detection by ESR - spin trapping}

In Figure 5 and Table 4, radicals generated from the Fe(II)/oxidizing agent interactions are discussed. First, the photoredox $\mathrm{Fe}^{*} / \mathrm{Ar}_{2} \mathrm{I}^{+}$reaction is leading to an $\mathrm{Ar} \bullet / \mathrm{PBN}$ radical adduct as: the spectra show excellent fitting using hyperfine coupling constants (HFCCs) of aN $=14.1, a \beta-H=2.1$ which corresponds: i) to the experimental literature ${ }^{53}$ and ii) to theoretical HFCCs calculated at UB3LYP/NO7D level $(\mathrm{aN}=15.82 ; \mathrm{a} \beta-\mathrm{H}=1.99)$ for the radical adduct optimized in Figure $5 \mathrm{~A}$ (right).

Second, the Fe/APS redox reaction is leading to a radical/PBN adduct that was assigned to $\mathrm{SO}_{4}{ }^{\bullet-}$ /PBN radical adduct with the experimental HFCCs of: $\mathrm{aN}=13.6, \mathrm{a} \beta-\mathrm{H}=1.9$. Indeed, the theoretical values for a $\mathrm{SO}_{4}{ }^{\bullet} / \mathrm{PBN}$ radical adduct (in water) are very close to these value ( $\mathrm{aN}=13.62 ; \mathrm{a} \beta-\mathrm{H}=1.83$ Table 4; the structure of this radical adduct is given in Figure 5B (right)). The values are close to the ones computed in water as the anionic radical adduct was extracted from water which is likely to result in the presence of solvating water in the toluene extracted and analyzed. 

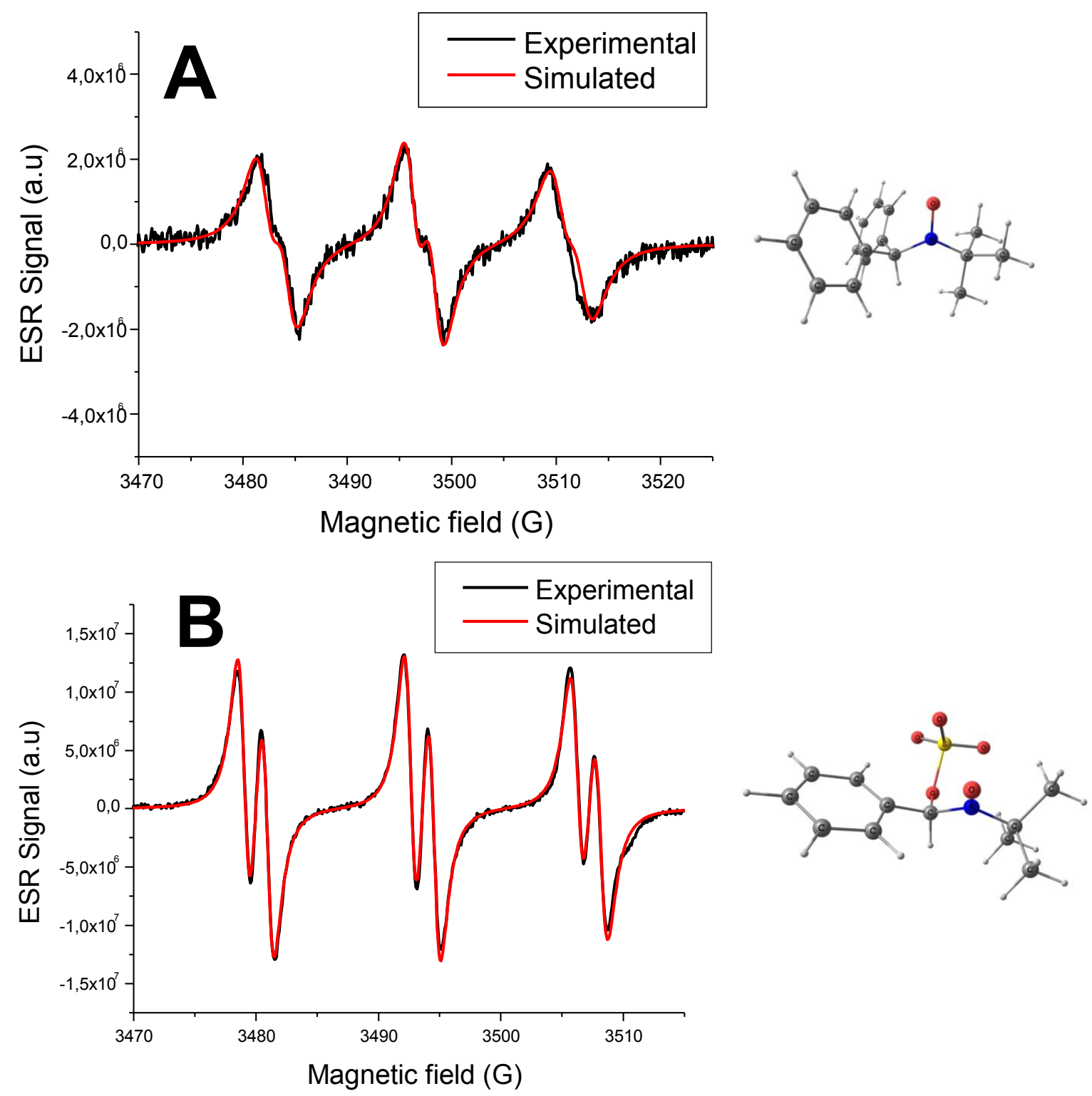

Figure 5: Determination of the radicals generated: ESR-ST spectra in toluene (PBN as spin trap, $\mathrm{N}_{2}$ degassed solutions) A: Irradiation (by a LED@780 nm, $80 \mathrm{~mW} / \mathrm{cm}^{2}$ ) of Fe7/diphenyliodonium hexafluorophosphate system and simulated spectra (WINSIM software). (right) the optimized structure (at UB3LYP/6-31G(d) level of theory) of a Ph\%/PBN radical adduct. B: Toluene extracted after 10s mixing of Fe (in toluene) with an APS/water solution and simulated spectra (WINSIM software). (right): the optimized structure (at UB3LYP/6-31G(d) level of theory) of a $\mathrm{SO}_{4}{ }^{\circ} / \mathrm{PBN}$ radical adduct. 
Table 4: Hyperfine coupling constants (HFCCS) experimentally determined (fit of the experimental spectra) or calculated by molecular modeling for the radical/PBN adducts (DFT level).

\begin{tabular}{|c|c|c|c|c|}
\hline Radical adduct & \multicolumn{2}{|c|}{ SO $_{4}{ }^{\bullet} / \mathrm{PBN}$} & \multicolumn{2}{c|}{$\mathrm{Ph} \cdot / \mathrm{PBN}$} \\
\hline Experimental HFCCS & $a_{\mathrm{N}}=13.6^{\mathrm{a}}$ & $a_{\beta-\mathrm{H}}=1.9^{\mathrm{a}}$ & $a_{\mathrm{N}}=14.1^{\mathrm{b}}$ & $a_{\beta-\mathrm{H}}=2.1^{\mathrm{b}}$ \\
\hline $\begin{array}{c}\text { DFT HFCCS } \\
\text { calculations }^{\mathrm{c}}\end{array}$ & $a_{\mathrm{N}}=13.62^{\mathrm{d}}$ & $a_{\beta-\mathrm{H}}=1.83^{\mathrm{d}}$ & $a_{\mathrm{N}}=15.82^{\mathrm{e}}$ & $a_{\beta-\mathrm{H}}=1.99^{\mathrm{e}}$ \\
\hline
\end{tabular}

${ }^{a}$ : in toluene (extracted from water); ${ }^{b}$ : in toluene; : at UB3LYP/NOTD (hfc constants)//UB3LYP/6$31 G(d)$ (geometry) level of theories; ${ }^{d}$ : in water; ${ }^{e}$ : in benzene.

\subsection{2/ Cyclic voltammetry (CV) and mechanistic proposition}

Finally, compared to Figure $6 \mathrm{~A}$ for Fe(II) alone, Figures $6 \mathrm{~B}$ and $6 \mathrm{C}$ show the regeneration of $\mathrm{Fe}(\mathrm{II})$ thanks to the presence of reducing agents (phosphine or amine) in CV. Indeed, there is a constant reoxidation occurring (not seen for Fe alone (Figure 6A) or when the sweeping rate is very fast not giving enough time for the reducing agent to regenerate Fe(II) from Fe(III) (Figure S7)). The slower the sweeping rate, the more re-oxidation of $\mathrm{Fe}(\mathrm{II})$ is seen (Figure $6(\mathrm{~B} \& \mathrm{C})$ ). These facts point to the reactions corresponding to the bottom of the catalytic cycles presented in Scheme 3, (Fe(III) + Red -> $\mathrm{Fe}(\mathrm{II})+\mathrm{Red}^{\bullet+}$ ) when the $\mathrm{Fe}(\mathrm{II})->\mathrm{Fe}(\mathrm{III})$ oxidation is occurring at the $\mathrm{CV}$ electrode as $\mathrm{E}>\mathrm{E}_{\mathrm{ox}}(\mathrm{Fe}(\mathrm{II}))$. Interestingly, even if the oxidation potential of $2 \mathrm{dppba}(1.0 \mathrm{~V}$ vs SCE) or DMABA (0.7 V vs SCE, same reactivity as 4-N,N TMA ${ }^{54}$ ) are not very low, reaction with Fe(III) (reduction potential of $0.3 \mathrm{~V}$ vs SCE) is still occurring. 

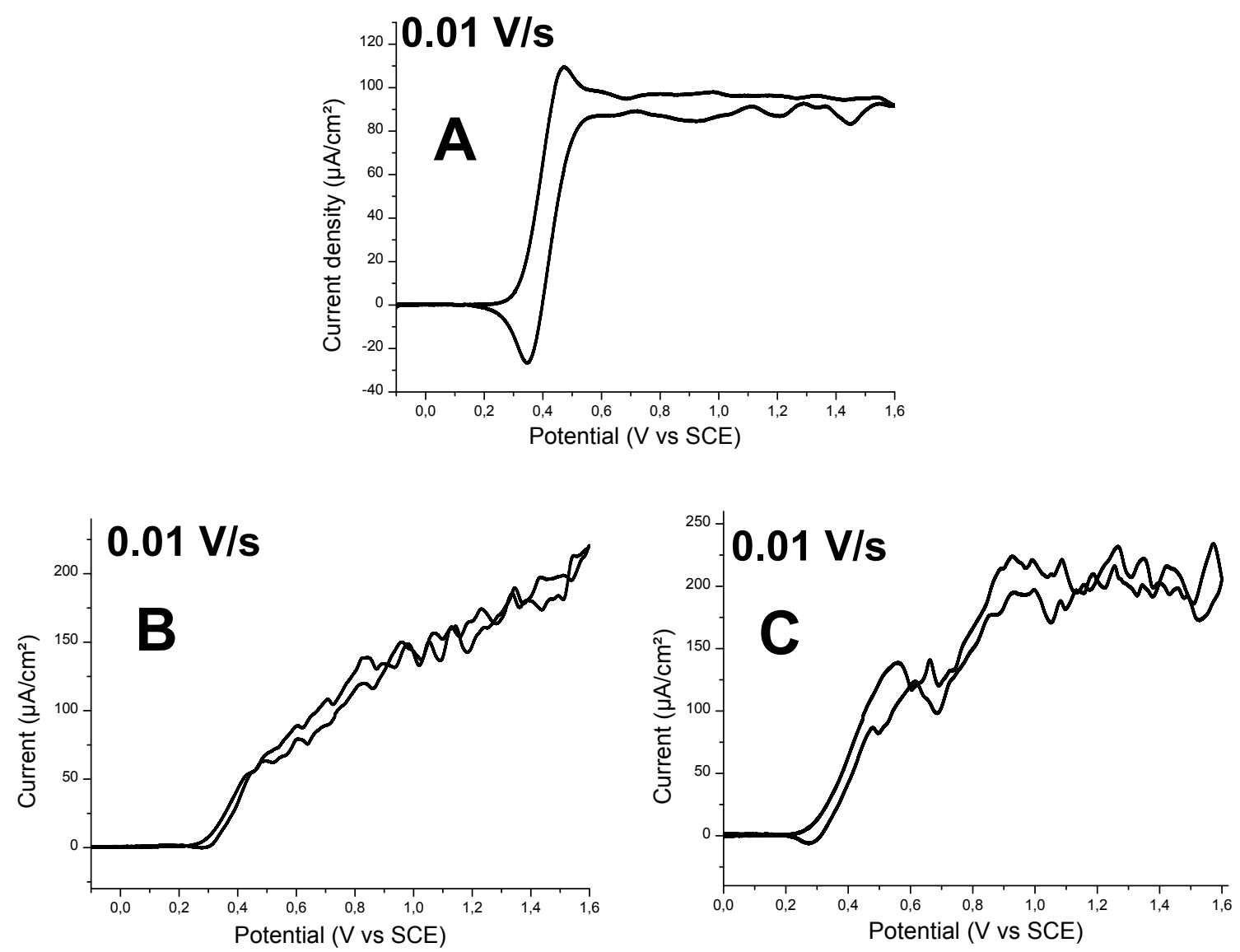

Figure 6: Regeneration of $\mathrm{Fe}(\mathrm{II})$ in catalytic cycles using cyclic voltammetry (CV) experiments in ACN (containing $0.2 \mathrm{M}$ tetrabutylammonium hexafluorophosphate, $\mathrm{N}_{2}$ degassed) for $\mathrm{A}$ : Fe alone B: $\mathrm{Fe}+$ 2dppba and C: Fe + amine (4-N,N TMA).

To sum up, under NIR irradiation, we propose in Scheme 3 a Fe(II)*/Ar $\left.{ }_{2}\right|^{+}$photoredox reaction that generated aryl radicals. Fe(III) produced can be reduced by phosphines, amines or VitC. This regenerates Fe(II) completing the catalytic cycle (Scheme 3 right). Without light, the Fe(II)/APS redox reaction is directly generating radicals $\left(\mathrm{SO}_{4}{ }^{\bullet-}\right.$ ) (Scheme 3 left). Similarly, $\mathrm{Fe}(\mathrm{III})$ reactions with phosphine enable completion of the catalytic cycle. 


\section{Photoredox (hv)}

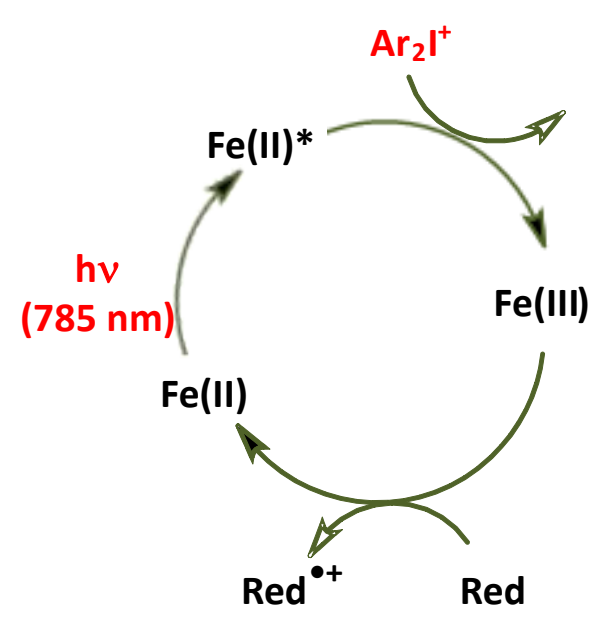

\section{Redox (no light)}

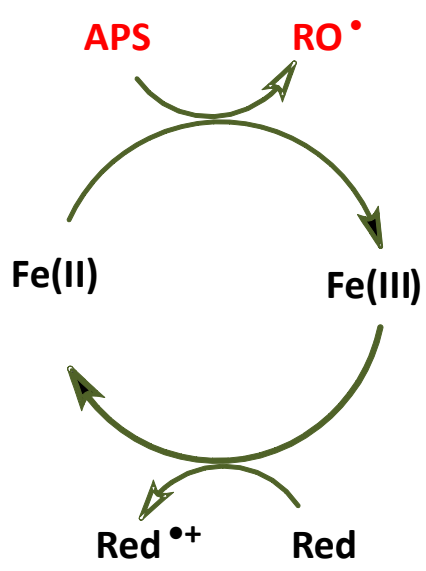

\section{Red $=$ Phosphines, amines or Vitamin C}

Scheme 3: Proposed photocatalytic (photoredox, under NIR irradiation) and redox catalytic (no light) mechanisms for the ferrocene/reducing agent (Red)/oxidizing agents considered in this study. $\mathrm{Ar}_{2} \mathrm{I}^{+}$ stands for iodonium salt and APS for amonium persulfate.

\section{Conclusion:}

Near infrared (NIR) photoredox catalysis using Fe(II) compounds are presented here for the first time. It was applied to the free radical photopolymerization of methacrylates (that requires high radical generating rate). The $\mathrm{Fe}(\mathrm{II})^{*} /$ lodonium $\left(\mathrm{Ar}_{2} \mathrm{l}^{+}\right)$reaction developed can be drastically improved thanks to the presence of reducing agents (phosphines, amines or VitC). The performances for a $\mathrm{Fe}(\mathrm{II}) / \mathrm{Ar}_{2} \mathrm{I}^{+} /$amine systems under a $785 \mathrm{~nm}$ irradiation are clearly outranking visible light references (such as camphorquinone/amine/phosphine) as higher final conversion can be reached (e.g. 83\% against $60 \%$ for the reference). Interestingly, the $\mathrm{Fe}(\mathrm{II})$ catalysts can also be active without light in redox free radical polymerization when mixed with ammonium persulfate and a reducing agent. It makes possible the development of orthogonal chemistries such as redox photoactivated polymerization: a redox reaction can take place without light and NIR light can be used on demand to 
trigger a second light induced reaction. This study paves the way towards the use of Fe(II)structures for highly efficient (photo)redox catalysis upon mild conditions (NIR light, room temperature and under air).

Supporting information available: Figures S1 and S2: synthesis of the different Fe complexes; Figure S3: emission spectrum of the LD@785nm; Figure S4: Frontier molecular orbitals and UV-vis calculated spectra of the Fe complexes; Figure S5: Photopolymerization profiles upon LED@660 and 530 nm; Figure S6: other redox polymerizations; Figure S7: other CV experiments.

Acknowledgments: This work was made possible by the financial support of ANR FastPrinting and VISICAT. The DGA (Direction Générale de l'Armement, France) is acknowledged for its financial support through the PhD grant of Damien Brunel. 


\section{References:}

1 D. Cambié, C. Bottecchia, N. J. W. Straathof, V. Hessel and T. Noël, Chem. Rev., 2016, 116, 1027610341.

2 S. Shi, C. Croutxé-Barghorn and X. Allonas, Prog. Polym. Sci., 2017, 65, 1-41.

3 J. Lalevée and J.-P. Fouassier, Dyes and Chomophores in Polymer Science, John Wiley \& Sons, 2015.

4 K. Ueno, T. Oshikiri, Q. Sun, X. Shi and H. Misawa, Chem. Rev., 2018, 118, 2955-2993.

5 M. H. Shaw, J. Twilton and D. W. C. MacMillan, J. Org. Chem., 2016, 81, 6898-6926.

6 N. Corrigan, S. Shanmugam, J. Xu and C. Boyer, Chem. Soc. Rev., 2016, 45, 6165-6212.

7 S. Dadashi-Silab, S. Doran and Y. Yagci, Chem. Rev., 2016, 116, 10212-10275.

8 N. Zivic, M. Bouzrati-Zerelli, A. Kermagoret, F. Dumur, J.-P. Fouassier, D. Gigmes and J. Lalevée, ChemCatChem, 2016, 8, 1617-1631.

9 J. Chen and W. R. Browne, Coord. Chem. Rev., 2018, 374, 15-35.

$10 \mathrm{~J}$. Lalevee and J.-P. Fouassier, Photopolymerisation Initiating Systems, The Royal Society of Chemistry, 2018.

11 T. Brömme, D. Oprych, J. Horst, P. S. Pinto and B. Strehmel, RSC Adv, 2015, 5, 69915-69924.

12 C. Schmitz, A. Halbhuber, D. Keil and B. Strehmel, Prog. Org. Coat., 2016, 100, 32-46.

13 B. Strehmel, S. Ernst, K. Reiner, D. Keil, H. Lindauer and H. Baumann, Z. Für Phys. Chem., 2014, 228, 129-153.

14 C. Kütahya, C. Schmitz, V. Strehmel, Y. Yagci and B. Strehmel, Angew. Chem. Int. Ed., 2018, 57, 7898-7902.

15 S. Shanmugam, J. Xu and C. Boyer, Angew. Chem. Int. Ed., 2016, 55, 1036-1040.

16 N. Corrigan, J. Xu and C. Boyer, Macromolecules, 2016, 49, 3274-3285.

17 I. Janowska, J. Zakrzewski, K. Nakatani, J. A. Delaire, M. Palusiak, M. Walak and H. Scholl, J. Organomet. Chem., 2003, 675, 35-41.

18 I. Janowska, J. Zakrzewski, K. Nakatani, M. Palusiak, M. Walak and H. Scholl, J. Organomet. Chem., 2006, 691, 323-330.

19 G. Qian and Z. Y. Wang, Chem. Asian J., 2010, 5, 1006-1029.

20 E. Stankovic, S. Toma, R. Van Boxel, I. Asselberghs and A. Persoons, J. Organomet. Chem., 2001, 637-639, 426-434.

21 J.-P. Fouassier and J. F. RABEK, Radiation Curing in Polymer Science and Technology, Springer Science \& Business Media, 1993.

22 S. C. Ligon, B. Husár, H. Wutzel, R. Holman and R. Liska, Chem. Rev., 2014, 114, 557-589.

23 D. C. Neckers, W. Jager and SITA Technology Limited, Chemistry \& Technology for UV \& EB Formulation for Coatings, Inks \& Paints, Photoinitiation for Polymerization: UV \& EB at the Millenium, Wiley, Chichester, 1999.

24 R. S. Davidson, Exploring the Science, Technology and Applications of U.V. and E.B. Curing, Sita Tecnology Limited, 1999.

25 B. Wenn, M. Conradi, A. Demetrio Carreiras, D. M. Haddleton and T. Junkers, Polym. Chem., 2014, 5, 3053-3060.

26 P. Wu, A. K. Feldman, A. K. Nugent, C. J. Hawker, A. Scheel, B. Voit, J. Pyun, J. M. J. Fréchet, K. B. Sharpless and V. V. Fokin, Angew. Chem., 2004, 116, 4018-4022.

27 N. J. Treat, B. P. Fors, J. W. Kramer, M. Christianson, C.-Y. Chiu, J. R. de Alaniz and C. J. Hawker, ACS Macro Lett., 2014, 3, 580-584.

28 P. Garra, F. Dumur, D. Gigmes, A. Al Mousawi, F. Morlet-Savary, C. Dietlin, J. P. Fouassier and J. Lalevée, Macromolecules, 2017, 50, 3761-3771.

29 P. Garra, C. Dietlin, F. Morlet-Savary, F. Dumur, D. Gigmes, J. P. Fouassier and J. Lalevée, Polym. Chem., 2017, 8, 7088-7101.

30 P. Garra, F. Dumur, F. Morlet-Savary, C. Dietlin, D. Gigmes, J. P. Fouassier and J. Lalevée, J. Polym. Sci. Part Polym. Chem., 2017, 55, 3646-3655.

31 P. Garra, A. Kermagoret, A. Mousawi, F. Dumur, D. Gigmes, F. Morlet-Savary, C. Dietlin, J. P. Fouassier and J. Lalevée, Polym. Chem., 2017, 8, 4088-4097. 
32 P. Garra, F. Dumur, F. Morlet-Savary, C. Dietlin, J. P. Fouassier and J. Lalevée, Macromolecules, 2016, 49, 6296-6309.

33 P. Garra, F. Morlet-Savary, C. Dietlin, J. P. Fouassier and J. Lalevée, Macromolecules, 2016, 49, 9371-9381.

34 M. Bielawski, D. Aili and B. Olofsson, J. Org. Chem., 2008, 73, 4602-4607.

35 J.-T. Chen and H.-P. Chu, J. Chem. Eng. Data, 2007, 52, 650-654.

36 P. Garra, M. Carré, F. Dumur, F. Morlet-Savary, C. Dietlin, D. Gigmes, J.-P. Fouassier and J. Lalevée, Macromolecules, 2018, 51, 679-688.

37 C. Dietlin, S. Schweizer, P. Xiao, J. Zhang, F. Morlet-Savary, B. Graff, J.-P. Fouassier and J. Lalevée, Polym. Chem., 2015, 6, 3895-3912.

38 B. Falk, S. M. Vallinas and J. V. Crivello, J. Polym. Sci. Part Polym. Chem., 2003, 41, 579-596.

39 J. V. Crivello and J. H. W. Lam, J. Polym. Sci. Polym. Chem. Ed., 1981, 19, 539-548.

40 P. Garra, A.-H. Bonardi, A. Baralle, A. Al Mousawi, F. Bonardi, C. Dietlin, F. Morlet-Savary, J.-P. Fouassier and J. Lalevée, J. Polym. Sci. Part Polym. Chem., 2018, 56, 889-899.

$41 \mathrm{~J}$. Foresman and E. Frish, Gaussian Inc Pittsbg. USA.

42 P. Xiao, F. Dumur, J. Zhang, J. P. Fouassier, D. Gigmes and J. Lalevée, Macromolecules, 2014, 47, 3837-3844.

43 E. F. Belogolova, T. I. Vakul'skaya and V. F. Sidorkin, Phys. Chem. Chem. Phys., 2015, 17, 1273512746.

44 Rehm Dieter and Weller Albert, Isr. J. Chem., 1970, 8, 259-271.

45 A. A. Mousawi, A. Kermagoret, D.-L. Versace, J. Toufaily, T. Hamieh, B. Graff, F. Dumur, D. Gigmes, J. P. Fouassier and J. Lalevée, Polym. Chem., 2016, 8, 568-580.

46 S. Fery-Forgues, B. Delavaux-Nicot, D. Lavabre and K. Rurack, J. Photochem. Photobiol. Chem., 2003, 155, 107-114.

47 M. Bouzrati-Zerelli, M. Maier, C. P. Fik, C. Dietlin, F. Morlet-Savary, J. P. Fouassier, J. E. Klee and J. Lalevée, Polym. Int., 2017, 66, 504-511.

48 B. Steyrer, B. Busetti, G. Harakály, R. Liska and J. Stampfl, Addit. Manuf., 2018, 21, 209-214.

49 A. S. Sarac, Prog. Polym. Sci., 1999, 24, 1149-1204.

50 P. Kalenda, Eur. Polym. J., 1995, 31, 1099-1102.

51 P. Garra, F. Dumur, A. A. Mousawi, B. Graff, D. Gigmes, F. Morlet-Savary, C. Dietlin, J. P. Fouassier and J. Lalevée, Polym. Chem., 2017, 8, 5884-5896.

52 Q. Li, C.-F. Wang and S. Chen, Ind. Eng. Chem. Res., 2018, 57, 3083-3090.

53 A. Al Mousawi, F. Dumur, P. Garra, J. Toufaily, T. Hamieh, F. Goubard, T.-T. Bui, B. Graff, D. Gigmes, J. Pierre Fouassier and J. Lalevée, J. Polym. Sci. Part Polym. Chem., 2017, 55, 1189-1199.

54 P. Garra, B. Graff, F. Morlet-Savary, C. Dietlin, J.-M. Becht, J.-P. Fouassier and J. Lalevée, Macromolecules, 2018, 51, 57-70. 
Ferrocene-based (photo)redox polymerization under long wavelengths Patxi Garra ${ }^{1,2}$, Damien Brunel ${ }^{3}$, Guillaume Noirbent ${ }^{3}$, Bernadette Graff ${ }^{1,2}$, Fabrice MorletSavary $^{1,2}$, Céline Dietlin ${ }^{1,2}$,V. F. Sidorkin ${ }^{4}$, Frédéric Dumur ${ }^{3}$, David Duché5, Didier Gigmes ${ }^{3}$, Jean-Pierre Fouassier ${ }^{1,2}$, Jacques Lalevé $e^{1,2^{*}}$

TOC graphic

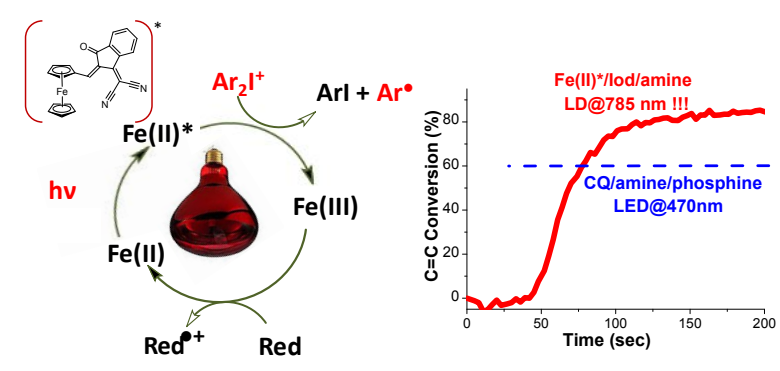




\title{
Ferrocene-based (photo)redox polymerization under long wavelengths
}

\section{Patxi Garra ${ }^{1,2}$, Damien Brunel ${ }^{3}$, Guillaume Noirbent ${ }^{3}$, Bernadette Graff ${ }^{1,2}$, Fabrice Morlet- Savary ${ }^{1,2}$, Céline Dietlin ${ }^{1,2}$, V. F. Sidorkin ${ }^{4}$, Frédéric Dumur ${ }^{3}$, David Duché ${ }^{5}$, Didier Gigmes ${ }^{3}$, Jean-Pierre Fouassier ${ }^{1,2}$, Jacques Lalevée ${ }^{1,2^{*}}$}

\author{
${ }^{1}$ Université de Haute-Alsace, CNRS, IS2M UMR 7361, F-68100 Mulhouse, France \\ 2Université de Strasbourg, France \\ ${ }^{3}$ Aix Marseille Univ, CNRS, ICR UMR 7273, F-13397 Marseille, France \\ ${ }^{4}$ A. E. Favorsky Irkutsk Institute of Chemistry, Siberian Branch of the Russian \\ Academy of Sciences, Favorsky, 1, Irkutsk 664033, Russian Federation. \\ ${ }^{5}$ Aix Marseille Univ, CNRS, IM2NP UMR 7334, F-13397 Marseille, France \\ *Corresponding author: jacques.lalevee@uha.fr
}

\begin{abstract}
:
Ferrocene-based photoredox catalysis is proposed here for the first time. Aryl radicals generated from a $\mathrm{Fe}(\mathrm{II}) * / \mathrm{Ar}_{2} \mathrm{I}^{+}$reaction can be used as initiating species for efficient free radical photopolymerization of methacrylate resins. Remarkably, these photoredox catalysts can also be used for redox free radical polymerization (without light) in combination with ammonium persulfate for a unique access to dual cure (photochemical/thermal redox) systems. The addition of a third component (amine, phosphine or Vitamin C reducing agents) enables the regeneration of the catalysts and greatly enhances the radical generation. The motivation of these dual cure systems is to develop orthogonal chemistries where a latent redox polymerization (without light) is able to cure any thickness of polymer (or composite) in combination with fast photopolymerization processes in the irradiated areas. Chemical mechanisms will be discussed in detail using cyclic voltammetry, electron spin resonance spin trapping (ESR-ST), UV-vis-NIR spectroscopy, free energy calculations and molecular modeling at density functional theory (DFT) level. This study represents, to the best of our knowledge, the first photochemically active Iron catalysts that are also efficient in thermal redox catalysis.
\end{abstract}




\section{Introduction}

The shift towards higher actinic wavelengths in light induced reactions is a constant challenge in many academic/industrial works. ${ }^{1-4}$ During the last decade ${ }^{5}$, the use of visible light in photoredox catalysis instead of harmful UV irradiations allowed significant advances in i) the selectivity of the photoreaction and ii) in the harmfulness of the actinic setup. Particularly, visible light-emitting diodes (LED) and laser diodes (LD) with their sharp emission spectra allows taylor-made light absorption by photoredox catalysts. Nevertheless, photoredox catalysis - partial and convenient regeneration of the catalyst - remained mostly restricted to actinic lights below $500 \mathrm{~nm} \cdot \cdot^{6-9}$ Indeed, near infrared (NIR) induced photoredox catalysis remains an old dream which is particularly difficult to achieve as a NIR photon is much less energetic than a UV one (e.g. at $900 \mathrm{~nm}$, it is three times less energetic than at $300 \mathrm{~nm})$.

Out of the challenge, there is a real interest in using NIR wavelengths: it offers several advantages such as an excellent penetration in filled, dispersed or even heterogeneous samples, and a higher selectivity of the photoreaction as the process is less energetic. ${ }^{10}$ Therefore, there is a clear need to answer these questions: i) is it possible to actually perform a photoredox reaction under NIR lights and ii) can the photoreaction occur at high rate? In the literature, two elegant examples of direct NIR photoreactions can be more particularly mentioned : i) the work of Strehmel et coworkers around cyanine sensitization of iodonium salts ${ }^{11-14}$ and ii) the work of Boyer et coworkers using a bacteriochlorophyl derivative or an aluminium phtalocyanine complex in photocontrolled radical polymerization. ${ }^{15,16}$ In these cases, either slow reactions or rather high irradiances were required. We propose in the present manuscript to explore newly developed ferrocene dyes (Fe(II)) as potential photoredox catalysts for the reduction of iodonium salts $\left(\mathrm{Ar}_{2} \mathrm{I}^{+}\right)$. These ferrocene dyes were mainly proposed in the literature for applications in non-linear optics. ${ }^{17,18}$ The shift towards higher wavelengths of the maximum of absorption in these compounds is made possible through their substitution by donor and/or acceptor (scheme 1) to induce a bathochromic charge-transfer 
transition, ${ }^{19}$ more particularly by introducing strong acceptors on the cyclopentadienyl ring (scheme 1). ${ }^{20}$

We propose to apply the photo-oxidation reaction of Fe(II) in presence of an iodonium salt leading to a reaction between the excited state of the ferrocenes and the iodonium salt $\left(\mathrm{Fe}(\mathrm{II})^{*} / \mathrm{Ar}_{2} \mathrm{I}^{+}\right)$ - to the highly challenging field of photopolymerization: the radicals generated will be useful to induce the free radical polymerization (FRP) of a methacrylate resin. Indeed, in that field, high reaction rates are required to overcome the inhibition reactions (e.g. the oxygen inhibition). ${ }^{21-27}$ Also, there is a real challenge to have access to filled samples (thanks to NIR photopolymerization) for thick photocomposites. ${ }^{28-30}$ Additionally and for the first time, we will also explore the possibility to use $\mathrm{Fe}$ (II) to decompose ammonium persulfate (APS) without light in redox polymerization: with two cartridges (one containing the oxidizing agent, the other one containing the reducing agent or system) $)^{31}$ are mixed together to induce the FRP of methacrylates. The motivation of this is to develop orthogonal chemistries where a latent redox polymerization (without light) is able to cure any thickness of polymer (or even composite); light can then be used on demand to accelerate and enhance the slow redox processes. This dual-curing was recently defined as redox photoactivated polymerization. ${ }^{29,32,33}$ The chemical mechanisms involved in the polymerization process will be discussed thanks to the molecular modeling of the reactants/intermediates and to UV-vis-NIR absorption, cyclic voltammetry (CV) and electron spin resonance spin trapping (ESR-ST) experiments. 


\section{Ferrocenes (Fe(II))}

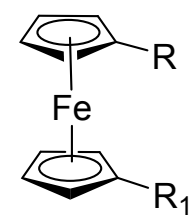

$\mathrm{R}=\mathrm{R}_{1}=\mathrm{H} ; \mathbf{F e}$ $\mathrm{R}=(\mathrm{HC}=\mathrm{O}) ; \mathrm{R}_{1}=\mathrm{H} ; \mathrm{Fe} 1$

$\mathrm{R}=\mathrm{R}_{1}=\mathrm{CH}_{3} ; \mathrm{Fe} 2$

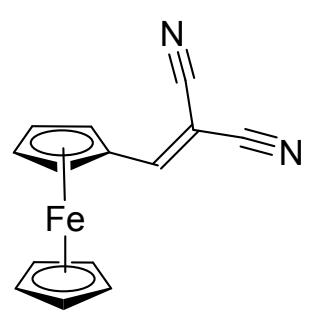

Fe5

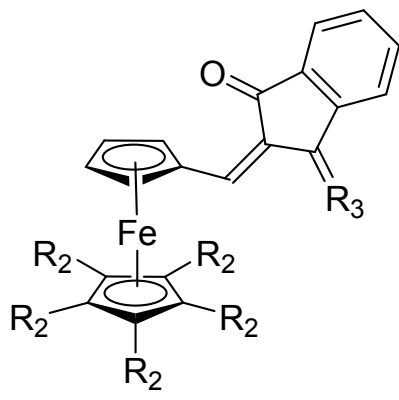

$\mathrm{R}_{2}=\mathrm{H} ; \mathrm{R}_{3}=\mathrm{O} ; \mathrm{Fe} 6$

$\mathrm{R}_{2}=\mathrm{H} ; \mathrm{R}_{3}=\mathrm{C}(\mathrm{CN})_{2} ; \mathrm{Fe} 7$

$\mathrm{R}_{2}=\mathrm{CH}_{3} ; \mathrm{R}_{3}=\mathrm{C}(\mathrm{CN})_{2} ;$ Fe7Me

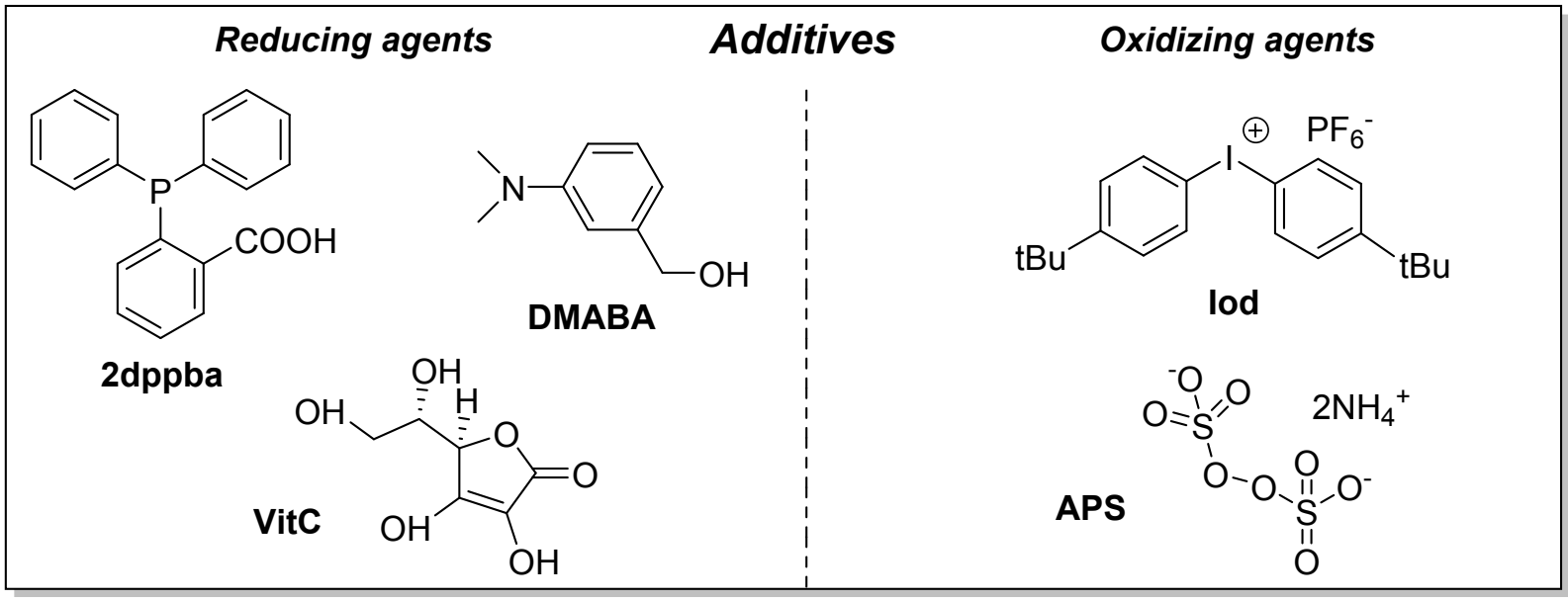

Scheme 1: Compounds investigated in the present study

\section{Experimental section}

\section{1/ Chemical compounds}

All the reactants were selected with the highest purity available and used as received; their chemical structures are summed-up in Schemes 1 and 2. Ferrocene (Fe), 1,1'-dimethylferrocene (Fe2), 4- $N, N$ trimethylaniline (4-N,N TMA), 3-(dimethylamino)benzyl alcohol (DMABA), 2diphenylphosphinobenzoic acid (2dppba), ascorbic acid (VitC), $N$-tert-butyl- $\alpha$-phenyl-nitrone (PBN), and ammonium persulfate (APS) were purchased from Sigma-Aldrich. Di-tert-butyl-diphenyl iodonium hexafluorophosphate (lod) was obtained from Lambson Ltd (UK). Toluene, acetonitrile (ACN) and dichloromethane (DCM) were purchased from Carlo Erba. 
Synthesis of the ferrocene derivatives were directly inspired by the literature (see Supplementary information, Figures S1 and S2). ${ }^{34}$

The efficiency of the different photoinititing systems (PISs) was checked in benchmarked methacrylate resins (viscosities given in Table 1): i) a first reference methacrylate mixture (resin 1 , Scheme 2) with a low viscosity of 0.053 Pa.s containing 33.3 wt \% of 1,4-butanediol-dimethacrylate (1,4-BDMA), 33.3 wt \% of hydroxypropylmethacrylate (HPMA), 33.3 wt \% of urethane-dimethacrylate; ii) a second methacrylate resin noted resin 2 (Scheme 2) having a much higher viscosity (5.7 Pa.s) with a BisGMA/TEGDMA (30/70 wt\%) blend and iii) pure hydroxyethylmethacrylate (HEMA). All the monomers were obtained from Sigma Aldrich.

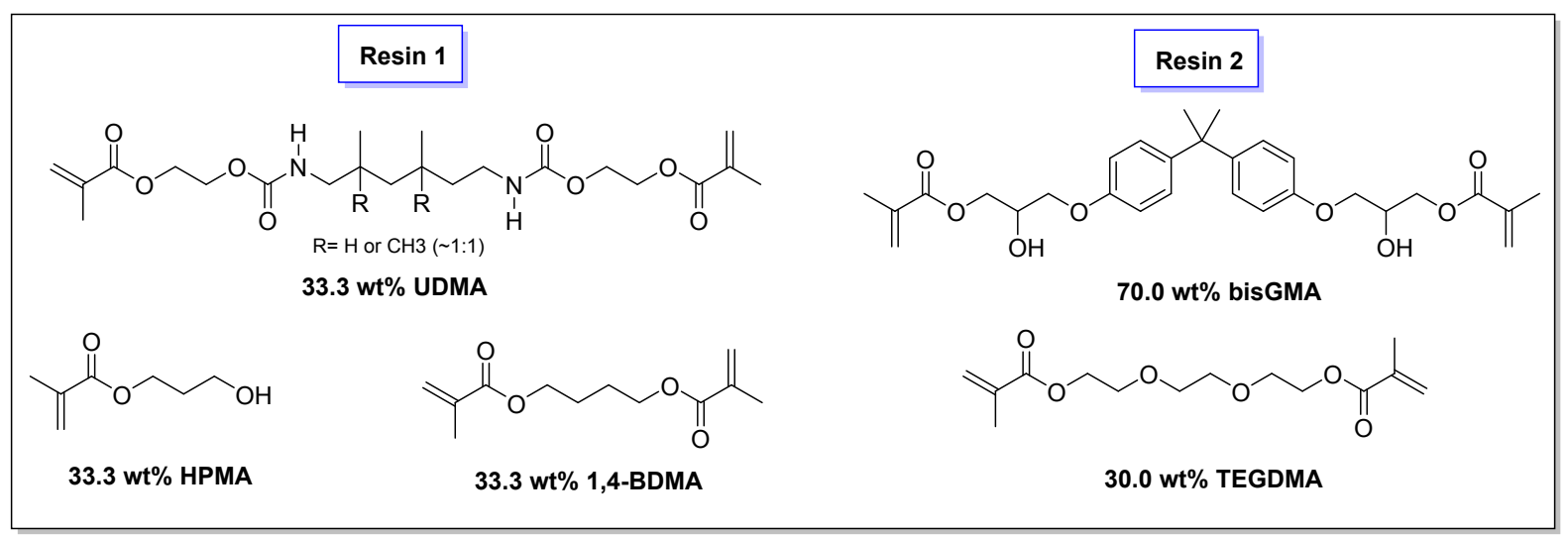

Scheme 2. Composition of the methacrylate resins (resins 1\&2) used.

Table 1: Viscosities of monomers (or solvent) used in the study 35,36

\begin{tabular}{|c|c|}
\hline Fluids & Viscosities (at $\mathbf{2 5}^{\mathbf{}} \mathbf{C}$ ): \\
\hline water & 0.001 Pa.s \\
\hline HEMA & 0.004 Pa.s \\
\hline Resin 1 & 0.053 Pa.s \\
\hline Resin 2 & 5.7 Pa.s \\
\hline
\end{tabular}

\section{2/ RT-FTIR spectroscopy}

A Jasco 6600 Real-Time Fourier Transformed Infrared Spectrometer (RT-FTIR) was used to follow the $\mathrm{C}=\mathrm{C}$ double bond conversion versus time for polymerizations of $1.4 \mathrm{~mm}$ thick samples. All the 
photopolymerization experiments were carried out at room temperature (RT) $\left(21-25^{\circ} \mathrm{C}\right)$ under air (oxygen inhibition expected ${ }^{22}$ ).

The evolution of the near infrared methacrylate $C=C$ double bond peak was followed from 6130 to $6200 \mathrm{~cm}^{-1}$. A laser diode LD@785 nm (CNI lasers) having an irradiance of $400 \mathrm{~mW} / \mathrm{cm}^{2}$ at the sample position was used for the photopolymerization experiments (see emission spectrum in Figure S3). The intensity of this laser diode can also be increased to $2.55 \mathrm{~W} / \mathrm{cm}^{2}$. A LED@405 nm (Thorlabs, 110 mW/cm²), LED@470nm (Thorlabs, $80 \mathrm{~mW} / \mathrm{cm}^{2}$ ), a LED@530 nm (Thorlabs, $30 \mathrm{~mW} / \mathrm{cm}^{2}$ ) and a LED@660 nm (Thorlabs, $80 \mathrm{~mW} / \mathrm{cm}^{2}$ ) were also used. The emission spectra are already available in the literature. ${ }^{37}$

\section{3/ Definition of the two components used for redox experiments}

All redox formulations were prepared from the bulk resins in two separate cartridges at room temperature (RT) $\left(21-23^{\circ} \mathrm{C}\right)$ : a first cartridge with the oxidizing agent (APS) with the same amount of water (for solubility) and the other one containing the Fe(II) with or without additional reducing agent. A 1:1 Sulzer mixpac ${ }^{\circledR}$ mixer was used to mix both components together at the beginning of each polymerization experiment. The contents of reduction or oxidation agents will be given in weight with respect to the final resin after mixing.

\section{4/ Redox polymerization followed by optical pyrometry}

The use of optical pyrometry to follow polymerization reactions was developed by Crivello et al. ${ }^{38,39}$ Optical pyrometry is an interesting technique to monitor polymerization ${ }^{38,40}$ : qualitative assessment of the polymerization is provided (through exothermicity) with simultaneous measurement of the gel time. Gel time will be defined here as the time to reach the temperature maximum. Temperature versus time profiles were followed here using an Omega OS552-V1-6 Industrial Infrared Thermometer (Omega Engineering ${ }^{\circledR}$, Inc., Stamford, CT) having a sensitivity of \pm 1 ${ }^{\circ} \mathrm{C}$ for $2 \mathrm{~g}$ samples (thickness $\sim 4 \mathrm{~mm}$ ).

\section{5/ UV-visible-NIR absorption spectroscopy}


UV-vis-NIR absorption spectra in $\mathrm{ACN}$ (quartz cell) were acquired using a $\operatorname{Varian}^{\circledR}$ Cary 3 spectrophotometer.

\section{6/ Computational Procedure}

Geometry optimizations ${ }^{41}$ were calculated at UB3LYP/6-31G* level; geometries were frequency checked. The electronic absorption spectra were calculated from the time-dependent density functional theory at MPW1PW91/6-31G* level of theory on the relaxed geometries calculated at the UB3LYP6-31G*level of theory. The molecular orbitals (MOs) involved in these transitions were extracted.

\section{7/ Electron Spin Resonance-Spin Trapping (ESR - ST)}

\subsection{1/ Experimental}

Electron spin resonance experiments were carried out using a X-band spectrometer (Bruker EMXplus Biospin). ESR-ST experiments were performed using $N$-tert-butyl- $\alpha$-phenylnitrone (PBN) as a spin trapping agent in a similar way as described in other works. ${ }^{42} \mathrm{For}$ the Fe7*/lod interaction, the radical adducts were directly observed at room temperature under nitrogen saturated media in a toluene solution after NIR irradiation (under a LED@780 nm (Thorlabs) operating at $80 \mathrm{~mW} / \mathrm{cm}^{2}$ ). For the Fe(II)/APS interaction, a first solution was prepared with APS in water when a second one contained ferrocene and PBN in toluene. After a short mixing of both phases (10 seconds), the toluene phase was extracted and inserted in an ESR tube (under air). That latter was then degassed under nitrogen and analyzed at room temperature. The ESR spectra simulations were carried out using the WINSIM software.

\subsection{2/ ESR Spectra calculations}

For ESR spectra calculations, the radical/spin trap adducts were optimized at anUB3LYP/6$31 \mathrm{G}$ (d) level of theory. ${ }^{41} \mathrm{~A}$ solvent effect on the geometry of radical/PBN adducts was estimated in the 
framework of the conductor-like polarizable continuum model, C-PCM. ${ }^{43}$ Thegeometries were frequency checked. An UB3LYP method was combined with the NO7D basis set in order to calculate of the isotropic hyperfine coupling constants (HFCCs) according to a method recently published. ${ }^{43}$

\section{8/ Cyclic Voltammetry (CV)}

The redox potentials ( $E_{o x}$ VS. SCE) of the reducing agents were determined by cyclic voltammetry (at $0.1 \mathrm{~V} / \mathrm{s}$, uncertainty of $\pm 0.05 \mathrm{~V}$ ) in an $\mathrm{ACN}$ solution containing $0.2 \mathrm{M}$ tetrabutylammonium hexafluorophosphate (Aldrich) as a supporting electrolyte. A platinum electrode was used as a working electrode and a saturated calomel electrode (SCE) was used as a reference electrode.

\section{9/ Free Energy Calculations for Electron Transfer $\left(\Delta G_{e t}\right)$}

The free energy change $\Delta G_{\text {et }}$ for an electron transfer reaction was calculated from the classical equation (eq. 1$)^{44}$ where $E_{o x}, E_{r e d}, E_{S}$, and $C$ are the oxidation potential of the electron donor, the reduction potential of the electron acceptor (here $-0.59 \mathrm{~V}$ vs SCE for $\operatorname{lod}^{3,12}$ ), the excited state energy and the Coulombic term for the initially formed ion pair, respectively. $\mathrm{C}$ is neglected as usually done in polar solvents.

$$
\Delta G_{\text {et }}=E_{o x}-E_{r e d}-E_{S}+C
$$

As no fluorescence was detected for the ferrocene derivatives, we used the UV-vis absorption end tail of the UV-vis absorption band for the calculation of the excited state energy as commonly done. ${ }^{45}$ This method generally leads to a slight underestimation of the excited state energy.

\section{Results and discussion}

\section{1/ Light and NIR photoredox catalysis behavior}

\subsection{1/ Light absorption properties}

The light absorption properties of the ferrocene derivatives studied are presented in Figure 1 and the results are summed up in Table 2 for different excitation wavelengths. Two transitions are 
causing some visible light absorption in the ferrocenes bearing acceptor moieties: a donor-acceptor charge-transfer transition (DA-CT) which is the lowest energy transition (highest wavelength) and an interligand $\pi-\pi^{*}$ transition (LL-CT, lower wavelength). ${ }^{20}$ Interestingly, a tuning of the acceptor moiety strongly influences the DA-CT (see changes of HOMO/LUMO in Figure S4) thus inducing a bathochromic shift and an enhancement of the absorptivity in the visible domain. Particularly, the derivatives Fe4 and Fe7 are absorbing NIR light with respectively $\varepsilon(785 \mathrm{~nm})=90 \mathrm{M}^{-1} \cdot \mathrm{cm}^{-1}$ and $\varepsilon(785 \mathrm{~nm})=190 \mathrm{M}^{-1} \cdot \mathrm{cm}^{-}$ ${ }^{1}$. Noteworthy, it was recently shown that the derivative Fe7 can undergo some slight solvatochromic shift to higher wavelengths $\left(\Delta \lambda_{\max }=19 \mathrm{~nm}\right)$ when going from hexane to chloroform through an increase of the acceptor strength in the complex. ${ }^{17}$ Finally, the original Fe7Me compound shows a greatly enhanced and red shifted light absorption (Figure1, curve i). It was indeed expected as the donor part involved in the last transition (DA-CT) is enhanced by the methyl groups on the cyclopentadienyl ring. Numerically, an enhanced absorption ability is evidenced for Fe7Me compared to Fe7, with a molar extinction coefficient of $\varepsilon(785 \mathrm{~nm})=3700 \mathrm{M}^{-1} \cdot \mathrm{cm}^{-1}$ for Fe7Me against $190 \mathrm{M}^{-1} \cdot \mathrm{cm}^{-1}$ for the Fe7 derivative.

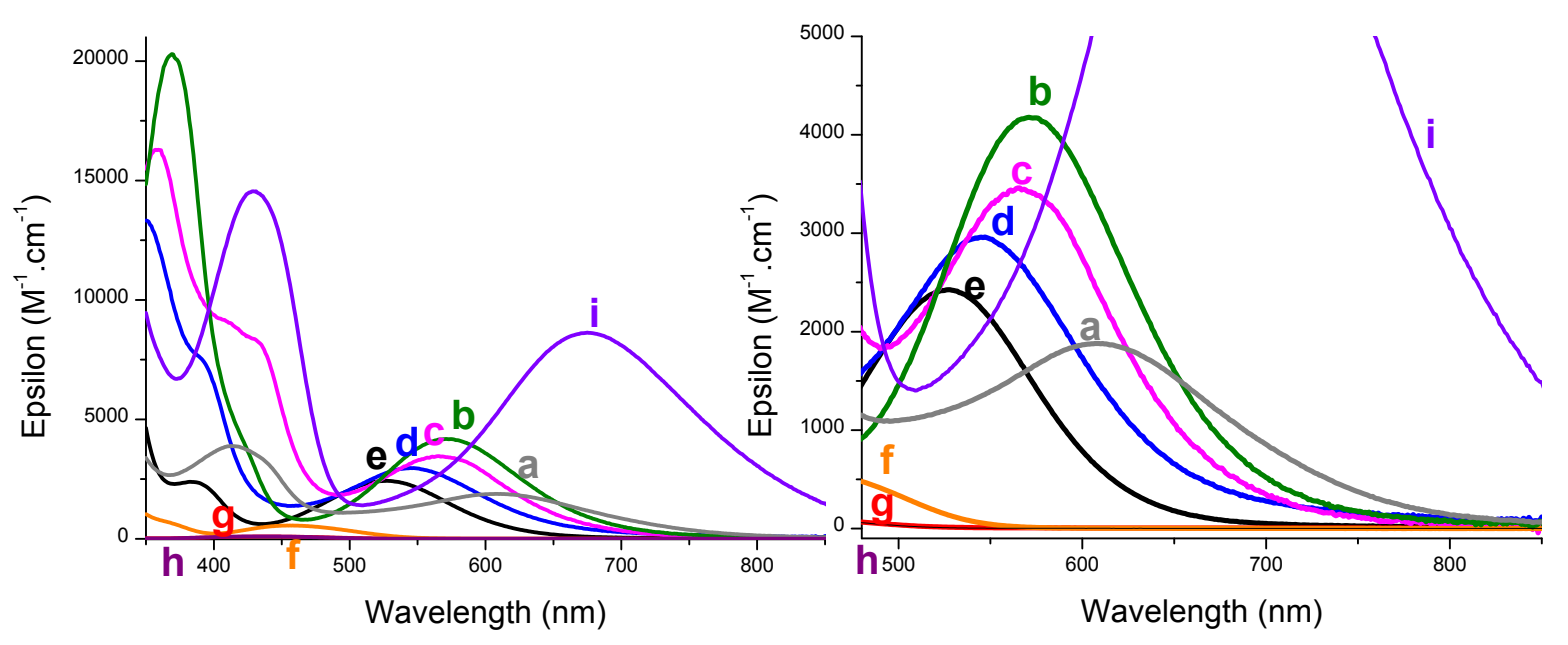

Figure 1: UV-vis-NIR Absorption properties in ACN of the ferrocene derivatives studied here: (a): Fe7; (b):Fe4; (c):Fe6; (d):Fe3; (e):Fe5; (f): Fe1; (g): Fe; (h): Fe2; (i): Fe7Me. 
Table 2: Main calculated (at an UB3LYP/6-31G* level of theory, see Figure S4) and experimental light absorption properties for the ferrocene derivatives studied.

\begin{tabular}{|c|c|c|c|c|}
\hline $\begin{array}{l}\text { Ferrocene } \\
\text { derivative }\end{array}$ & $\begin{array}{c}\lambda_{\max }(\text { calc. })^{\mathrm{a}} \\
\mathrm{nm}\end{array}$ & $\begin{array}{c}\lambda_{\max }(\exp .) \\
\mathrm{nm}\end{array}$ & $\begin{array}{c}\varepsilon(405 \mathrm{~nm}) \\
M^{-1} \cdot \mathrm{cm}^{-1}\end{array}$ & $\begin{array}{c}\varepsilon(785 \mathrm{~nm}) \\
M^{-1} \cdot \mathrm{cm}^{-1}\end{array}$ \\
\hline $\mathrm{Fe}$ & $<450$ & 440 & 75 & $\sim 0$ \\
\hline Fe1 & 549 & 455 & 230 & $\sim 0$ \\
\hline Fe2 & $<450$ & 438 & 75 & $\sim 0$ \\
\hline $\mathrm{Fe} 3$ & 601 & 545 & 5500 & $<30$ \\
\hline Fe4 & 611 & 571 & 6800 & 90 \\
\hline Fe5 & 584 & 525 & 5980 & $\sim 0$ \\
\hline Fe6 & 598 & 565 & 9220 & $<15$ \\
\hline Fe7 & 631 & 609 & 3780 & 190 \\
\hline Fe7Me & 659 & 675 & 11440 & 3700 \\
\hline
\end{tabular}

a: molecular modeling data.

Next, we tried to calculate the free energy change for an electron transfer to lod $\left(\Delta G_{\text {et }}\right)$ for these different derivatives at the lowest excited state energy using $\mathrm{CV}$ and the light absorption properties (Table 3). All the Fe derivatives exhibited excellent reversible oxidation in $\mathrm{CV}$ ranging from $0.22 \mathrm{~V}$ to $0.74 \mathrm{~V}$ (vs SCE). The introduction of methyl donor moieties in Fe2 lowers the oxidation potential compared to reference $\mathrm{Fe}(0.22 \mathrm{~V}$ against $0.33 \mathrm{~V})$ in line with the litterature. ${ }^{46}$ Similarly, the introduction of an acceptor moiety enhances the oxidation potential in Fe1 ( $\left.E_{o x}=0.65 \mathrm{~V}\right), \mathrm{Fe} 3\left(\mathrm{E}_{\mathrm{ox}}=0.62\right.$ V), Fe4 $\left(E_{o x}=0.65 \mathrm{~V}\right)$, Fe5 $\left(E_{o x}=0.74 \mathrm{~V}\right)$, Fe6 $\left(E_{o x}=0.59 \mathrm{~V}\right)$, Fe7 ( $\left.E_{o x}=0.65 \mathrm{~V}\right)$. Interestingly, the original Fe7Me compound has strong donor moieties (five methyl groups on the bottom cyclopentadienyl ring) which results in a lower oxidation potential $\left(E_{o x}=0.4 V\right)$ in line with the ferrocene literature ${ }^{46}$ but also a lower excited state energy (as the light absorption was red shifted) which leads to a $\Delta G_{\text {et }}$ for electron transfer roughly similar to the one of Fe7 (-0.37 eV for Fe7Me against $-0.31 \mathrm{eV}$ for Fe7). The * Fe/lod electron transfer is found possible for all the derivatives $\left(\Delta \mathrm{G}_{\mathrm{et}}<-0.3 \mathrm{eV}\right)$. We will apply this photooxidation reaction to photopolymer synthesis in the next part of the article (§3.1.2). 
Table 3: Calculation of Gibbs energy for electron transfer $\Delta G_{\mathrm{et}}$ for the photooxidation reaction with lod $\left(\mathrm{Ar}_{2} \mathrm{I}^{+}, \mathrm{E}_{\mathrm{red}}=-0.59 \mathrm{~V}\right.$ vs SCE$)$ using experimental parameters (see equation in §2.9).

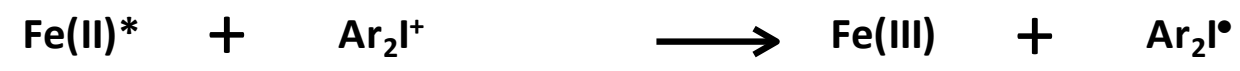

\begin{tabular}{|c|c|c|c|}
\hline $\begin{array}{c}\text { Ferrocene } \\
\text { derivative }\end{array}$ & $\mathrm{E}_{\text {ox }}(\mathbf{V}$ vs SCE $)$ & $\mathrm{E}_{\mathbf{s}}(\mathbf{e V})$ & $\Delta \mathbf{G}_{\text {et }}(\mathrm{eV})$ \\
\hline $\mathrm{Fe}$ & 0.33 & 2.25 & -1.33 \\
\hline Fe1 & 0.65 & 2.21 & -0.97 \\
\hline Fe2 & 0.22 & 2.34 & -1.53 \\
\hline Fe3 & 0.62 & 1.63 & -0.42 \\
\hline Fe4 & 0.65 & 1.63 & -0.39 \\
\hline Fe5 & 0.74 & 1.88 & -0.55 \\
\hline Fe6 & 0.59 & 1.66 & -0.48 \\
\hline Fe7 & 0.65 & 1.55 & -0.31 \\
\hline Fe7Me & 0.40 & 1.36 & -0.37 \\
\hline
\end{tabular}

\subsection{2/ Application to visible light and NIR induced polymerization}

Under mild LED@405 nm irradiation, slow polymerization efficiencies (final C=C function conversion (FC) below $40 \%$ after 400s, Figure $2 \mathrm{~A}$ ) are recorded for derivatives $\mathrm{Fe} / \mathrm{lod}$, Fe5/lod, Fe3/lod and Fe4/lod when no photoinitiating ability was recorded for Fe6 and Fe7. The low LED@405 nm irradiance may be involved. Poor polymerization is also obtained for Fe3/lod and Fe5/lod for other low irradiance visible LEDs at $660 \mathrm{~nm}$ and at 540 nm (Figure S5). More interestingly, the introduction of a third component, the2-diphenylphoshphinobenzoic acid also noted 2dppba (Scheme 1), spectacularly increases the radical production rate with more than $70 \%$ conversion after 25 s for an irradiation @ 405 $\mathrm{nm}$ (Figure 2A). As a reminder, a final conversion of $60 \%$ was obtained for a reference visible light (470 $\mathrm{nm}$ ) three-component system: camphorquinone (CQ) /amine(ethyl4(dimethylamino)benzoate)/phosphine(4-diphenylphosphino styrene) using the same resin and setup ${ }^{47}$ Similarly, Fe2/lod is not efficient under the LED@470 nm in the low viscosity resin (Figure 2B, 
curve 1); when adding reducing agent such as VitC in Fe2/lod/VitC (FC=66 \%) or 2 dppba in $\mathrm{Fe} 2 / \mathrm{lod} / 2 \mathrm{dppba}(\mathrm{FC}=78 \%$ ) spectacularly enhances radical generating rate under air.
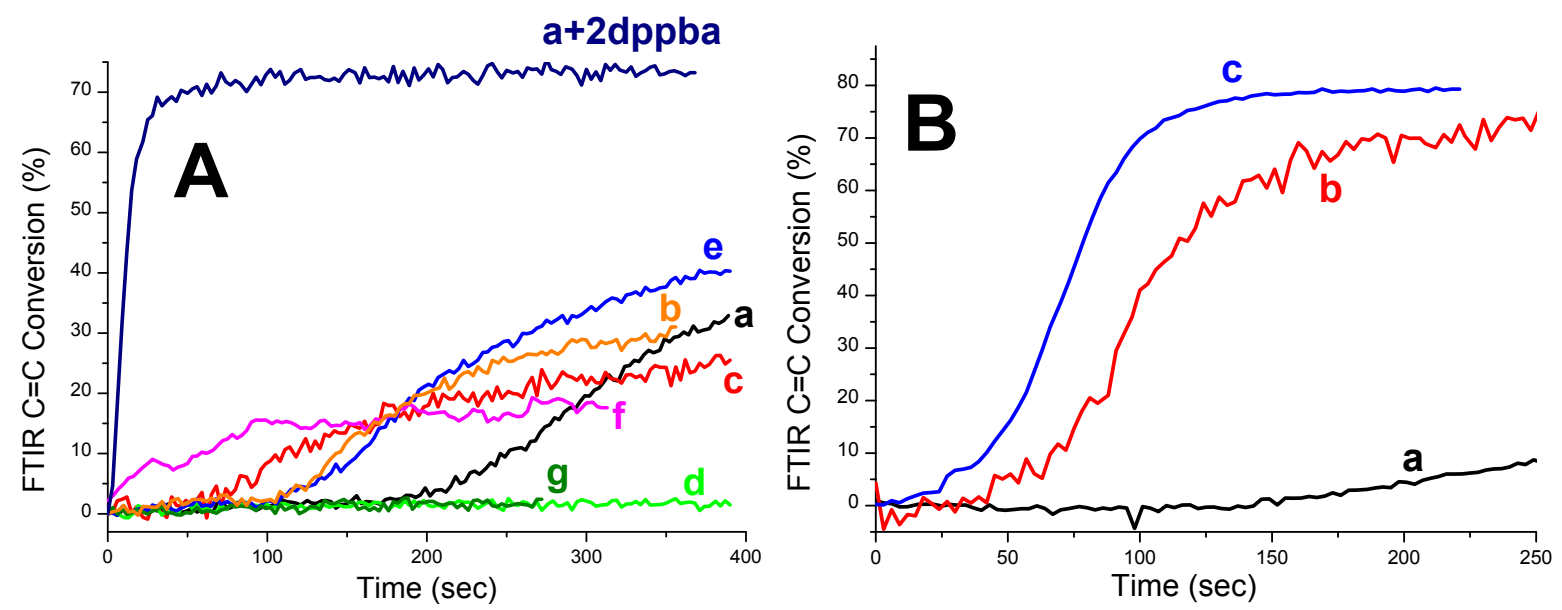

Figure 2: Photopolymerization profiles (methacrylate $C=C$ function conversion vs. irradiation time, irradiation starts at t=0s) measured in RT-FTIR; 1.4 mm thick samples, in air. A: upon LED@405nm irradiation (110 mW/ $\left.\mathrm{cm}^{2}\right)$, in resin 2, for 0.5 wt\% Fe(II) and 1.0 wt\% lod. Initiating systems: (a): Fe/lod; (a+2dppba): Fe/lod/2dppba (1.5 wt\%); (b): Fe5/lod; (c): Fe3/lod; (d): Fe6/lod;(e):Fe1/lod;(f): Fe4/lod(g): Fe7/lod. B: upon LED@470nm irradiation ( $80 \mathrm{~mW} / \mathrm{cm}^{2}$ ), in resin 1, for 0.3 wt\% Fe2 and 2.0 wt\% lod. Initiating systems: (a): Fe2/lod; (b): Fe2/lod/2.5 wt\% VitC (+10 wt\% water);(c): Fe2/lod/1.5 wt\% 2 dppba.

Next, under mild LD@785 nm irradiation (Figure 3A, $0.4 \mathrm{~W} / \mathrm{cm}^{2}$ ), photopolymerization efficiency is recorded for the first time for a NIR Fe(II)*/Ar $2 I^{+}$interaction. In detail, Fe4/lod system is not efficient when 0.1 wt\% Fe(II) is used but more efficient for 0.5 wt\% Fe4. Fe7Me/lod system is not at all efficient (though light absorption was enhanced at $785 \mathrm{~nm}$, see Table 2) which could be due to a lower excited states energy (Table 3). On the contraryFe7/lod system is still efficient at 1000 ppm (0.1 wt\%) Fe(II) (Figure $3 \mathrm{~A}$ curve a, $\mathrm{FC}=30 \%$ ) and can be improved for more concentrated Fe7 content $(0.5$ wt $\%$, Figure $3 \mathrm{~A}$ curve $\mathrm{b}, \mathrm{FC}=40 \%)$. This can be even improved using reducing agents in $\mathrm{Fe} 7 / \mathrm{lod} / 2 \mathrm{dppba}$ ( $\mathrm{FC}=48 \%$ after 300s Figure 3A curve c) or in Fe7/lod/DMABA (FC=50\% after 250s, Figure 3A curve d). Finally, that last formulation can be outstandingly enhanced when using a higher irradiance $\left(2.55 \mathrm{~W} / \mathrm{cm}^{2}\right.$, Figure $3 \mathrm{~B}$, curve b): up to $83 \% \mathrm{C}=\mathrm{C}$ conversion is obtained for a multifunctional resin. This result clearly outranks the previous visible light reference (CQ/amine/phosphine) as only a $60 \%$ conversion was 
obtained upon blue light $(470 \mathrm{~nm})$ irradiation. The improvement in conversion could be related to a slightly higher reaction temperature due to the high irradiance..$^{48}$ Under selected conditions, the $\mathrm{Fe}(\mathrm{II}) * / \mathrm{Ar}_{2} \mathrm{I}^{+} /$reducing agent NIR photocatalysis can be very efficient. Noteworthy, the Fe(II)/reducing agent systems are not strong enough to reduce the iodonium salt without light as all formulations were stable for more than 1 day at room temperature (iodonium salt have a too low reduction potential).
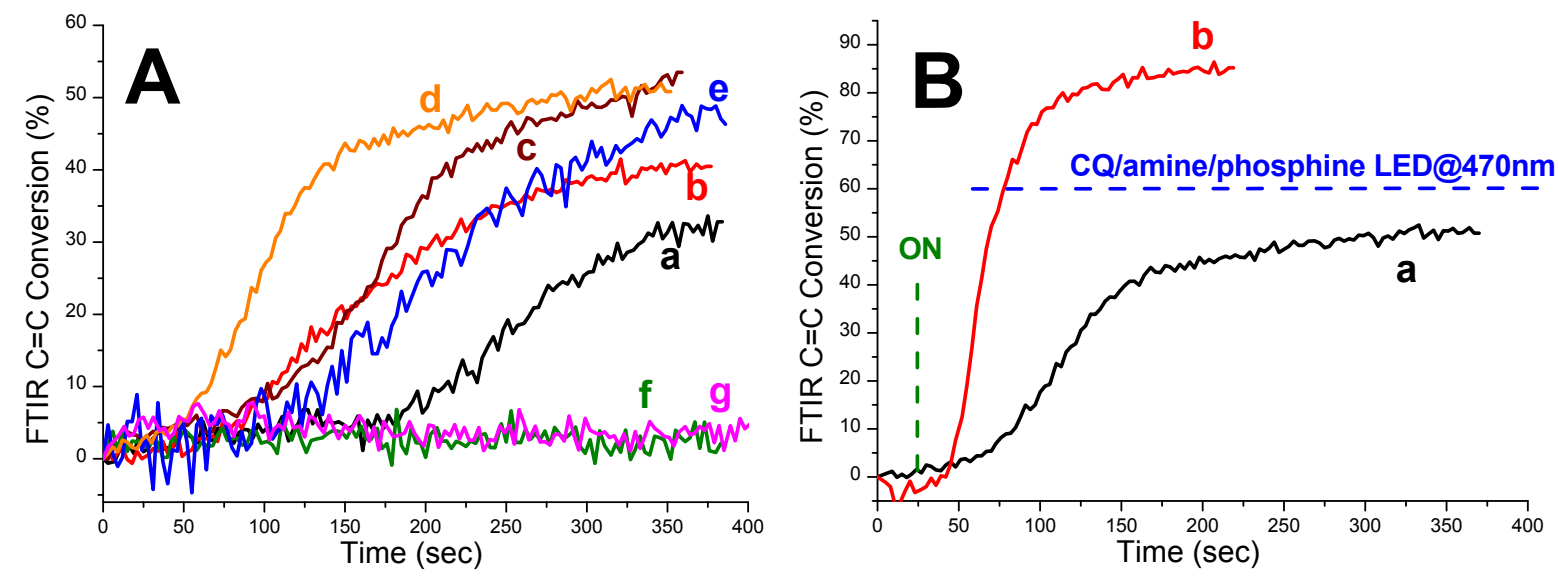

Figure 3: Photopolymerization profiles (methacrylate $\mathrm{C}=\mathrm{C}$ function conversion vs. irradiation time) measured in RT-FTIR for the resin 2; $1.4 \mathrm{~mm}$ thick samples, in air, upon NIR (LD@785nm) irradiation for $2.0 \mathrm{wt} \%$ lod and $1.5 \mathrm{wt} \%$ Reducing agent (2dppba or DMABA). A: $400 \mathrm{~mW} / \mathrm{cm}^{2}$ irradiation starts at t=0s (a): 0.1 wt\% Fe7/lod; (b):0.5 wt\% Fe7/lod; (c): 0.5 wt\% Fe7/lod/2dppba; (d): 0.5 wt\% Fe7/lod/DMABA; (e): 0.5 wt\% Fe4/lod; (f): 0.1 wt\% Fe4/lod);(g): 0.5 wt\% Fe7Me/lod. B: (curves, light irradiation starts at $\mathrm{t}=25 \mathrm{~s}$ ) for $0.5 \mathrm{wt} \% \mathrm{Fe} / / \mathrm{lod} / \mathrm{DMABA}$ upon (a): $400 \mathrm{~mW} / \mathrm{cm}^{2}$ irradiance and(b): 2.55 $\mathrm{W} / \mathrm{cm}^{2}$ irradiance. Embedded: Final conversion (60\%) obtained for a reference visible light $(470 \mathrm{~nm}) 3$ component PIS: CO/amine(ethyl 4-(dimethylamino)benzoate)/phosphine(4-diphenylphosphino styrene) using the same resin and setup but using the LED@470 nm.47

\section{2/ Fe(II) compatibility with redox initiated FRP}

Next, as Fe(II) complexes are able to decompose peroxides (though this reaction was i) slow and ii) under nitrogen in the literature ${ }^{49,50}$ ), we attempted to perform a redox decomposition of 
ammonium persulfate (APS) using newly developed catalytic cycles (without light). This could be useful in order to combine the ${ }^{*} \mathrm{Fe}(\mathrm{II}) / \mathrm{Ar}_{2} \mathrm{I}^{+}$photoredox catalysis with a potential $\mathrm{Fe}(\mathrm{II}) / \mathrm{APS}$ redox catalysis (no need of light) for redox photoactivated polymerization and dual-cure systems. In Figure 4A, Fe/APS system (curve a) is not really efficient with no exothermicity (thus very slow monomer conversion). The introduction of a reducing agent such as 2 dppba is strongly enhancing the radical generation (Figure 4A, curve b) similarly to the $\mathrm{Cu}(\mathrm{I}) /$ peroxide/reducing agent systems very recently developed for redox FRP. ${ }^{31,51} \mathrm{An}$ exothermicity of $70{ }^{\circ} \mathrm{C}$ is obtained which is rather good for that resin (roughly, a maximum of $90-100{ }^{\circ} \mathrm{C}$ exothermicity can be obtained for a reference amine/peroxide redox FRP system in that resin (same setup)). As water was necessarily present to dissolve APS in the methacrylate resin, we could not follow the reaction by RT-FTIR. For the other Fe(II) derivatives (Figures 4A and 4B), mixed results are obtained in Fe(II)/APS/2dppba systems (1000 ppm Fe(II) used). The trend in efficiency follows the maximum $\mathrm{T}^{\circ} \mathrm{C}$ reached: $\mathrm{Fe} 4\left(60^{\circ} \mathrm{C}\right)>\mathrm{Fe} 3\left(38^{\circ} \mathrm{C}\right) \approx \mathrm{Fe} 7\left(37^{\circ} \mathrm{C}\right)>>\mathrm{Fe} 5=$ Fe1 = Fe6 (no exothermicity). It is not yet clear what is the main factor leading to a good reactivity but the oxidation potential of Fe5 (too high) could explains the observed poor efficiency. Also, the concentration of $\mathrm{Fe}(\mathrm{II})$ cannot be too high as Fe(II) is capable to reduce radicals (e.g in $\mathrm{r} 1$ ) into inactive anions as exemplified in the Figure S6 using $1.3 \mathrm{wt} \%$ of Fe(II) (then, the redox FRP is slow down for too high Fe(II) concentrations).

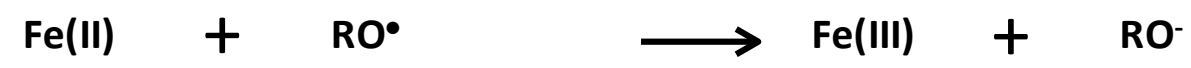

Remarkably, the redox FRP initiating system developed (Fe7/APS/2dppba) can be acceleratedon demand using NIR photoredox catalysis developed above (Figure 4C): Curing was occurring in only 400s using light (lod added for photoredox reaction) when 1300s were necessary without light. Noteworthy, the Fe/APS/2dppba redox initiating system is highly robust towards the oxygen inhibition as pure HEMA (viscosity close to water, see Table 1) is also polymerized in bulk (Figure 4D). Such systems could be applied to the synthesis of hydrogels. ${ }^{52}$ 

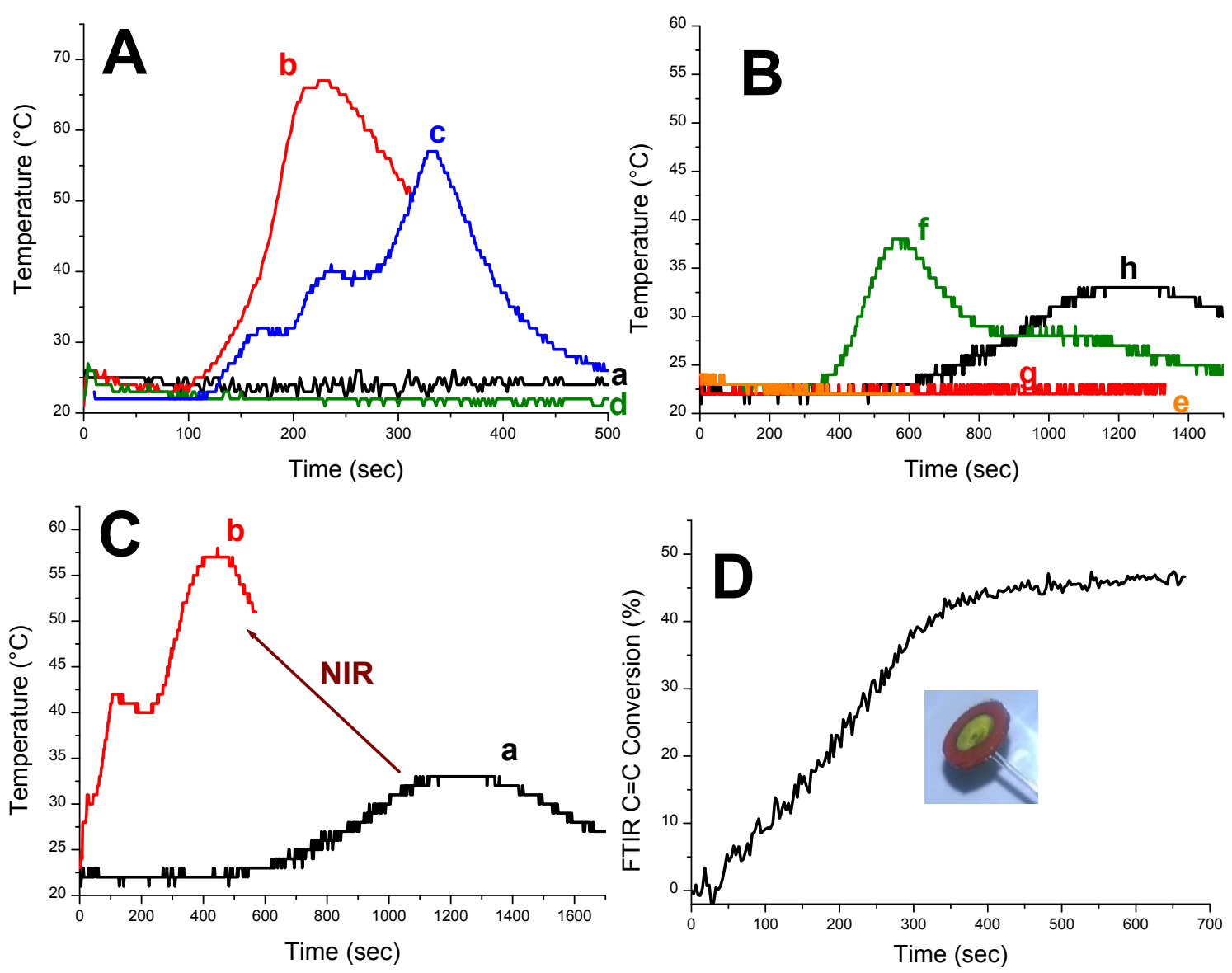

Figure 4: Redox polymerization A,B,C: Optical pyrometric measurements (Temperature vs. mixing time, $4 \mathrm{~mm}$ samples), under air for resin 1 for 2.0 wt\% APS (+2.0 wt\% water) mixed with $0.1 \mathrm{wt} \% \mathrm{Fe}(\mathrm{II})$ and (if mentioned) $1.5 \quad w t \% \quad 2 d p p b a ; A:(a) F e / A P S ; \quad$ (b)Fe/2dppba/APS;(c)

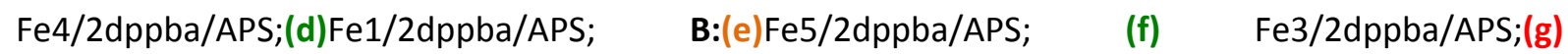
Fe6/2dppba/APS; (h)Fe7/2dppba/APS;C: (a) Fe7/2dppba/APS without light and (b) Fe7/2dppba/APS (+1.0 wt\% lod) under NIR light (redox photoactivation, LD@785 nm at 0.4 W/cm²);D: Redox polymerization profiles (methacrylate $\mathrm{C}=\mathrm{C}$ function conversion vs. mixing time) measured in RT-FTIR in pure HEMA; $1.4 \mathrm{~mm}$ thick samples, under air. Redox initiating system: $0.1 \mathrm{wt} \% \mathrm{Fe}+2 \mathrm{dppba}$ mixed with 2.5 w\% APS (+2.5 wt\% water). Embedded: image of the final HEMA polymer. 


\section{3/ Proposed chemical mechanisms}

\subsection{1/ Radical detection by ESR - spin trapping}

In Figure 5 and Table 4, radicals generated from the Fe(II)/oxidizing agent interactions are discussed. First, the photoredox $\mathrm{Fe}^{*} / \mathrm{Ar}_{2} \mathrm{I}^{+}$reaction is leading to an $\mathrm{Ar} \bullet / \mathrm{PBN}$ radical adduct as: the spectra show excellent fitting using hyperfine coupling constants (HFCCs) of aN $=14.1, a \beta-H=2.1$ which corresponds: i) to the experimental literature ${ }^{53}$ and ii) to theoretical HFCCs calculated at UB3LYP/NO7D level $(\mathrm{aN}=15.82 ; \mathrm{a} \beta-\mathrm{H}=1.99)$ for the radical adduct optimized in Figure $5 \mathrm{~A}$ (right).

Second, the Fe/APS redox reaction is leading to a radical/PBN adduct that was assigned to $\mathrm{SO}_{4}{ }^{\bullet-}$ /PBN radical adduct with the experimental HFCCs of: $\mathrm{aN}=13.6, \mathrm{a} \beta-\mathrm{H}=1.9$. Indeed, the theoretical values for a $\mathrm{SO}_{4}{ }^{\bullet} / \mathrm{PBN}$ radical adduct (in water) are very close to these value ( $\mathrm{aN}=13.62 ; \mathrm{a} \beta-\mathrm{H}=1.83$ Table 4; the structure of this radical adduct is given in Figure 5B (right)). The values are close to the ones computed in water as the anionic radical adduct was extracted from water which is likely to result in the presence of solvating water in the toluene extracted and analyzed. 

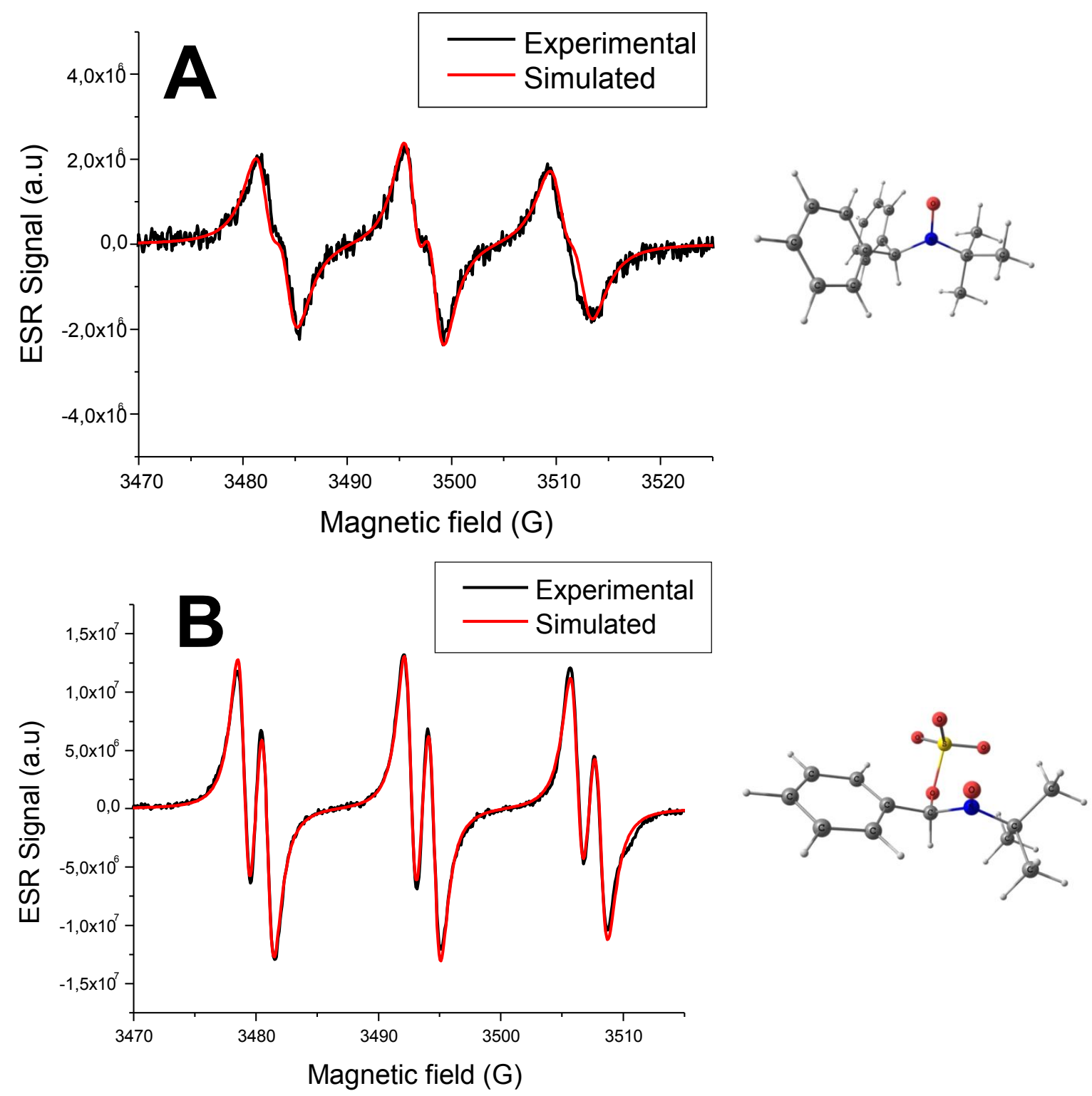

Figure 5: Determination of the radicals generated: ESR-ST spectra in toluene (PBN as spin trap, $\mathrm{N}_{2}$ degassed solutions) A: Irradiation (by a LED@780 nm, $80 \mathrm{~mW} / \mathrm{cm}^{2}$ ) of Fe7/diphenyliodonium hexafluorophosphate system and simulated spectra (WINSIM software). (right) the optimized structure (at UB3LYP/6-31G(d) level of theory) of a Ph\%/PBN radical adduct. B: Toluene extracted after 10s mixing of Fe (in toluene) with an APS/water solution and simulated spectra (WINSIM software). (right): the optimized structure (at UB3LYP/6-31G(d) level of theory) of a $\mathrm{SO}_{4}{ }^{\circ} / \mathrm{PBN}$ radical adduct. 
Table 4: Hyperfine coupling constants (HFCCS) experimentally determined (fit of the experimental spectra) or calculated by molecular modeling for the radical/PBN adducts (DFT level).

\begin{tabular}{|c|c|c|c|c|}
\hline Radical adduct & \multicolumn{2}{|c|}{ SO $_{4}{ }^{\bullet} /$ PBN } & \multicolumn{2}{c|}{ Ph $/$ PBN } \\
\hline Experimental HFCCS & $a_{\mathrm{N}}=13.6^{\mathrm{a}}$ & $a_{\beta-\mathrm{H}}=1.9^{\mathrm{a}}$ & $a_{\mathrm{N}}=14.1^{\mathrm{b}}$ & $a_{\beta-\mathrm{H}}=2.1^{\mathrm{b}}$ \\
\hline $\begin{array}{c}\text { DFT HFCCS } \\
\text { calculations }^{\mathrm{c}}\end{array}$ & $a_{\mathrm{N}}=13.62^{\mathrm{d}}$ & $a_{\beta-\mathrm{H}}=1.83^{\mathrm{d}}$ & $a_{\mathrm{N}}=15.82^{\mathrm{e}}$ & $a_{\beta-\mathrm{H}}=1.99^{\mathrm{e}}$ \\
\hline
\end{tabular}

${ }^{a}$ : in toluene (extracted from water); ${ }^{b}$ : in toluene; : at UB3LYP/NOTD (hfc constants)//UB3LYP/6$31 G(d)$ (geometry) level of theories; ${ }^{d}$ : in water; ${ }^{e}$ : in benzene.

\subsection{2/ Cyclic voltammetry (CV) and mechanistic proposition}

Finally, compared to Figure $6 \mathrm{~A}$ for Fe(II) alone, Figures $6 \mathrm{~B}$ and $6 \mathrm{C}$ show the regeneration of $\mathrm{Fe}(\mathrm{II})$ thanks to the presence of reducing agents (phosphine or amine) in CV. Indeed, there is a constant reoxidation occurring (not seen for Fe alone (Figure 6A) or when the sweeping rate is very fast not giving enough time for the reducing agent to regenerate Fe(II) from Fe(III) (Figure S7)). The slower the sweeping rate, the more re-oxidation of $\mathrm{Fe}(\mathrm{II})$ is seen (Figure $6(\mathrm{~B} \& \mathrm{C})$ ). These facts point to the reactions corresponding to the bottom of the catalytic cycles presented in Scheme 3, (Fe(III) + Red -> $\mathrm{Fe}(\mathrm{II})+\mathrm{Red}^{\bullet+}$ ) when the $\mathrm{Fe}(\mathrm{II})->\mathrm{Fe}(\mathrm{III})$ oxidation is occurring at the $\mathrm{CV}$ electrode as $\mathrm{E}>\mathrm{E}_{\mathrm{ox}}(\mathrm{Fe}(\mathrm{II}))$. Interestingly, even if the oxidation potential of $2 \mathrm{dppba}(1.0 \mathrm{~V}$ vs SCE) or DMABA (0.7 V vs SCE, same reactivity as 4-N,N TMA ${ }^{54}$ ) are not very low, reaction with Fe(III) (reduction potential of $0.3 \mathrm{~V}$ vs SCE) is still occurring. 

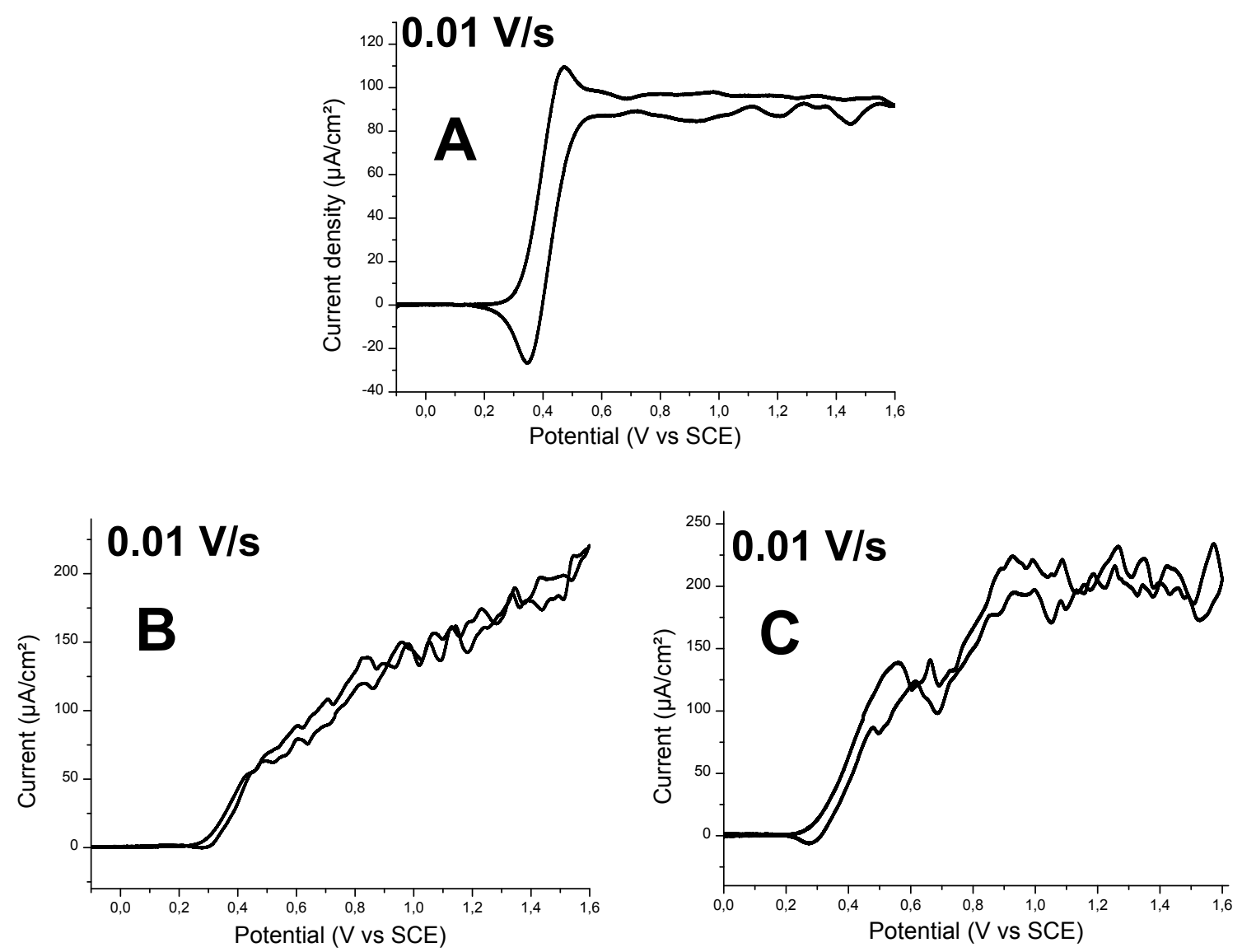

Figure 6: Regeneration of $\mathrm{Fe}(\mathrm{II})$ in catalytic cycles using cyclic voltammetry (CV) experiments in ACN (containing $0.2 \mathrm{M}$ tetrabutylammonium hexafluorophosphate, $\mathrm{N}_{2}$ degassed) for $\mathrm{A}$ : Fe alone B: $\mathrm{Fe}+$ 2dppba and C: Fe + amine (4-N,N TMA).

To sum up, under NIR irradiation, we propose in Scheme 3 a Fe(II)*/Ar ${ }_{2}{ }^{+}$photoredox reaction that generated aryl radicals. Fe(III) produced can be reduced by phosphines, amines or VitC. This regenerates Fe(II) completing the catalytic cycle (Scheme 3 right). Without light, the Fe(II)/APS redox reaction is directly generating radicals $\left(\mathrm{SO}_{4}{ }^{\bullet-}\right.$ ) (Scheme 3 left). Similarly, $\mathrm{Fe}(\mathrm{III})$ reactions with phosphine enable completion of the catalytic cycle. 


\section{Photoredox (hv)}

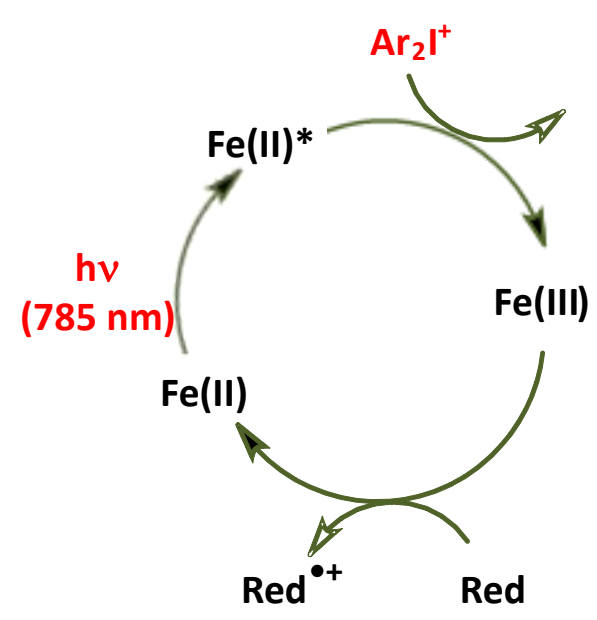

\section{Redox (no light)}

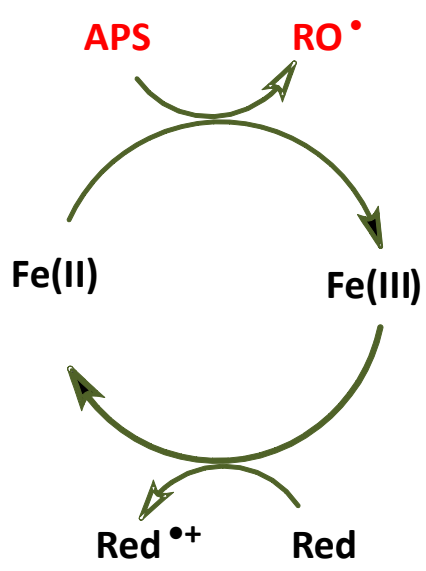

\section{Red $=$ Phosphines, amines or Vitamin C}

Scheme 3: Proposed photocatalytic (photoredox, under NIR irradiation) and redox catalytic (no light) mechanisms for the ferrocene/reducing agent (Red)/oxidizing agents considered in this study. $\mathrm{Ar}_{2} \mathrm{I}^{+}$ stands for iodonium salt and APS for amonium persulfate.

\section{Conclusion:}

Near infrared (NIR) photoredox catalysis using Fe(II) compounds are presented here for the first time. It was applied to the free radical photopolymerization of methacrylates (that requires high radical generating rate). The $\mathrm{Fe}(\mathrm{II})^{*} /$ lodonium $\left(\mathrm{Ar}_{2} \mathrm{l}^{+}\right)$reaction developed can be drastically improved thanks to the presence of reducing agents (phosphines, amines or VitC). The performances for a $\mathrm{Fe}(\mathrm{II}) / \mathrm{Ar}_{2} \mathrm{I}^{+} /$amine systems under a $785 \mathrm{~nm}$ irradiation are clearly outranking visible light references (such as camphorquinone/amine/phosphine) as higher final conversion can be reached (e.g. 83\% against $60 \%$ for the reference). Interestingly, the $\mathrm{Fe}(\mathrm{II})$ catalysts can also be active without light in redox free radical polymerization when mixed with ammonium persulfate and a reducing agent. It makes possible the development of orthogonal chemistries such as redox photoactivated polymerization: a redox reaction can take place without light and NIR light can be used on demand to 
trigger a second light induced reaction. This study paves the way towards the use of Fe(II)structures for highly efficient (photo)redox catalysis upon mild conditions (NIR light, room temperature and under air).

Supporting information available: Figures S1 and S2: synthesis of the different Fe complexes; Figure S3: emission spectrum of the LD@785nm; Figure S4: Frontier molecular orbitals and UV-vis calculated spectra of the Fe complexes; Figure S5: Photopolymerization profiles upon LED@660 and 530 nm; Figure S6: other redox polymerizations; Figure S7: other CV experiments.

Acknowledgments: This work was made possible by the financial support of ANR FastPrinting and VISICAT. The DGA (Direction Générale de l'Armement, France) is acknowledged for its financial support through the PhD grant of Damien Brunel. 


\section{References:}

1 D. Cambié, C. Bottecchia, N. J. W. Straathof, V. Hessel and T. Noël, Chem. Rev., 2016, 116, 1027610341.

2 S. Shi, C. Croutxé-Barghorn and X. Allonas, Prog. Polym. Sci., 2017, 65, 1-41.

3 J. Lalevée and J.-P. Fouassier, Dyes and Chomophores in Polymer Science, John Wiley \& Sons, 2015.

4 K. Ueno, T. Oshikiri, Q. Sun, X. Shi and H. Misawa, Chem. Rev., 2018, 118, 2955-2993.

5 M. H. Shaw, J. Twilton and D. W. C. MacMillan, J. Org. Chem., 2016, 81, 6898-6926.

6 N. Corrigan, S. Shanmugam, J. Xu and C. Boyer, Chem. Soc. Rev., 2016, 45, 6165-6212.

7 S. Dadashi-Silab, S. Doran and Y. Yagci, Chem. Rev., 2016, 116, 10212-10275.

8 N. Zivic, M. Bouzrati-Zerelli, A. Kermagoret, F. Dumur, J.-P. Fouassier, D. Gigmes and J. Lalevée, ChemCatChem, 2016, 8, 1617-1631.

9 J. Chen and W. R. Browne, Coord. Chem. Rev., 2018, 374, 15-35.

$10 \mathrm{~J}$. Lalevee and J.-P. Fouassier, Photopolymerisation Initiating Systems, The Royal Society of Chemistry, 2018.

11 T. Brömme, D. Oprych, J. Horst, P. S. Pinto and B. Strehmel, RSC Adv, 2015, 5, 69915-69924.

12 C. Schmitz, A. Halbhuber, D. Keil and B. Strehmel, Prog. Org. Coat., 2016, 100, 32-46.

13 B. Strehmel, S. Ernst, K. Reiner, D. Keil, H. Lindauer and H. Baumann, Z. Für Phys. Chem., 2014, 228, 129-153.

14 C. Kütahya, C. Schmitz, V. Strehmel, Y. Yagci and B. Strehmel, Angew. Chem. Int. Ed., 2018, 57, 7898-7902.

15 S. Shanmugam, J. Xu and C. Boyer, Angew. Chem. Int. Ed., 2016, 55, 1036-1040.

16 N. Corrigan, J. Xu and C. Boyer, Macromolecules, 2016, 49, 3274-3285.

17 I. Janowska, J. Zakrzewski, K. Nakatani, J. A. Delaire, M. Palusiak, M. Walak and H. Scholl, J. Organomet. Chem., 2003, 675, 35-41.

18 I. Janowska, J. Zakrzewski, K. Nakatani, M. Palusiak, M. Walak and H. Scholl, J. Organomet. Chem., 2006, 691, 323-330.

19 G. Qian and Z. Y. Wang, Chem. Asian J., 2010, 5, 1006-1029.

20 E. Stankovic, S. Toma, R. Van Boxel, I. Asselberghs and A. Persoons, J. Organomet. Chem., 2001, 637-639, 426-434.

21 J.-P. Fouassier and J. F. RABEK, Radiation Curing in Polymer Science and Technology, Springer Science \& Business Media, 1993.

22 S. C. Ligon, B. Husár, H. Wutzel, R. Holman and R. Liska, Chem. Rev., 2014, 114, 557-589.

23 D. C. Neckers, W. Jager and SITA Technology Limited, Chemistry \& Technology for UV \& EB Formulation for Coatings, Inks \& Paints, Photoinitiation for Polymerization: UV \& EB at the Millenium, Wiley, Chichester, 1999.

24 R. S. Davidson, Exploring the Science, Technology and Applications of U.V. and E.B. Curing, Sita Tecnology Limited, 1999.

25 B. Wenn, M. Conradi, A. Demetrio Carreiras, D. M. Haddleton and T. Junkers, Polym. Chem., 2014, 5, 3053-3060.

26 P. Wu, A. K. Feldman, A. K. Nugent, C. J. Hawker, A. Scheel, B. Voit, J. Pyun, J. M. J. Fréchet, K. B. Sharpless and V. V. Fokin, Angew. Chem., 2004, 116, 4018-4022.

27 N. J. Treat, B. P. Fors, J. W. Kramer, M. Christianson, C.-Y. Chiu, J. R. de Alaniz and C. J. Hawker, ACS Macro Lett., 2014, 3, 580-584.

28 P. Garra, F. Dumur, D. Gigmes, A. Al Mousawi, F. Morlet-Savary, C. Dietlin, J. P. Fouassier and J. Lalevée, Macromolecules, 2017, 50, 3761-3771.

29 P. Garra, C. Dietlin, F. Morlet-Savary, F. Dumur, D. Gigmes, J. P. Fouassier and J. Lalevée, Polym. Chem., 2017, 8, 7088-7101.

30 P. Garra, F. Dumur, F. Morlet-Savary, C. Dietlin, D. Gigmes, J. P. Fouassier and J. Lalevée, J. Polym. Sci. Part Polym. Chem., 2017, 55, 3646-3655.

31 P. Garra, A. Kermagoret, A. Mousawi, F. Dumur, D. Gigmes, F. Morlet-Savary, C. Dietlin, J. P. Fouassier and J. Lalevée, Polym. Chem., 2017, 8, 4088-4097. 
32 P. Garra, F. Dumur, F. Morlet-Savary, C. Dietlin, J. P. Fouassier and J. Lalevée, Macromolecules, 2016, 49, 6296-6309.

33 P. Garra, F. Morlet-Savary, C. Dietlin, J. P. Fouassier and J. Lalevée, Macromolecules, 2016, 49, 9371-9381.

34 M. Bielawski, D. Aili and B. Olofsson, J. Org. Chem., 2008, 73, 4602-4607.

35 J.-T. Chen and H.-P. Chu, J. Chem. Eng. Data, 2007, 52, 650-654.

36 P. Garra, M. Carré, F. Dumur, F. Morlet-Savary, C. Dietlin, D. Gigmes, J.-P. Fouassier and J. Lalevée, Macromolecules, 2018, 51, 679-688.

37 C. Dietlin, S. Schweizer, P. Xiao, J. Zhang, F. Morlet-Savary, B. Graff, J.-P. Fouassier and J. Lalevée, Polym. Chem., 2015, 6, 3895-3912.

38 B. Falk, S. M. Vallinas and J. V. Crivello, J. Polym. Sci. Part Polym. Chem., 2003, 41, 579-596.

39 J. V. Crivello and J. H. W. Lam, J. Polym. Sci. Polym. Chem. Ed., 1981, 19, 539-548.

40 P. Garra, A.-H. Bonardi, A. Baralle, A. Al Mousawi, F. Bonardi, C. Dietlin, F. Morlet-Savary, J.-P. Fouassier and J. Lalevée, J. Polym. Sci. Part Polym. Chem., 2018, 56, 889-899.

$41 \mathrm{~J}$. Foresman and E. Frish, Gaussian Inc Pittsbg. USA.

42 P. Xiao, F. Dumur, J. Zhang, J. P. Fouassier, D. Gigmes and J. Lalevée, Macromolecules, 2014, 47, 3837-3844.

43 E. F. Belogolova, T. I. Vakul'skaya and V. F. Sidorkin, Phys. Chem. Chem. Phys., 2015, 17, 1273512746.

44 Rehm Dieter and Weller Albert, Isr. J. Chem., 1970, 8, 259-271.

45 A. A. Mousawi, A. Kermagoret, D.-L. Versace, J. Toufaily, T. Hamieh, B. Graff, F. Dumur, D. Gigmes, J. P. Fouassier and J. Lalevée, Polym. Chem., 2016, 8, 568-580.

46 S. Fery-Forgues, B. Delavaux-Nicot, D. Lavabre and K. Rurack, J. Photochem. Photobiol. Chem., 2003, 155, 107-114.

47 M. Bouzrati-Zerelli, M. Maier, C. P. Fik, C. Dietlin, F. Morlet-Savary, J. P. Fouassier, J. E. Klee and J. Lalevée, Polym. Int., 2017, 66, 504-511.

48 B. Steyrer, B. Busetti, G. Harakály, R. Liska and J. Stampfl, Addit. Manuf., 2018, 21, 209-214.

49 A. S. Sarac, Prog. Polym. Sci., 1999, 24, 1149-1204.

50 P. Kalenda, Eur. Polym. J., 1995, 31, 1099-1102.

51 P. Garra, F. Dumur, A. A. Mousawi, B. Graff, D. Gigmes, F. Morlet-Savary, C. Dietlin, J. P. Fouassier and J. Lalevée, Polym. Chem., 2017, 8, 5884-5896.

52 Q. Li, C.-F. Wang and S. Chen, Ind. Eng. Chem. Res., 2018, 57, 3083-3090.

53 A. Al Mousawi, F. Dumur, P. Garra, J. Toufaily, T. Hamieh, F. Goubard, T.-T. Bui, B. Graff, D. Gigmes, J. Pierre Fouassier and J. Lalevée, J. Polym. Sci. Part Polym. Chem., 2017, 55, 1189-1199.

54 P. Garra, B. Graff, F. Morlet-Savary, C. Dietlin, J.-M. Becht, J.-P. Fouassier and J. Lalevée, Macromolecules, 2018, 51, 57-70. 
Ferrocene-based (photo)redox polymerization under long wavelengths Patxi Garra ${ }^{1,2}$, Damien Brunel ${ }^{3}$, Guillaume Noirbent ${ }^{3}$, Bernadette Graff ${ }^{1,2}$, Fabrice MorletSavary $^{1,2}$, Céline Dietlin ${ }^{1,2}$,V. F. Sidorkin ${ }^{4}$, Frédéric Dumur ${ }^{3}$, David Duché5, Didier Gigmes ${ }^{3}$, Jean-Pierre Fouassier ${ }^{1,2}$, Jacques Lalevé $e^{1,2^{*}}$

TOC graphic

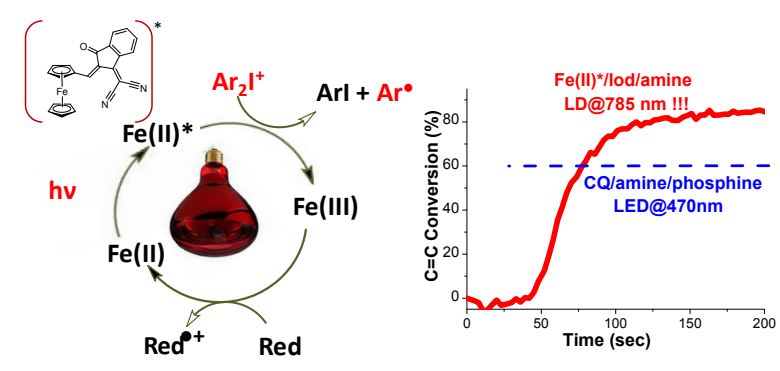




\title{
Supporting Information:
}

\section{Ferrocene-based (photo)redox polymerization under long wavelengths}

Patxi Garra ${ }^{1,2}$, Damien Brunel ${ }^{3}$, Guillaume Noirbent ${ }^{3}$, Bernadette Graff ${ }^{1,2}$, Fabrice MorletSavary ${ }^{1,2}$, Céline Dietlin ${ }^{1,2}$, V. F. Sidorkin ${ }^{4}$, Frédéric Dumur ${ }^{3}$, David Duché ${ }^{\text {, Didier Gigmes }}{ }^{3}$, Jean-Pierre Fouassier ${ }^{1,2}$, Jacques Lalevée $e^{1,2^{*}}$

\author{
${ }^{1}$ Université de Haute-Alsace, CNRS, IS2M UMR 7361, F-68100 Mulhouse, France \\ ${ }^{2}$ Université de Strasbourg, France \\ ${ }^{3}$ Aix Marseille Univ, CNRS, ICR UMR 7273, F-13397 Marseille, France \\ ${ }^{4}$ A. E. Favorsky Irkutsk Institute of Chemistry, Siberian Branch of the Russian \\ Academy of Sciences, Favorsky, 1, Irkutsk 664033, Russian Federation. \\ ${ }^{5}$ Aix Marseille Univ, CNRS, IM2NP UMR 7334, F-13397 Marseille, France \\ *Corresponding author: jacques.lalevee@uha.fr
}

\section{Synthesis of photoinitiators}

All reagents and solvents were purchased from Aldrich or Alfa Aesar and used as received without further purification. Mass spectroscopy was performed by the Spectropole of Aix-Marseille University. ESI mass spectral analyses were recorded with a 3200 QTRAP (Applied Biosystems SCIEX) mass spectrometer. The HRMS mass spectral analysis was performed with a QStar Elite (Applied Biosystems SCIEX) mass spectrometer. Elemental analyses were recorded with a Thermo Finnigan EA 1112 elemental analysis apparatus driven by the Eager 300 software. ${ }^{1} \mathrm{H}$ and ${ }^{13} \mathrm{C}$ NMR spectra were determined at room temperature in $5 \mathrm{~mm}$ o.d. tubes on a Bruker Avance 400 spectrometer of the Spectropole: ${ }^{1} \mathrm{H}(400 \mathrm{MHz})$ and ${ }^{13} \mathrm{C}(100 \mathrm{MHz})$. The ${ }^{1} \mathrm{H}$ chemical shifts were referenced to the solvent peaks $\mathrm{CDCl}_{3}(7.26 \mathrm{ppm})$, DMSO (2.49 ppm) and the ${ }^{13} \mathrm{C}$ chemical shifts were referenced to the solvent peak $\mathrm{CDCl}_{3}(77 \mathrm{ppm})$, DMSO $(49.5 \mathrm{ppm})$. All these carbazole photoinitiators were prepared with analytical purity up to accepted standards for new organic compounds ( $>98 \%)$ which was checked by high field NMR analysis. Ferrocenecarboxaldehyde Fe2 was synthesized as previously reported, without modifications and in similar yield [A.F. Neto, J. Miller, V. Faria de Andrade, S.Y. Fujimoto, M. 
Maísa de Freitas Afonso, F. Costa Archanjo, V.A. Darin, M.L. Andrade e Silva, Á. Donizete Lanchote Borges, G. Del Ponte, Zeitschrift für anorganische und allgemeine Chemie, 2002, 628, 209-216].

Figure S1. Synthetic pathways to Fe3-Fe7.
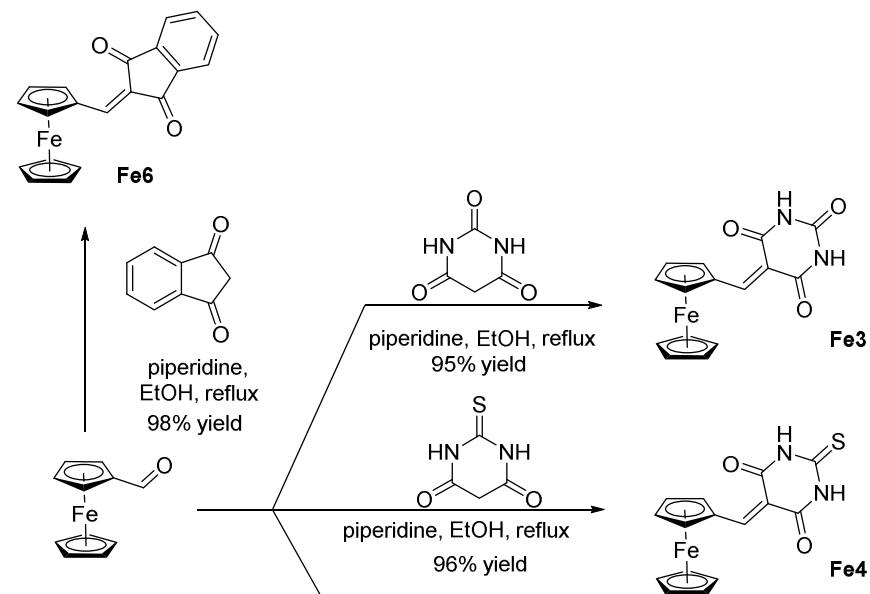

$98 \%$ yield
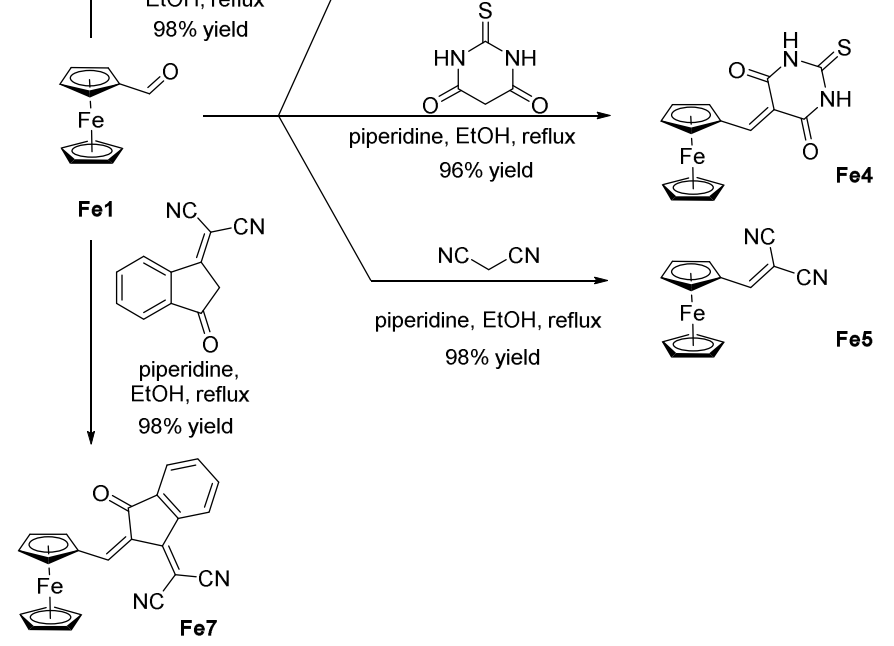

Figure S2. Synthetic pathways to Fe7Me.

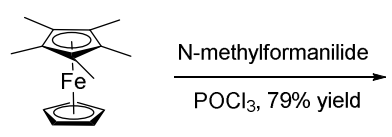

Fe8

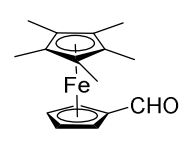

Fe9

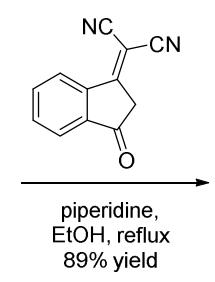

$89 \%$ yield

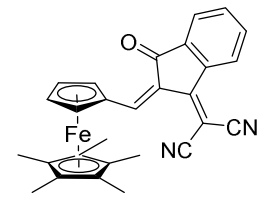

Fe7Me

Synthesis of [(tetrahydro-2,4,6-trioxo-5(2H)-pyrimidinylidene)methyl]ferrocene Fe3

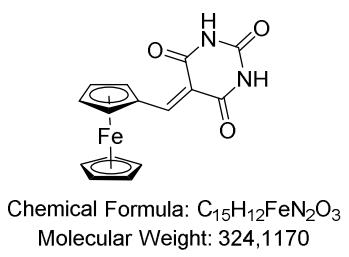

To a mixture of barbituric acid $(0.30 \mathrm{~g}, 2.34 \mathrm{mmol}, \mathrm{M}=128.09 \mathrm{~g} / \mathrm{mol})$ and ferrocene-carbaldehyde $(0.5$ g, $2.34 \mathrm{mmol}, 214.00 \mathrm{~g} / \mathrm{mol})$ in absolute ethanol $(50 \mathrm{~mL})$ was added a few drops of piperidine. 
Immediately, the color changed. The solution was introduced in an oil bath preheated at $90^{\circ} \mathrm{C}$. Within $10 \mathrm{~min}$, the reaction was finished (TLC control). The solvent was removed under reduced pressure. The residue was purified by column chromatography using DCM as the eluent. The different fractions were combined and the solvent removed under reduced pressure so that approximately $30 \mathrm{~mL} \mathrm{DCM}$ was remaining. Addition of pentane precipitated a solid that was filtered off, washed several times with pentane and dried under reduced pressure $\left(720 \mathrm{mg}, 95 \%\right.$ yield). ${ }^{1} \mathrm{H}$ NMR (DMSO-d 6 ) $\delta: 4.29(\mathrm{~s}, 5 \mathrm{H})$, $4.93(\mathrm{~s}, 2 \mathrm{H}), 5.35(\mathrm{~s}, 2 \mathrm{H}), 8.21(\mathrm{~s}, 1 \mathrm{H}), 10.98(\mathrm{~s}, 1 \mathrm{H}), 11.12(\mathrm{~s}, 1 \mathrm{H}) ;{ }^{13} \mathrm{C}$ NMR (DMSO-d 6 ) $8:$ 70.5, 75.3, 76.1, 111.3, 150.2, 157.7, 162.1, 163.8; HRMS (ESI MS) m/z: theor: 324.0197 found: 324.0199 ([M] ${ }^{+}$ detected)

Synthesis of [(tetrahydro-4,6-dioxo-2-thioxo-5(2H)-pyrimidinylidene)methyl]ferrocene Fe4

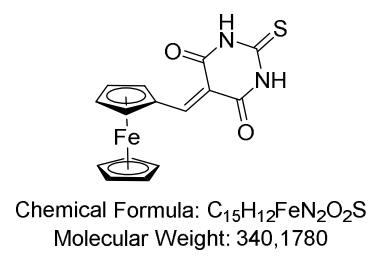

To a mixture of 4,6-dihydroxy-2-mercaptopyrimidine $(0.34 \mathrm{~g}, 2.34 \mathrm{mmol}, \mathrm{M}=144.15 \mathrm{~g} / \mathrm{mol})$ and ferrocene-carbaldehyde $(0.5 \mathrm{~g}, 2.34 \mathrm{mmol}, 214.00 \mathrm{~g} / \mathrm{mol}$ in absolute ethanol $(50 \mathrm{~mL})$ was added a few drops of piperidine. Immediately, the color changed. The solution was introduced in an oil bath preheated at $90^{\circ} \mathrm{C}$. Within $10 \mathrm{~min}$, the reaction was finished (TLC control). The solvent was removed under reduced pressure. The residue was purified by column chromatography using DCM as the eluent. The different fractions were combined and the solvent removed under reduced pressure so that approximately $30 \mathrm{~mL} \mathrm{DCM}$ was remaining. Addition of pentane precipitated a blue-green solid that was filtered off, washed several times with pentane and dried under reduced pressure $(764 \mathrm{mg}$, 96\% yield). ${ }^{1} \mathrm{H}$ NMR (DMSO-d 6 ) $\delta: 4.33(\mathrm{~s}, 5 \mathrm{H}), 5.04(\mathrm{~s}, 2 \mathrm{H}), 5.39(\mathrm{~s}, 2 \mathrm{H}), 8.26(\mathrm{~s}, 1 \mathrm{H}), 12.09(\mathrm{~s}, 1 \mathrm{H}), 12.21(\mathrm{~s}$, 1H); ${ }^{13} \mathrm{C}$ NMR (DMSO-d $)$ ) $8: 70.9,76.0,76.4,111.1,158.1,159.9,162.0,177.8 ;$ HRMS (ESI MS) m/z: theor: 339.9969 found: $340.0002\left([\mathrm{M}]^{+}\right.$. detected) 


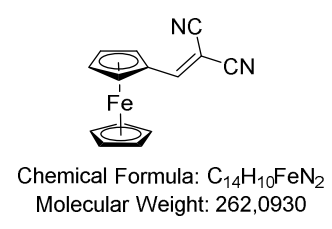

To a mixture of malononitrile $(0.16 \mathrm{~g}, 2.34 \mathrm{mmol}, \mathrm{M}=66.06 \mathrm{~g} / \mathrm{mol})$ and ferrocene-carbaldehyde $(0.5$ g, $2.34 \mathrm{mmol}, 214.00 \mathrm{~g} / \mathrm{mol}$ ) in absolute ethanol $(50 \mathrm{~mL}$ ) was added a few drops of piperidine. Immediately, the color changed. The solution was introduced in an oil bath preheated at $90^{\circ} \mathrm{C}$. Within $10 \mathrm{~min}$, the reaction was finished (TLC control). The solvent was removed under reduced pressure. The residue was purified by column chromatography using DCM as the eluent. The different fractions were combined and the solvent removed under reduced pressure so that approximately $30 \mathrm{~mL} \mathrm{DCM}$ was remaining. Addition of pentane precipitated a solid that was filtered off, washed several times with pentane and dried under reduced pressure (601 mg, 98\% yield). ${ }^{1} \mathrm{H} \mathrm{NMR}\left(\mathrm{CDCl}_{3}\right) \delta: 4.33(\mathrm{~s}, 5 \mathrm{H}), 4.85(\mathrm{~s}$, 2H), $4.98(\mathrm{~s}, 2 \mathrm{H}), 7.72(\mathrm{~s}, 1 \mathrm{H}) ;{ }^{13} \mathrm{C}$ NMR $\left(\mathrm{CDCl}_{3}\right) \delta: 71.3,71.9,74.2,75.4,114.5,115.3,163.4$; HRMS (ESI MS) m/z: theor: 262.0193 found: $262.0195\left([M]^{+}\right.$detected).

Synthesis of [(1,3-dihydro-1,3-dioxo-2H-inden-2-ylidene)methyl]ferrocene Fe6

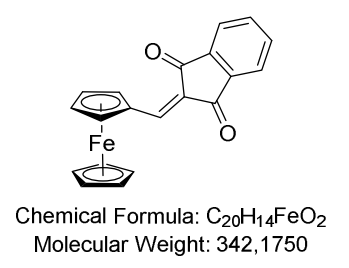

To a mixture of indane-1,3-dione $(0.34 \mathrm{~g}, 2.34 \mathrm{mmol}, \mathrm{M}=146.14 \mathrm{~g} / \mathrm{mol})$ and ferrocene-carbaldehyde $(0.5 \mathrm{~g}, 2.34 \mathrm{mmol}, 214.00 \mathrm{~g} / \mathrm{mol})$ in absolute ethanol $(50 \mathrm{~mL})$ was added a few drops of piperidine. Immediately, the color changed. The solution was introduced in an oil bath preheated at $90^{\circ} \mathrm{C}$. Within $10 \mathrm{~min}$, the reaction was finished (TLC control). The solvent was removed under reduced pressure. The residue was purified by column chromatography using DCM as the eluent. The different fractions were combined and the solvent removed under reduced pressure so that approximately $30 \mathrm{~mL} \mathrm{DCM}$ was remaining. Addition of pentane precipitated a solid that was filtered off, washed several times with pentane and dried under reduced pressure (780 mg, 98\% yield). ${ }^{1} \mathrm{H} \mathrm{NMR}\left(\mathrm{CDCl}_{3}\right) \delta: 4.23(\mathrm{~s}, 5 \mathrm{H}), 4.84-$ 
$4.85(\mathrm{~m}, 2 \mathrm{H}), 5.43-5.44(\mathrm{~m}, 2 \mathrm{H}), 7.75-7.79(\mathrm{~m}, 2 \mathrm{H}), 7.88(\mathrm{~s}, 1 \mathrm{H}), 7.93-7.97(\mathrm{~m}, 2 \mathrm{H}) ;{ }^{13} \mathrm{C} \mathrm{NMR}\left(\mathrm{CDCl}_{3}\right) \delta$ : 70.7, $75.2,75.3,76.2,77.2,122.6,122.8,134.5,134.6,139.9,142.3,149.4,189.5,190.5$; HRMS (ESI MS) $\mathrm{m} / \mathrm{z}$ : theor: 342.0343 found: $342.0342\left([\mathrm{M}]^{+}\right.$. detected)

Synthesis of [1-(dicyanomethylene)-1,3-dihydro-3-oxo-2H-inden-2-ylidene]methyl]ferrocene Fe7

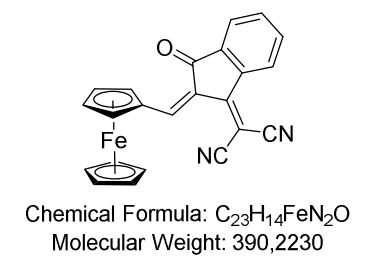

To a mixture of 2-(3-oxo-2,3-dihydro-1H-inden-1-ylidene)malononitrile (1.12 g, 5.79 mmol, $\mathrm{M}=194.19$ $\mathrm{g} / \mathrm{mol}$ ) and ferrocene-carbaldehyde $(1.24 \mathrm{~g}, 5.79 \mathrm{mmol}, 214.00 \mathrm{~g} / \mathrm{mol})$ in absolute ethanol $(50 \mathrm{~mL})$ was added a few drops of piperidine. Immediately, the color changed. The solution was introduced in an oil bath preheated at $90^{\circ} \mathrm{C}$. Within $10 \mathrm{~min}$, the reaction was finished (TLC control). The solvent was removed under reduced pressure. The residue was purified by column chromatography using DCM as the eluent. The different fractions were combined and the solvent removed under reduced pressure so that approximately $30 \mathrm{~mL}$ DCM was remaining. Addition of pentane precipitated a solid that was filtered off, washed several times with pentane and dried under reduced pressure ( $2.19 \mathrm{~g}, 97 \%$ yield). ${ }^{1} \mathrm{H} \mathrm{NMR}\left(\mathrm{CDCl}_{3}\right)$ 8: $4.35(\mathrm{~s}, 5 \mathrm{H}), 5.04(\mathrm{~s}, 2 \mathrm{H}), 5.34(\mathrm{~s}, 2 \mathrm{H}), 7.69-7.78(\mathrm{~m}, 2 \mathrm{H}), 7.86-7.88(\mathrm{~m}, 1 \mathrm{H}), 8.46(\mathrm{~s}$, 1H), $8.66(\mathrm{~d}, 1 \mathrm{H}, \mathrm{J}=7.0 \mathrm{~Hz}) ;{ }^{13} \mathrm{C} \mathrm{NMR}\left(\mathrm{CDCl}_{3}\right) \delta: 68.1,72.0,76.9,77.2,77.7,115.1,115.3,123.3,123.6$, 125.1, 134.2, 134.8, 137.3, 139.4, 149.6, 161.7, 187.2; HRMS (ESI MS) m/z: theor: 390.0456 found: $390.0458\left([\mathrm{M}]^{+} \cdot\right.$ detected $)$

Synthesis of 1,2,3,4,5-pentamethylferrocene Fe8

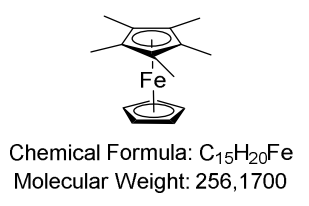

A suspension of anhydrous $\mathrm{FeCl}_{2}(4.05 \mathrm{~g}, 32 \mathrm{mmol} \mathrm{M}=126.74 \mathrm{~g} / \mathrm{mol})$ in dry THF (200 mL) was 
vigorously stirred in the dark $1 \mathrm{~h}$ to produce $\mathrm{FeCl}_{2} \cdot \mathrm{THF}$. Separately, $n$-butyllithium $(2.5 \mathrm{M}, 12.8 \mathrm{~mL}, 1$ eq.) was added dropwise to pentamethylcyclopentadiene $(5 \mathrm{~mL}, 31.93 \mathrm{mmol}, 4.35 \mathrm{~g}, \mathrm{M}=136.24 \mathrm{~g} / \mathrm{mol}$, $\mathrm{d}=0.87,1$ eq. $)$ in $\mathrm{THF}(50 \mathrm{~mL})$ at $-78^{\circ} \mathrm{C}$ and the mixture was then warmed and stirred at room temperature for $2 \mathrm{~h}$. Then, this solution was slowly transferred into the $\mathrm{FeCl}_{2} \cdot \mathrm{THF}$ solution and stirred at room temperature for $1 \mathrm{~h}$. Then, sodium cyclopentadienylide (2M, $16 \mathrm{~mL}, 31.93 \mathrm{mmol}, 1$ eq.) was slowly added to the solution and stirring was maintained overnight. The solution was quenched with water and the solvent removed under reduced pressure. The residue was dissolved in DCM. The organic phase was washed with water several times. The organic phase was dried over magnesium sulfate and the solvent removed under reduced pressure. The targeted pentamethylferrocene was obtained under the form of an orange powder (5.49 g, $67 \%$ yield). ${ }^{1} \mathrm{H} N M R\left(\mathrm{CDCl}_{3}\right) \delta: 1.93(\mathrm{~s}, 15 \mathrm{H})$, 3.69 (s, 5H); ${ }^{13} \mathrm{C} \mathrm{NMR}\left(\mathrm{CDCl}_{3}\right)$ ס: 11.4, 71.2, 80.2; HRMS (ESI MS) m/z: theor: 256.0914 found: 256.0915 $\left([\mathrm{M}]^{+}\right.$. detected). Analyses were consistent with those previously reported in the literature (D. Kang, F. Ricci, R. J. White, K. W. Plaxco, Anal. Chem. 2016, 88, 10452-10458).

Synthesis of 1'-formyl-1,2,3,4,5-pentamethylferrocene Fe9

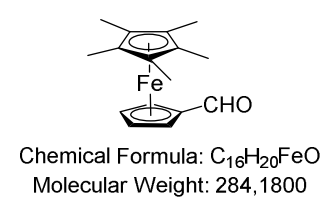

1,2,3,4,5-Pentamethylferrocene $(2.56 \mathrm{~g}, 10 \mathrm{mmol}, \mathrm{M}=256.17 \mathrm{~g} / \mathrm{mol})$ was dissolved in $\mathrm{N}$ methylformanilide $(20 \mathrm{~mL})$ and phosphorus oxychloride $(2.6 \mathrm{~g}, 1.6 \mathrm{~mL}, 16.96 \mathrm{mmol}, \mathrm{M}=153.33 \mathrm{~g} / \mathrm{mol}$, $d=1.645$ ) was added. The solution was stirred at room temperature for 3 days while being protected from light. The reaction mixture was hydrolyzed at $0^{\circ} \mathrm{C}$ with $100 \mathrm{~mL}$ of an aqueous solution of sodium acetate (20\%). The solution was stirred for $30 \mathrm{~min}$. at room temperature and the solution was then saturated with sodium chloride and extracted with ether several times. The residue was filtered on a plug of silicagel, providing 1'-formyl-1,2,3,4,5-pentamethylferrocene Fe9 as a red solid $(2.24 \mathrm{~g}, 79 \%$ yield). ${ }^{1} \mathrm{H} N M R\left(\mathrm{CDCl}_{3}\right) \delta: 1.83\left(\mathrm{~s}, 15 \mathrm{H}, \mathrm{CH}_{3}\right), 4.16(\mathrm{t}, 2 \mathrm{H}, \mathrm{J}=1.9 \mathrm{~Hz}), 4.25(\mathrm{t}, 2 \mathrm{H}, \mathrm{J}=1.9 \mathrm{~Hz}), 9.70(\mathrm{~s}, 1 \mathrm{H}$; $\mathrm{CHO}) ;{ }^{13} \mathrm{CNMR}\left(\mathrm{CDCl}_{3}\right) \delta: 11.2,72.0,77.6,80.4,82.6,193.9 ; \mathrm{HRMS}$ (ESI MS) m/z: theor: 284.0864 found: 
$284.0865\left([\mathrm{M}]^{+}\right.$. detected). Analyses were consistent with those previously reported in the literature (J. Moreau, L. Challier, N. Lalaoui, F. Mavré, V. Noël, B. Limoges, B. Schöllhorn, C. Fave, Chem. Eur. J. 2014, $20,2953-2959)$.

Synthesis of 1-[1-(dicyanomethylene)-1,3-dihydro-3-oxo-2H-inden-2-ylidene]methyl]-1',2',3', 4',5'penta-methylferrocene Fe7Me

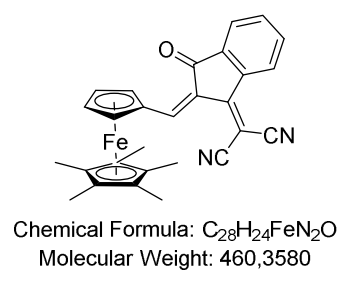

To a mixture of 2-(3-oxo-2,3-dihydro- $1 H$-inden-1-ylidene)malononitrile (1.12 g, $5.79 \mathrm{mmol}, \mathrm{M}=194.19$ $\mathrm{g} / \mathrm{mol})$ and 1'-formyl-1,2,3,4,5-pentamethylferrocene Fe9 (1.64 g, $5.79 \mathrm{mmol}, 284.18 \mathrm{~g} / \mathrm{mol})$ in absolute ethanol $(50 \mathrm{~mL}$ ) was added a few drops of piperidine. Immediately, the color changed. The solution was introduced in an oil bath preheated at $90^{\circ} \mathrm{C}$. Within $10 \mathrm{~min}$, the reaction was finished (TLC control). The solvent was removed under reduced pressure. The residue was purified by column chromatography using DCM as the eluent. The different fractions were combined and the solvent removed under reduced pressure so that approximately $30 \mathrm{~mL} \mathrm{DCM}$ was remaining. Addition of pentane precipitated a solid that was filtered off, washed several times with pentane and dried under reduced pressure $\left(2.37 \mathrm{~g}, 89 \%\right.$ yield). ${ }^{1} \mathrm{H}$ NMR $\left(\mathrm{CDCl}_{3}\right) \delta: 1.72(\mathrm{~s}, 15 \mathrm{H}), 4.70(\mathrm{t}, 2 \mathrm{H}, \mathrm{J}=1.9 \mathrm{~Hz}), 5.02(\mathrm{~s}$, $2 \mathrm{H}), 7.67-7.75(\mathrm{~m}, 2 \mathrm{H})$, 7.83-7.86 (m, $1 \mathrm{H}), 8.45(\mathrm{~s}, 1 \mathrm{H})$, 8.70-8.73 (m, $1 \mathrm{H}) ;{ }^{13} \mathrm{C} \mathrm{NMR}\left(\mathrm{CDCl}_{3}\right)$ 8: 10.8, 65.3, 72.0, 75.9, 78.6, 80.6, 83.4, 84.8, 115.8, 115.9, 121.7, 123.2, 125.0, 133.7, 134.4, 137.1, 139.7, 149.6, 160.5, 187.8; HRMS (ESI MS) m/z: theor: 460.1238 found: 460.1240 ([M] $]^{+}$detected). 


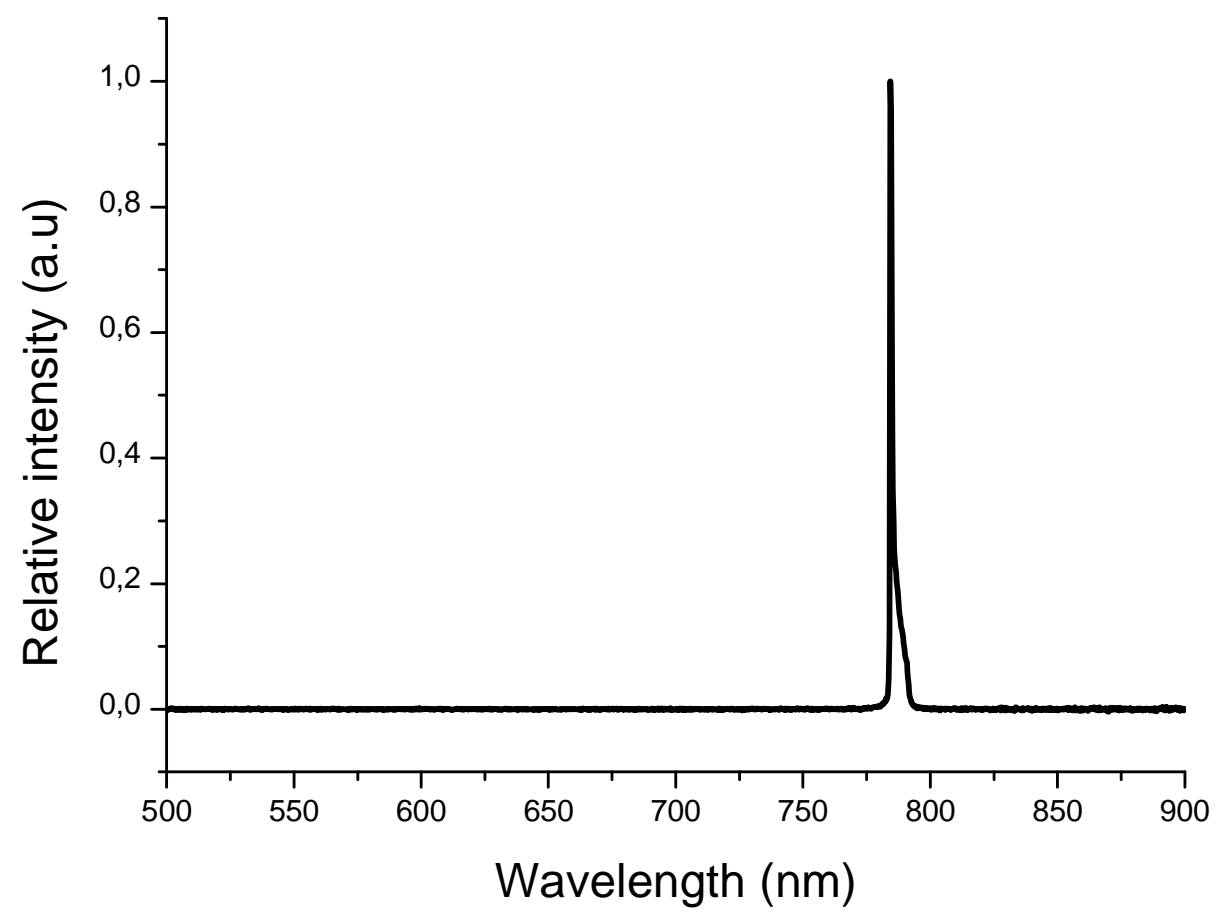

Figure S3: Emission spectra of the laser diode (LD@785 nm) used. 
Figure S4: Frontier molecular orbitals and UV-vis calculated spectra of the ferrocene derivatives (UB3LYP/6-31G* level of theory)

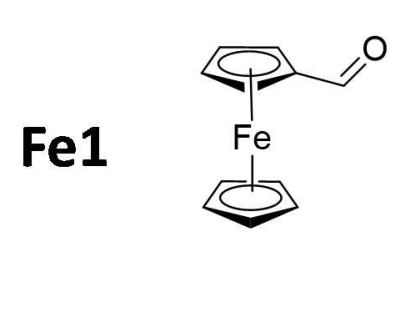

LUMO
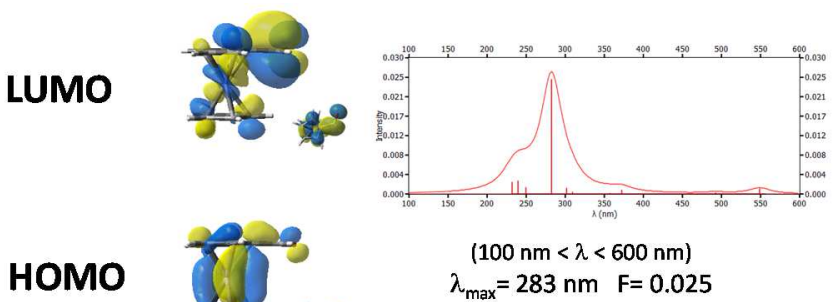

HOMO

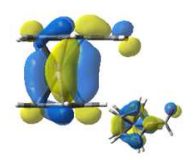

$(100 \mathrm{~nm}<\lambda<600 \mathrm{~nm})$ $\lambda_{\text {max }}=283 \mathrm{~nm} \quad F=0.025$ $\lambda_{\text {max }}=549 \mathrm{~nm} \quad \mathrm{~F}=0.0012$ $\lambda_{\text {max }}=372 \mathrm{~nm} \quad \mathrm{~F}=0.0010$<smiles>O=C1NC(=O)C(=Cc2ccccc2Oc2ccccc2)C(=O)N1</smiles>

LUMO
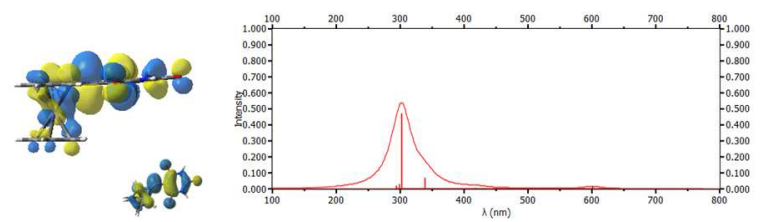

HOMO

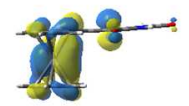

$(100 \mathrm{~nm}<\lambda<800 \mathrm{~nm})$

$\lambda_{\max }=303 \mathrm{~nm} \quad \mathrm{~F}=0.475$

$\lambda_{\max }=601 \mathrm{~nm} \quad \mathrm{~F}=0.016$ 

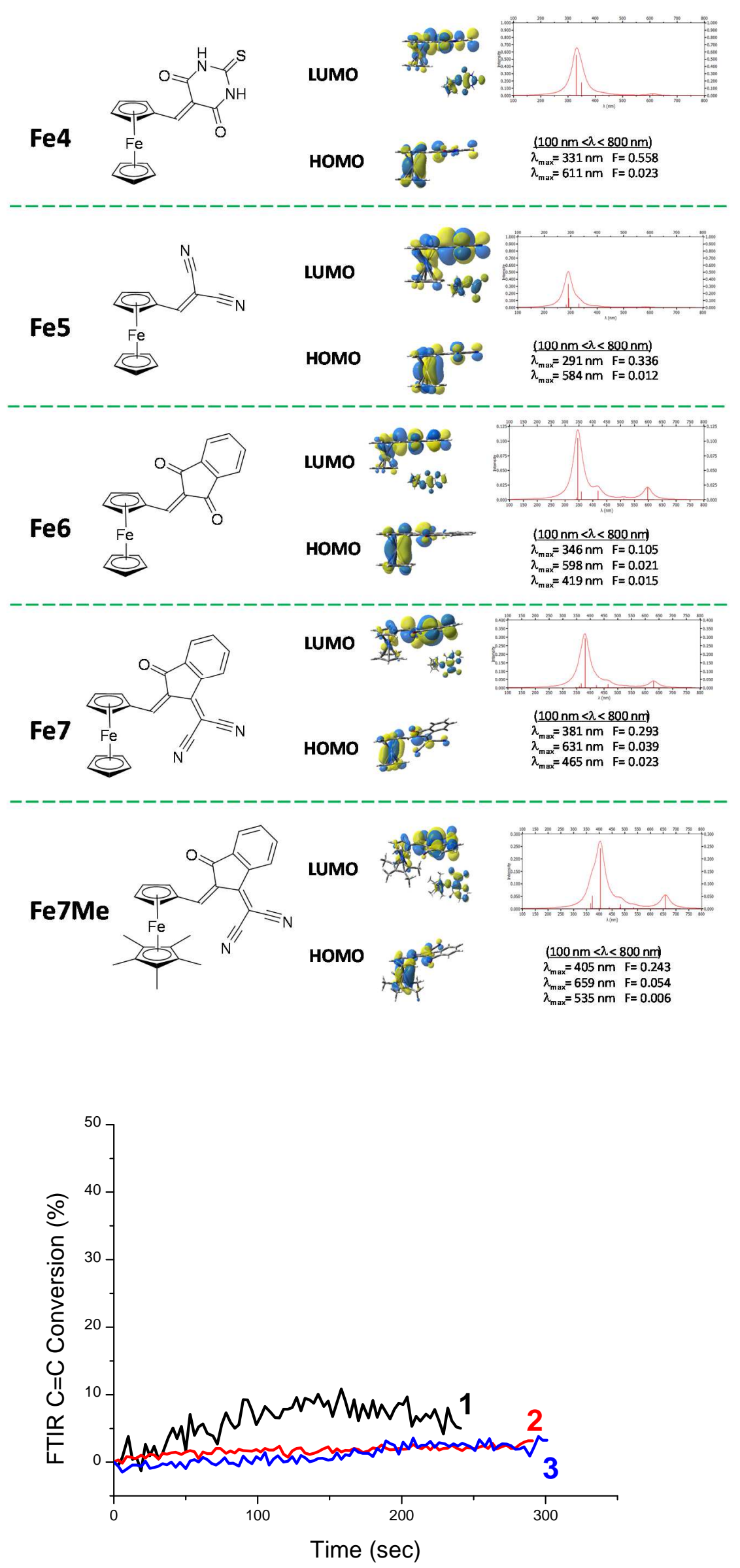
Figure S5: Photopolymerization profiles (methacrylate $\mathrm{C}=\mathrm{C}$ function conversion vs. irradiation time) measured in RT-FTIR for the resin 2; $1.4 \mathrm{~mm}$ thick samples, in air for $2.0 \mathrm{wt} \%$ lod and $0.5 \mathrm{wt} \% \mathrm{Fe}$ (II)

(1): Fe5/lod upon LED@660nm (80 mW/cm²) irradiation (2): Fe3/Iod upon LED@660nm (80 $\mathrm{mW} / \mathrm{cm}^{2}$ ) irradiation (3): Fe3/lod upon LED@530nm (30 mW/ $\left.\mathrm{cm}^{2}\right)$ irradiation.

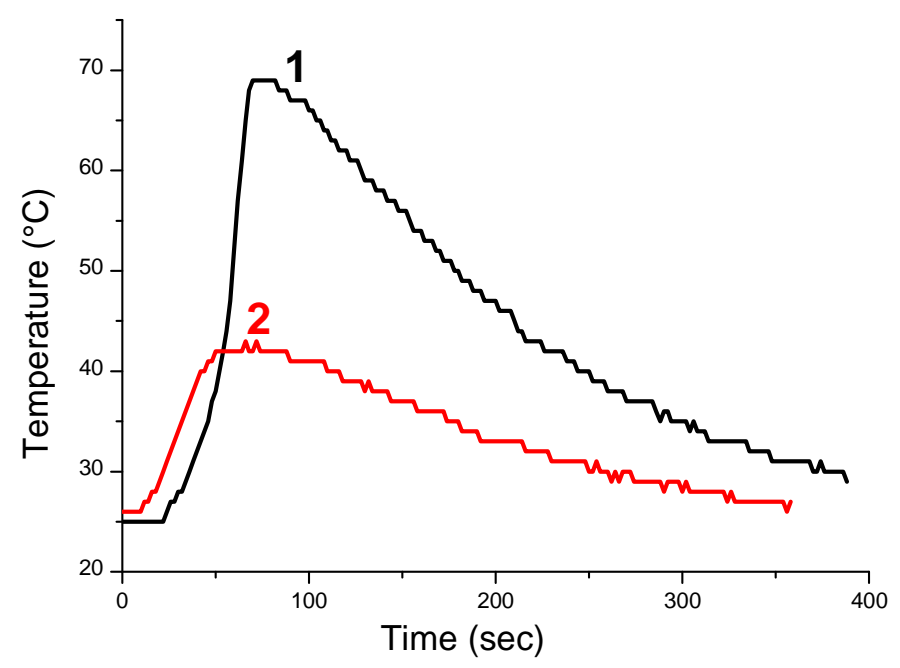

Figure S6: Redox polymerization: Optical pyrometric measurements (Temperature vs. mixing time, 4 $\mathrm{mm}$ samples), in air in the model methacrylate resin for $2.0 \mathrm{wt} \%$ APS (+2.0 wt\% water) mixed $1.5 \mathrm{wt} \%$ 2dppba and with (1) 0.3 wt\% Fe and (2) 1.3 wt\% Fe. 

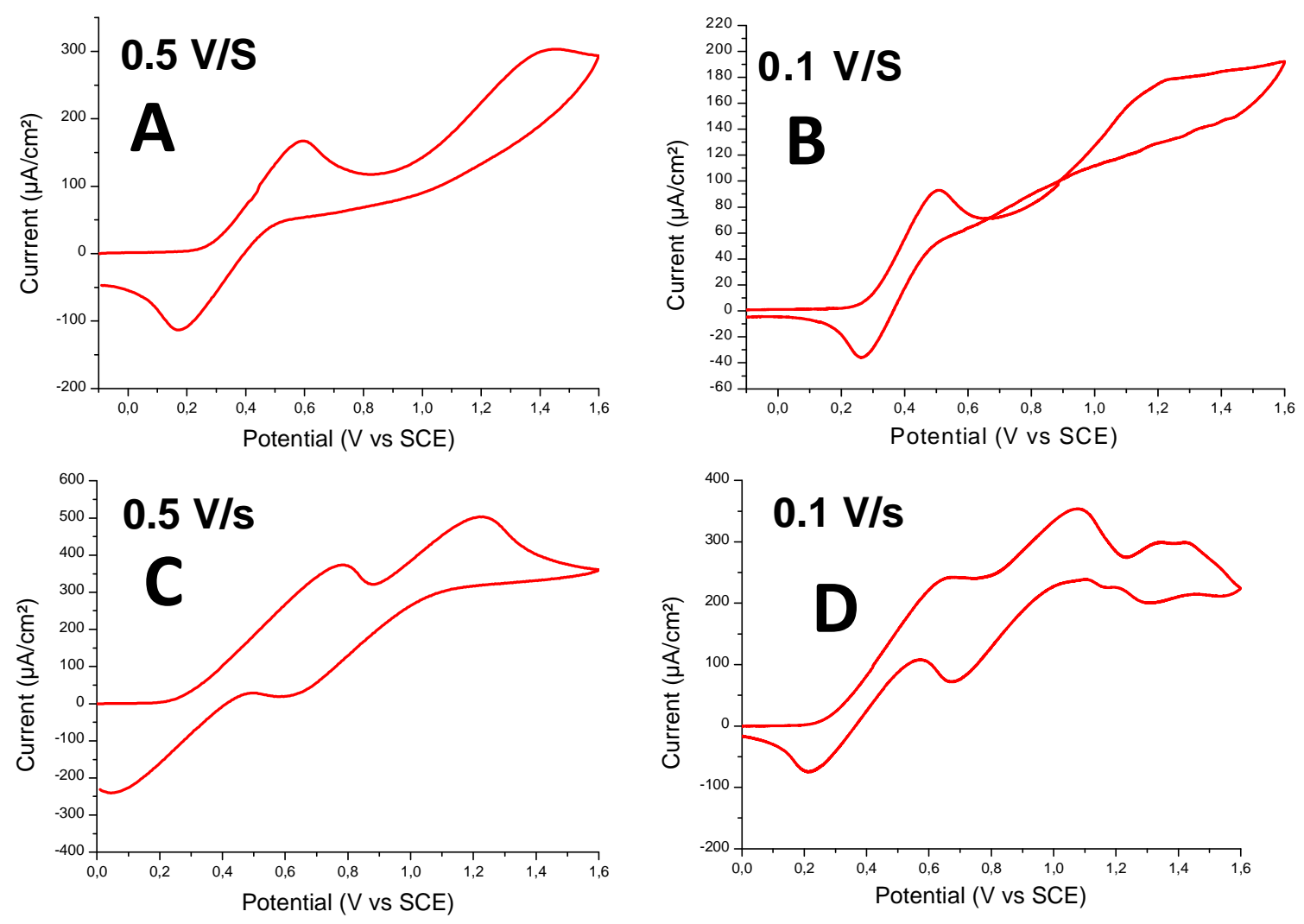

Figure S7: Cyclic voltammetry (CV) experiments in $\mathrm{ACN}$ (containing $0.2 \mathrm{M}$ tetrabutylammonium hexafluorophosphate, $\mathrm{N}_{2}$ degassed)) for $\mathbf{A}, \mathbf{B}: \mathrm{Fe}+2 \mathrm{dppba}$ and $\mathbf{C , D} \mathrm{Fe}+$ amine (4-N,N TMA). 

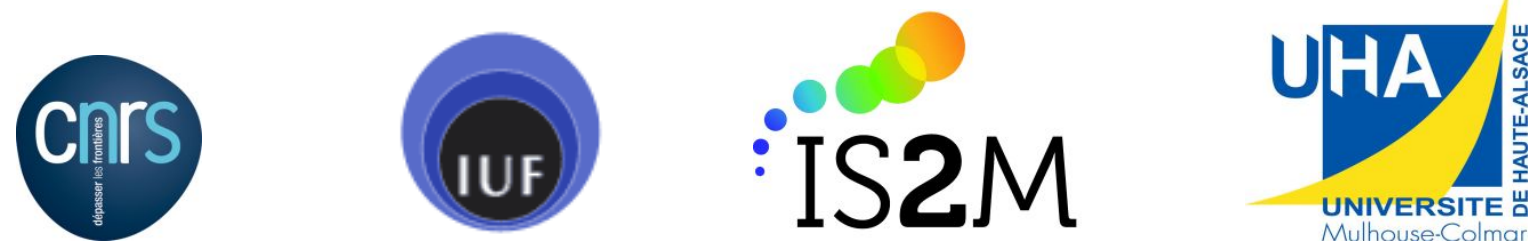

Prof. Jacques Lalevée

Institut Universitaire de France (IUF)

Institut de Science des Matériaux de Mulhouse (IS2M), CNRS - UMR 7361.

15 rue Jean Starcky, 68057 Mulhouse (FRANCE).

February, 6 $^{\text {th }}, 2018$

\section{Dear Prof. Tanja Junkers}

Following your letter, please find a revised version of our paper.

We are pleased to note that both reviewers supported publication, however they suggest some minor revisions/comments:

Reviewer 1 stated that "This is an interesting paper on ferrocene based redox and photoredox catalysis for radical polymerization. I recommend its publication"

Reviewer 2 stated that "Lalevee and co-workers present an excellent paper, which describes for the time the use of ferrocene-based photoredox catalysts."..." In my opinion, this paper will generate lot of interests in the field of polymer chemistry and material synthesis."

We would like to thank the reviewers for their comments and suggested revisions which were highly interesting to improve the paper for publication in this high impact journal. The actual version has been changed and all the comments were taken into account.

We would be very grateful if you could consider the publication of this manuscript.

\section{Best Regards}

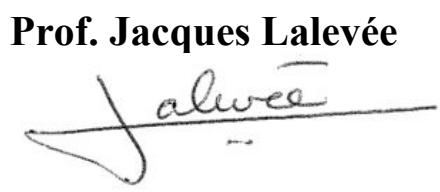




\section{Responses to reviewers:}

\section{Reviewer 1:}

Recommendation: Publish as is, or with minor revisions as noted.

Comments: "This is an interesting paper on ferrocene based redox and photoredox catalysis for radical polymerization. I recommend its publication. The authors may consider the following point."

\section{Answer:}

We thank very much the reviewer 2 for his comments.

\section{Minor revision:}

The addition of reducing agents initiates the polymerization even in the absence of light. The authors should show or discuss if these reducing agents can reduce the iodonium salt as well."

\section{Answer:}

We thank the reviewer for his comments. We fully agree with reviewer 1 . The reducing system (containing reducing agents) only initiates the polymerization without light for ammonium persulfate as an oxidizing agent; they are inefficient to reduce iodonium salt (oxidizing agents with too low reduction potential). The manuscript was updated in order to take into account this fact.

\section{Reviewer 2:}

Recommendation: Publish as is, or with minor revisions as noted.

Comments: "Lalevee and co-workers present an excellent paper, which describes for the time the use of ferrocene-based photoredox catalysts. The system can be activated by visible light as well as by redox offering new opportunity for the design of functional materials. The advantage to use a system independent of the light. The authors clearly stated the current challenges and explained their approach. In my opinion, this paper will generate lot of interests in the field of polymer chemistry and material synthesis. Therefore, I strongly recommend for publication. Minor comments: "

\section{Answer:}

\section{$\underline{\text { Revisions: }}$}

We thank very much the reviewer 2 for his comments.

(1) "In the introduction, the authors mention some work on NIR, perhaps they could cite this system: Macromolecules, 2016, 49 (9), pp 3274-3285, which used aluminium Phthalocyanine to initiate a free radical polymerization or a RAFT polymeriation under low light intensity NIR..". 
Answer:

We agree with reviewer 2 . The reference list was updated.

(2) "please change discussions to discussion."

Answer:

This typo was fixed. 